\title{
RACE IN EDUCATION
}

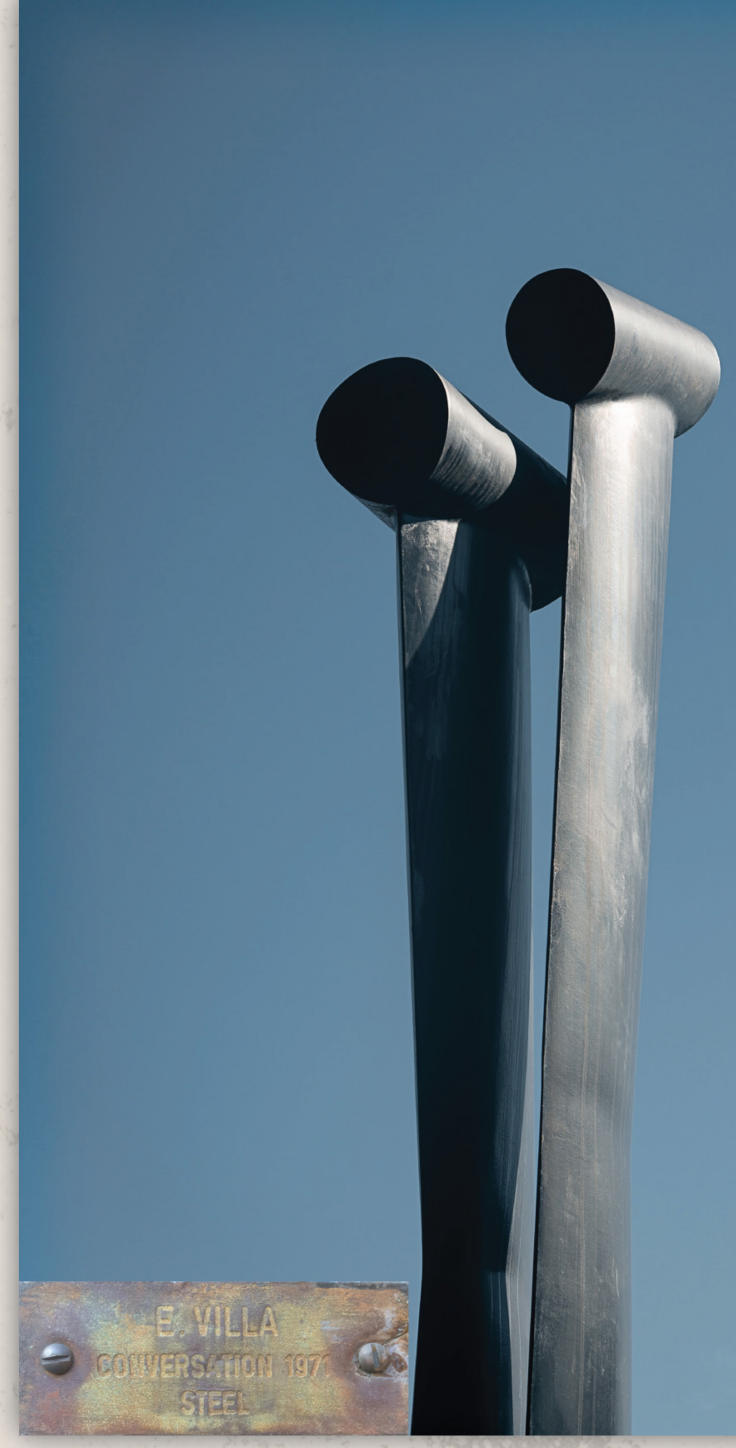

GERHARD MARÉ

EDITOR EDDCA

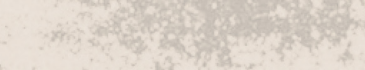




\section{RACE IN \\ EDUCATION}

EDITOR

GERHARD MARÉ

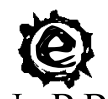

SUN PRESS 
Race in Education

Published by AFRICAN SUN MeDIA under the SUN PReSS imprint

All rights reserved

Copyright (C) 2019 AFRICAN SUN MeDIA and STIAS

This publication was subjected to an independent double-blind peer evaluation by the publisher.

The authors and the publisher have made every effort to obtain permission for and acknowledge the use of copyrighted material. Refer all enquiries to the publisher.

No part of this book may be reproduced or transmitted in any form or by any electronic, photographic or mechanical means, including photocopying and recording on record, tape or laser disk, on microfilm, via the Internet, by e-mail, or by any other information storage and retrieval system, without prior written permission by the publisher.

Views reflected in this publication are not necessarily those of the publisher.

First edition 2019

ISBN 978-1-928480-14-3

ISBN 978-1-928480-15-0 (e-book)

https://doi.org/10.18820/9781928480150

Set in Arno Pro 12/14

Cover design, typesetting and production by AFRICAN SUN MeDIA

Cover image: Edoardo Villa (1915-2011) steel sculpture Conversation (1971), located at School of Mechanical Engineering building, Howard College campus, University of KwaZulu-Natal. (Photographer (C) Andrew Griffins)

SUN PReSS is a licensed imprint of AFRICAN SUN MeDIA. Scholarly, professional and reference works are published under this imprint in print and electronic format.

This publication can be ordered directly from:

www.sun-e-shop.co.za

www.store.it.si (e-books)

www.africansunmedia.co.za 


\section{The STIAS series}

The Stellenbosch Institute for Advanced Study (STIAS) was born from a simple but powerful conviction: in this part of the world special initiatives are required to create and maintain an environment where we can generate and engage with conceptual frameworks and knowledge that may guide us in tracking and co-shaping global academic developments and that will allow us to address the 'big' questions and issues South Africa and the African continent face, also in a global context.

STIAS has been moulded in the tradition of Institutes for Advanced Study across the globe. It distinguished itself by encompassing all disciplines from the natural to the social sciences and humanities (with a particular emphasis on research grounded in multi-disciplinarity), by maintaining a focus on the African and South African context, and by striving towards contemporary relevance, also by actively creating avenues for communicating the results of its research projects to a wider public.

The STIAS series publications, of which this is the thirteenth volume, are thus aimed at a broad public which will naturally vary with specific research themes. Straddling the academic world and the forum of an engaging public is a challenge that STIAS accepts; we trust that each STIAS publication reflects the 'creative space for the mind' in which it is rooted, stimulates public interest and debate, and contributes to informed decision making at various levels of our society.

Further information about STIAS and its research programme may be found at www.stias.ac.za.

Hendrik Geyer STIAS Director

Stellenbosch

October 2018

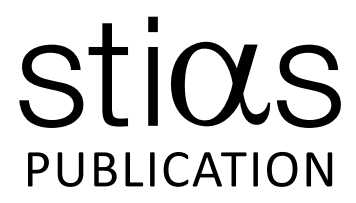




\section{CONTENTS}

List of Tables ...................................................................... vii

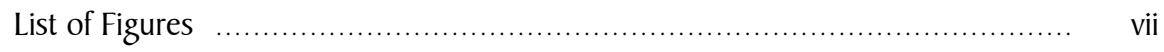

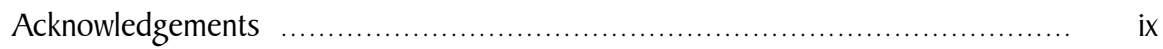

An Introduction …...........................................................

Gerhard Maré

$1 \quad$ Perceptions on socially just pedagogies in higher education $\ldots \ldots \ldots \ldots \ldots \ldots . .5$

Vivienne Bozalek and Michalinos Zembylas

Theoretical framework …................................................. 7

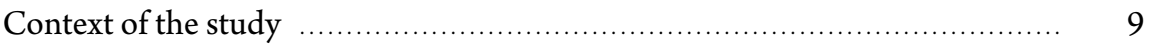

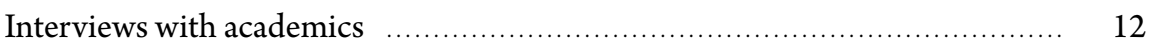

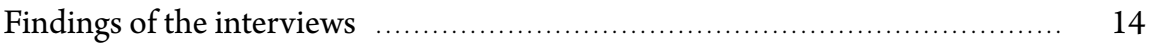

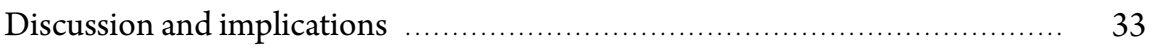

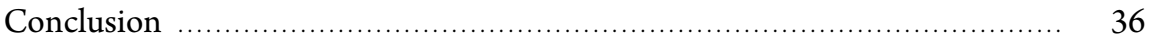

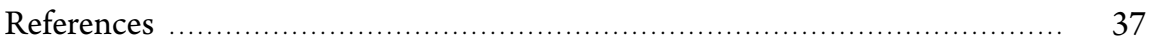

$2 \quad$ Exploring being human today: Equipping teachers for diversity $\ldots \ldots \ldots \ldots \ldots \quad 41$ Janet Condy, Lena Green and Daniela Gachago

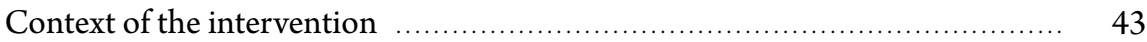

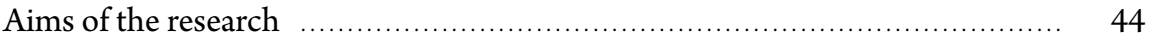

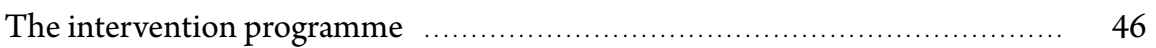

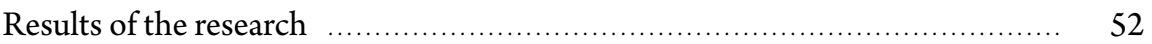

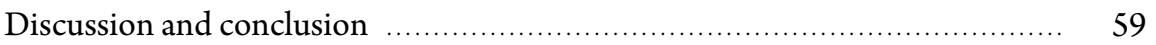

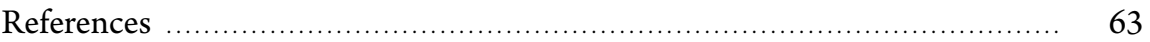

3 Non-racialism, racialism, racism: The power of youthful dreams .......... 69

Kira Erwin and Kathryn Pillay

Non-racialism ................................................................. 70

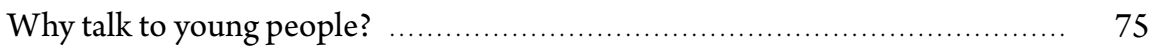

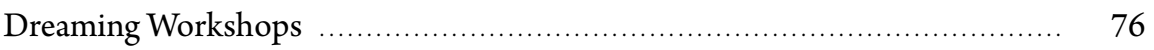

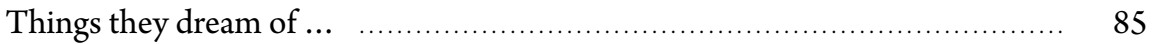

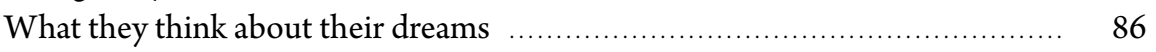

Non-racialism, racialism and racial stereotypes ............................ 87

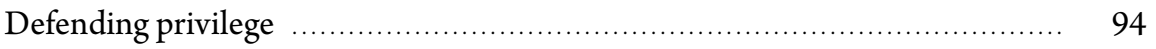

Forms of togetherness, anti-essentialism and negotiating difference $\ldots \ldots \ldots \ldots . . . . \quad 97$

Concluding thoughts ........................................................ 101

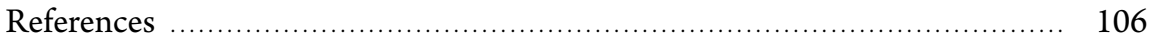


$4 \quad$ Racial classification and the spectre that haunts

Handri Walters

The formation of subjects: a coloured category 115

A project of ruination 126

Debris and ruins 128

Conclusion: the spectre that haunts 129

References

List of Contributors 


\section{LIST OF TABLES}

1.1 Full-time equivalent (FTE) student enrolments at 23 universities by

"race" and year - comparison of 2008 and 2012 (\%)

1.2 Interviews conducted with academics on socially just pedagogies at HEIs in Cape Town

2.1 The overlapping of knowledge and emerging gaps in this complex research project

3.1 Prevalence of branch themes in the Dreaming Trees

\section{LIST OF FIGURES}

2.1 "Trees of Life" created during the research project exploring effectiveness of a pedagogical intervention with final-year education students

2.2 Students practising thinking moves during a dialogic enquiry $\ldots \ldots \ldots \ldots \ldots \ldots \ldots \ldots$

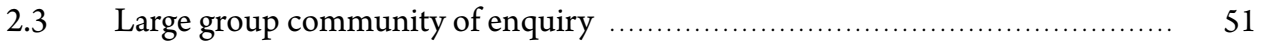

2.4 A journey from personal experience to a systemic understanding of difference

3.1 Example of the student work in the first Dreaming Session

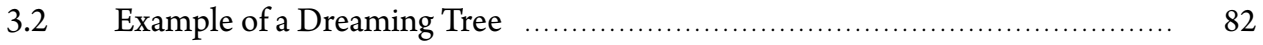

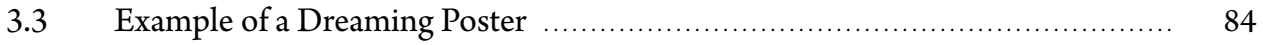




\section{ACKNOWLEDGEMENTS}

Nina Jablonski and Gerhard Maré, the conveners of The Effects of Race (EoR) project, wish to acknowledge the Knut and Alice Wallenberg Foundation for financial aid through the four-year duration of the initiative. It allowed core members, and the project participants - whose work is presented in this volume in the STIAS series - to meet under extremely supportive conditions provided at the Wallenberg Centre. At STIAS, Hendrik Geyer and Christoff Pauw warrant special acknowledgement for their generous financial support of the targeted projects including a doctoral degree - run under the aegis of the long-term initiative of the Being Human Today: The Effects of Race project. On behalf of all EoR members, we wish to thank them for what they enabled. The publications serve as a small token of that appreciation. 


\title{
AN INTRODUCTION
}

\author{
Gerhard Maré
}

The Effects of Race (EoR) project was established within the framework of "Being Human Today", the long-term programme of the Stellenbosch Institute for Advanced Study (STIAS). "Being Human Today" posed the questions, "What does it mean to be human and how is that constituted?" and "What is the nature of the world in which we aspire to be human?" These questions informed the EoR project, because resilient notions of race and the actions that flow from them limit or even deny a shared humanity.

The EoR project at STIAS took shape in 2013 through discussions between STIAS director Hendrik Geyer and convenors Nina Jablonski and Gerhard Maré, and meetings with academics from diverse backgrounds and disciplines. The project had two major goals. The first was to fill the gaps in our current knowledge about race thinking and racialism with new, integrative, transdisciplinary and transformative scholarship; the second was to apply this scholarship to the design of educational and social interventions to counter the development of stereotypes and racist attitudes. 
The EoR project operated through two complementary and interacting groups. The first was the Core Group, to be composed of STIAS Fellows and Visiting Scholars who had records of distinguished scholarship on some aspect of race. The second was the assemblage of Project Groups, which resulted from a competitive process of grant proposal submission to STIAS in early 2014. Members of the Core Group made commitments to meet and work together at STIAS for a period of about two weeks each year in July or August, beginning in 2014 and continuing for at least three years. Members of the selected Project Groups undertook their work independently over the same period, but came together every year at STIAS to interact with each other and members of the Core Group. The projects benefited from annual participation through reporting on progress; and receiving, and providing, exciting ideas through sharing in Core Group discussion. In effect, they became valued regular and collegial collaborators with the overall intent of The Effects of Race project.

Four of the projects completed submissions for this book. The fifth, while not submitting a contribution, completed a book related to the work they presented to the project from 2014 to 2017 (Minkley, Van Bever Donker, Lalu \& Truscott, 2017). The submissions presented here summarise and further reflect on research completed during the period of funding.

As the call for research participants did not narrowly prescribe the selection of content, each of the four chapters here reflect internal, but not necessarily collective, coherence. However, at the same time each addresses issues related to social justice and perspectives on change in the educational field in South Africa, and as such cannot avoid touching on race and inequality; concerns also prominent in group discussions within EoR. The projects on which the chapters are based were, in addition, undertaken during a time - 2015 and 2016 especially - of intense protest and turmoil at higher education institutions in South Africa. This context is mentioned as central in the first two chapters, and in passing in the third.

It must be mentioned that the conveners deliberately did not set a word limit to the chapters as we felt, correctly, that we wished an adequate summary of the projects as whole and not to focus on a specific issue to meet a word count limit. This means that they are presented so as to adequately present full pictures to a wider readership. "Being Human Today" broadly embraces the content of all the chapters. Readers will also find overlapping issues between the chapters, especially Chapters 1 and 2 (in terms of the concerns addressed); and also Chapters 2 and 3 (in terms of methodology and intent). Chapter 4 is an interesting outlier in its historical investigation of the shared concern with "being human". All the chapters indicate paths of activism with broader impact and with challenging ideas about achieving social change in South African society, and in other societies. 
Methodologically, and theoretically too, innovation and imagination are employed and suggestions offered for further work. All authors provide useful reference lists for further reading.

In brief summary: Chapter 1, "Perceptions on Socially Just Pedagogies in Higher Education", uses the notion of "participatory parity", or "the ability to interact as equals in higher education". This aim is executed by considering the views and experiences of academics, gathered through interviews across a wide range of disciplines and faculties in higher education institutions (HEIs) in South Africa's Western Cape province. Those who were selected identify themselves as practising socially just pedagogies. For the purposes of their research, the authors define socially just pedagogies as "the educators' efforts to transform policies and enact pedagogies that improve the learning and life opportunities of typically underserved students". They draw attention to the turbulent time in which their research and writing took place, and draw positive value from that:

(Re)thinking about the meaning and practices of socially just pedagogies, especially in times of turmoil, re-energises the debates and renews the ways with which struggles for social justice can be enriched in higher education.

Ideas are presented for extending the research and, thus, also focusing discussion on the issues of social justice the research process raises.

The authors of Chapter 2, drawing on two approaches in teacher training - digital storytelling (DST) and philosophy for/with children (P4C) - seriously reflect on the implementation of such a curriculum over two years. They illustrate the results through revealing quotations from the participating students. During teaching preparation, the participants are addressing, problems with "current practice in education, [which] ... predominantly promotes decontextualised celebrations of multiple identities and difference, without addressing critical issues of power and social forces". Through processes of collective learning - "learning as a respectful and reasoning community" - and therefore getting participants to reveal their own stories and listen to those of others, teaching preparation is described as a transformative experience. Their research indicates the potential of such approaches for future teachers who will be operating in a society still in complex transition.

Chapter 3 raises important issues in relation to the continuation of racialism amongst scholars in senior levels at five schools. Thinking in terms of "natural" race groupings, despite a very strong rejection of racism and racial discrimination in South African society, participants in the "Dreaming Workshop" research project achieve this apparent contradiction through the conflation of culture and race groupings. As the authors put it: "In this paradigm, anyone who openly rejects their racialised identity is by proxy seen as rejecting their culture." The innovative and productive methodology of eliciting non-tutored responses gives value to the 
findings, and sets examples for practice and further such studies. As with the DST and $\mathrm{C} 4 \mathrm{C}$ techniques employed in training teachers, described in Chapter 2, here is another example of research that is also social practice. The value of the approach has been recognised in some cases by the schools involved in the project.

Finally, Chapter 4 reflects on volkekunde (physical anthropology) and its enormous immediate influence on what was formerly taught at tertiary education institutions, and on the introduction of the apartheid system, the motivation and justification for it, and its maintenance. The author explores the European origins of the ideas of natural kinds within humanity, and then the "scientific" techniques and instruments used to prove racist theories of a hierarchy of races. The project itself was triggered by the author's discovery of instruments that served the purposes of measuring race, employed by lecturers, in this case at Stellenbosch University, from the early twentieth century - hair and eye samples, measuring instruments, and the findings and immediate and longitudinal consequences of such "research". The chapter also reveals the training of those who practised these explorations on humans, those subjects who were classified as "coloured", most immediately problematic in the political arguments for distinct "races". In this final chapter, Walters leaves us with words appropriate to this publication as a whole, and arguably to The Effects of Race project itself:

The spectre of racial classification was made manifest in these objects [the measuring implements]. It embodied the ruins of an archaic science, but also the ruins of a society that functions according to racial classification. When age-old, archaic scientific objects can cause an upheaval, when it is able to haunt, its ghost has not been laid to rest.

There is global evidence that "ghosts" of notions of essentialist differences between human "groups" continue to haunt in various forms. People draw upon ideas of religion, race, ethnicity, gender and sexuality, and nation to draw distinctions. Racism, xenophobia, sexism, and right-wing populism are ongoing and increasing phenomena. In addition, genetic science has introduced new forms of "proof" which lends itself to misuse, to confirm "common sense perceptions".

The valuable contributions of the authors in this publication not only warn against such notions, but offer ways of exploring, exposing, and challenging the ghosts and the fears engendered through their contemporary forms.

\section{References}

Jablonski, N.G. \& Maré, G. (eds). 2018. The Effects of Race. Stellenbosch: AFRICAN SUN MeDIA. https://doi.org/10.18820/ 9781928357858
Minkley, G.; Van Bever Donker, M.; Lalu, P. \& Truscott, R. (eds). 2017. Remains of the Social: Desiring the post-apartheid. Johannesburg: Wits University Press. 


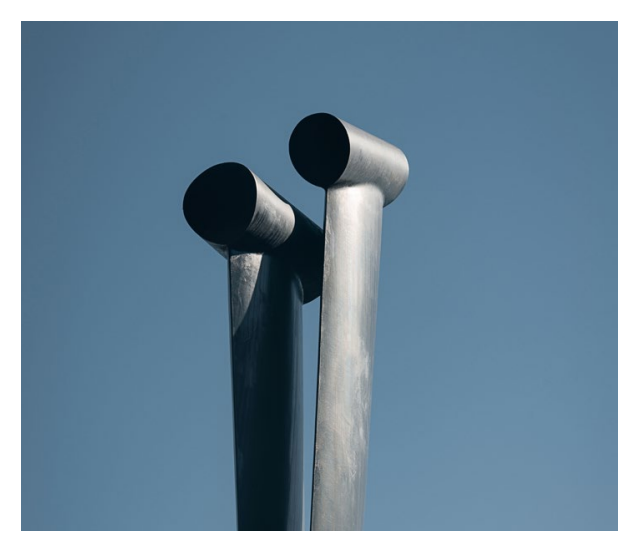

\section{PERCEPTIONS ON SOCIALLY JUST PEDAGOGIES IN HIGHER EDUCATION}

Vivienne Bozalek and Michalinos Zembylas

This chapter distils the perceptions and experiences of educators at institutions in the Western Cape, South Africa. It has been written at a time of crisis for South African higher education, brought to the fore by two years of student protests, in 2015 and 2016, calling for higher education to be decolonised and for better access to education. The protests resulted in multiple disruptions of examinations and academic programmes. The protesters' demands were initiated by the \#RhodesMustFall (\#RMF) student protests at the University of Cape Town, focusing on symbols of imperialism and whiteness (Luescher \& Klemenčič, 2016; Nyamnjoh, 2016) and calling first for the statue of Cecil John Rhodes to be removed from campus, and then more globally for decolonisation as their sentiments spread to other higher education institutions (HEIs) both nationally and internationally. The \#FeesMustFall (\#FMF) movement, with the student-led protests being ignited at a large number of HEIs across South Africa in 2015 and 2016, demanded equitable access to higher education, especially for those students who experience race/class and financial barriers to gaining access (Nicolson, 2016). 
These protests were indicative of the continuing problems of inequality in South African higher education (and other educational sectors) (Bozalek \& Boughey, 2012; Cooper, 2015), and the constraints that these conditions make for achieving what Fraser $(2008,2009,2013)$ calls "participatory parity", namely the ability to interact as equals in higher education. This chapter contributes to ongoing discussions about the meanings and practices of social justice in higher education by considering the views and experiences of academics across a wide range of disciplines and faculties in HEIs in the Western Cape who identify themselves as practising socially just pedagogies. $(\mathrm{Re})$ thinking about the meaning and practices of socially just pedagogies, especially in times of turmoil, re-energises the debates and renews the ways with which struggles for social justice can be enriched in higher education.

The chapter is based on a small section of research which was part of a larger National Research Foundation (2016) study (Grant No. 90384), which examined both students' experiences related to participatory parity in achieving qualitative educational outcomes and higher educators' perceptions and experiences related to social justice and socially just pedagogies. "Participatory parity", a concept that Nancy Fraser $(2008,2009,2013)$ equates with social justice, refers to the ability to interact on an equal footing in particular circumstances - such as students in the same disciplines across differently placed HEIs being in a position to achieve similar qualitative outcomes. Achieving participatory parity is regarded as particularly important for South Africa, where inequalities continue to plague the field of higher and other levels of education. The focus of this chapter is specifically on examining how a group of educators in higher education understand social justice and enact it in their pedagogical practices. The engagement of these educators with a set of important foundational issues must be undertaken if we are to disrupt inequities and injustices in the sector. The understandings identified and discussed in this chapter have the potential to not only help us delve into educators' thinking and practice, but they also question uncritical assumptions about socially just pedagogies in South Africa and beyond.

The meaning of the term "social justice" is hotly debated throughout the field of education (North, 2006; Leibowitz \& Bozalek, 2016; Moje, 2007), but here we define socially just pedagogies as the educators' efforts to transform policies and enact pedagogies that improve the learning and life opportunities of typically under-served students (Cochran-Smith, 2004; Irvine, 2003; Ladson-Billings, 1994) while equipping and empowering all students to work for a more socially just society themselves (Freire, 1970; Kincheloe \& Steinberg, 1998; King, 2005). Examining how to ameliorate the educational experiences of marginalised students and empowering all students to be agents of change will have more chances of success if higher educators understand the tremendous challenges and potential implied in attempts to promote participatory parity in HEIs. 
The \#RMF and \#FMF movements provide a fascinating focus of events that constitute South Africa as a large "experimental lab" of new ideas that could further the project of socially just pedagogies. While this chapter focuses specifically on higher educators in Western Cape HEIs, other studies from the same NRF research project have examined the experiences and perceptions of events in Gauteng (see, for example, Leibowitz and Naidoo, 2017). In addition to this, a much larger NRF study on "Professionalising Teaching and Learning in Higher Education" was conducted by Brenda Leibowitz and a research team from eight HEIs: researchers conducted interviews with vice-chancellors, deputy vice-chancellors, deans and 20 lecturers from each of the eight universities in South Africa regarding perceptions of teaching and learning. The interviews reveal that, although higher educators generally are reflexive about their teaching, very few engage with socially just practices and social justice teaching as described in this chapter (Council on Higher Education, 2017; Leibowitz, Bozalek \& Kahn, 2017). In this study, most of the 160 lecturers who were interviewed about their conceptions of good teaching referred to the importance of enabling active student learning rather than transmission of knowledge from the lecturer; of alignment to desired course outcomes; and of competency in their field of study (Council on Higher Education, 2017). These 160 lecturers thus tended to focus on conventional conceptions of teaching and learning such as curriculum alignment and student-centred learning.

\section{Theoretical framework}

As a guiding framework, this chapter uses some ideas from Nancy Fraser's (2008, 2009) construct of social justice, which she equates with participatory parity. Participatory parity, the ability to interact as equals, is influenced by the distribution of resources (economic dimension); by whether the attributes or knowledges of groups, individuals or institutions are valued or devalued (cultural dimension); and by whether certain individuals or groups of people are included or excluded from learning contexts and have a political voice (political dimension). These three dimensions of participatory parity can either be addressed in higher education pedagogies in ameliorative ways, addressing some of the symptoms; or in transformative ways, which are more fundamental and address the root causes of institutional arrangements that prevent participatory parity in pedagogical practices (Bozalek, 2017; Fraser, 2008, 2013). The student protest movements calling for decolonising of the curriculum can be seen to be part of the cultural dimension of participatory parity, drawing attention to the revaluing of indigenous knowledges, and different, more democratising ways of practising pedagogy in higher education (Pillay, 2016). The calls for equitable access, pertaining to the economic dimension of Fraser's construct of social justice, relate to an equitable distribution of resources such as funding, labour, time, etc. to foster 
participatory parity. The third, political dimension for bringing about participatory parity, is representation, inclusion and voice. In this dimension, the student movements themselves have brought greater political agency, representation and voice to students, who have been able to exert a potent political force in South African higher education, sometimes bringing HEIs to a standstill through temporary closure (Luescher \& Klemenčič, 2016). How does this three-dimensional understanding of social justice contribute to the notion of socially just pedagogies?

First of all, few would disagree with the most basic intention of socially just pedagogies: improving the learning and life opportunities of typically marginalised students (Cochran-Smith, 2004; Delpit, 1995; Irvine, 2003; Ladson-Billings, 1994). Perhaps more controversial is the accompanying goal of empowering all students to act as agents of change in response to societal injustice (Ayers, 1998; Freire, 1970; King, 2005). In the South African context, for example, this goal could easily be misinterpreted as urging students to be disruptive of current affairs in HEIs. And yet, in light of the gross injustices in South African HEIs, the empowering of students to take action and disrupt the socially unjust situation should be seen as an important component of socially just pedagogies.

Beyond disagreements on the basic meaning of social justice for educators, there is also confusion in that different groups (theoreticians, policymakers and practitioners), embrace varying goals, and operate in relation to different domains, content, audiences, and agents of socially just pedagogies. Each of these components intersects with and influences the others, in both conflicting and complementary tensions, their very interconnectedness contributing to the confusion (see North, 2006, for a thorough discussion of several of these components). For instance, socially just pedagogies may indeed encompass varied goals. Some may argue that the goal is simply the recognition of specific cultural groups that have been marginalised. Others might emphasise that social justice is more accurately demonstrated in the redistribution of material goods and opportunities for those social groups that have been denied political, economic, and educational access because of institutional practices and policies. The issue is not either the one or the other, but rather, as Fraser writes (2008, 2009, 2013), all three dimensions of social justice, namely, recognition (cultural), redistribution (economic) and participation (political).

Finally, there is the question of what the role of the socially just pedagogue is in the higher education classroom (Carolissen, Canham, Fourie, Graham, Segalo \& Bowman, 2017; Osman \& Hornsby, 2017). Should socially just pedagogues be activists, providing sound academic instruction, equitable policies, and critical exposure to justice-related issues? Does this have a place in the classroom or should they encourage activism outside of that context (Giroux, 1988; Kincheloe, 2005; McLaren, 2003; O’Donnell, Chávez Chávez \& Pruyn, 2004), limiting their role 
to engaging in critical analysis of societal and institutional inequities (CochranSmith, 2004; Darling-Hammond, 2004; King, 2005; Nieto, 2000) and working for structural reform (Carlisle, Jackson \& George, 2006; Taylor \& Sobel, 2003)?

The complexity of these competing/complementary goals, domains, and educators' roles in relation to socially just pedagogies creates many tensions and possibilities that deserve deeper investigation, especially in terms of how higher educators themselves perceive and experience these tensions and possibilities (see Chubbuck and Zembylas, 2008).

\section{Context of the study}

The White Paper for Post-School Training and Education (Department of Higher Education and Training, 2013) notes that South African (SA) higher education (HE) is geared towards white, male and middle-class students and staff. Furthermore, the Soudien Report on "Transformation, Social Cohesion and the Elimination of Discrimination in the Higher Education Sector" (Department of Education, 2008) points out that there remains a disjuncture between policy intentions and the actual experiences of students and educators in the HE sector. Much of the literature on higher education in SA has tended to foreground how students are "underprepared" for study and need to adapt to the normative assumptions of higher education institutions (HEIs). The effect of these studies is to reinforce various types of deficit discourses, which have the effect of pathologising large groups of black working-class students attempting to enter the HE sector. Rather than focusing on students' deficits, it is important to consider how institutions themselves and those who work in them would have to change their practices and policies to respond to the different needs of learners (Leibowitz \& Bozalek, 2016), as well as valuing the subjugated knowledges that students bring with them (Bozalek, 2004; Soudien, 2012).

The focus of this chapter is specifically on the perceptions of HEI educators regarding social justice and related concepts, as well as their experiences of practising what they see as socially just pedagogies across four differently located and positioned HEIs in the Western Cape: ${ }^{1}$ Cape Peninsula University of Technology (CPUT), Stellenbosch University (SU), the University of Cape Town (UCT), and the University of the Western Cape (UWC). Both the University of Cape Town and Stellenbosch University are historically advantaged institutions (HAIs): UCT catered in the past largely for English-speaking white students; SU catered largely for Afrikaans-speaking white students. UWC is a historically disadvantaged

1 The STIAS project, "Being Human Today: The Effects of Race", provided the funding for the transcriptions of the interviews. This chapter, therefore, focuses solely on the analysis of these interview transcripts. 
institution (HDI), or historically black university (HBU), which was originally designed in the 1960s under apartheid as an HEI for the so-called "coloured" population, but in the 1970s became known as the intellectual home of the left and opened its doors to all students, including rural African women students. CPUT is a merged institution which combined a black and a white technikon to become a university of technology. According to Cooper and Subotzky's classification of HEIs in South Africa (2001:2, Table 1.1 below), UCT is an English historically white university (HWU); SU an Afrikaans HWU; UWC a non-African historically black university (HBU); and CPUT a merger of a historically white technikon (HWT) (Cape Technikon) and a historically black technikon (HBT), the Peninsula Technikon (Pentech).

Currently, South African higher education is divided into three bands of institutions five upper band, seven middle band and eleven lower band categories, grouped according to their research intensiveness as indicated by postgraduate enrolments and staff publications. Cooper (2015) shows how the continued socio-economic and racial inequalities are masked in official categorisations of HEIs in South Africa in Table 1.1 below, which indicates the figures of student enrolment in 2008 and 2012 in HEIs in these bands. As can be noted in the table, Stellenbosch University continues to recruit large groups of white students (69\% in 2008 and $68 \%$ in 2012), while the historically black or disadvantaged institutions, mainly represented in the third band, are almost all populated by South African African students. UCT is shown to have remained constant in its enrolment across 2008 and 2012 , with $39 / 34 \%$ white, $7 / 7 \%$ Indian, $15 / 13 \%$ coloured, $19 / 23 \%$ South African African and 20/23\% foreign or unknown enrolments in 2008 and 2012, respectively. UWC in the second band is also quite consistent over the 2008/2012 period, with $4 / 4 \%$ white, $7 / 5 \%$ Indian, $48 / 46 \%$ coloured, $32 / 36 \%$ South African African, and $9 / 9 \%$ foreign or unknown enrolments in 2008 and 2012. CPUT as a merged University of Technology (UoT) is represented in the third band, of institutions that continue to enrol students from other racial categories, probably because they are merged institutions which amalgamated historically advantaged and disadvantaged institutions. The figures for CPUT are also quite consistent over the five-year period, with $17 / 14 \%$ white, $1 / 1 \%$ Indian, $33 / 29 \%$ coloured, 42/48\% South African African, and 7/9\% foreign or unknown enrolments in 2008 and 2012. It appears that the most transformation in terms of racial categories has taken place at CPUT, with nearly half the student enrolments in 2012 being South African Africans. Considering the South African population statistics regarding apartheid racial categorisation categories (79.2\% black African; $8.9 \%$ white; 8.9\% coloured; 2.5\% Indian or Asian; 0.5\% "other") (Brand South Africa, 2017), it is clear from this and Table 1.1 that the racialised representation of students has not altered in significant ways, which was anticipated in the Higher Education White Paper (1997). 


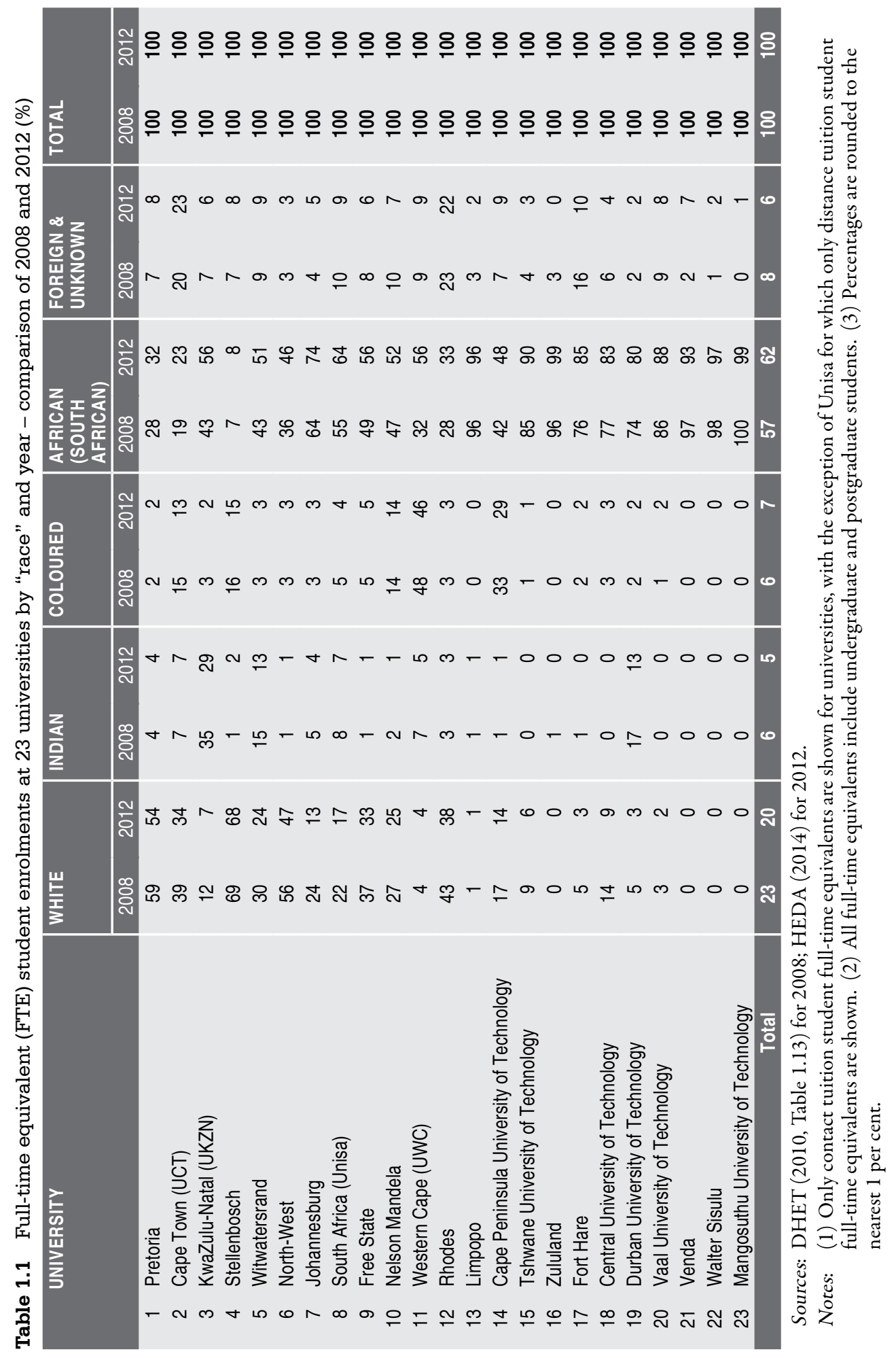

Perceptions on socially just pedagogies in higher education 
This background information, including the racialised profiles and access to resources of HEIs (Bozalek \& McMillan, 2017; Cooper, 2015), provides a sobering picture of the whole system of higher education in South Africa, and some reasons why student protests were so extensive across the country. It is crucial to know the historical background and current status of the HEIs that employ the academics who were interviewed for the research focused on in this chapter, as this provides the backdrop and context for what they do to engage with social justice issues at their institutions, which are different, and which thus also influences the way in which they practise socially just pedagogies.

\section{Interviews with academics}

Academics who were identified by others in their institutions, or who identified themselves, as practising socially just pedagogies were interviewed in Cape Town and Stellenbosch at UCT, SU, UWC and CPUT between 2014 and 2016. A total of 27 interviews were conducted with academic staff in from a range of disciplines, faculties, departments and centres at these HEIs, as demonstrated in Table 1.2.

Table 1.2 Interviews conducted with academics on socially just pedagogies at HEIs in Cape Town

\begin{tabular}{|c|c|c|c|c|}
\hline $\begin{array}{l}\text { HIGHER EDUCATION } \\
\text { INSTITUTION }\end{array}$ & FACULTY & $\begin{array}{l}\text { DEPARTMENT/ } \\
\text { CENTRE }\end{array}$ & \begin{tabular}{|l} 
NUMBER \\
OF PEOPLE \\
INTERVIEWED
\end{tabular} & PSEUDONYMS \\
\hline \multirow[t]{10}{*}{$\begin{array}{l}\text { University of the } \\
\text { Western Cape }\end{array}$} & $\begin{array}{l}\text { Economic and } \\
\text { Management } \\
\text { Sciences }\end{array}$ & Business and Finance & 2 & $\begin{array}{l}\text { Shafiek } \\
\text { Graham }\end{array}$ \\
\hline & $\begin{array}{l}\text { Community and } \\
\text { Health Sciences }\end{array}$ & Physiotherapy & 1 & Edgar \\
\hline & $\mathrm{N} / \mathrm{A}$ & Writing Centre & 1 & Beryl \\
\hline & Arts & History & 1 & Jane \\
\hline & Law & Constitutional Law & 1 & Carl \\
\hline & $\mathrm{N} / \mathrm{A}$ & $\begin{array}{l}\text { Teaching and } \\
\text { Learning }\end{array}$ & 1 & Rebecca \\
\hline & Arts & $\begin{array}{l}\text { Women's and Gender } \\
\text { Studies }\end{array}$ & 2 & $\begin{array}{l}\text { Kate } \\
\text { Margaret }\end{array}$ \\
\hline & Natural Sciences & Physics & 2 & $\begin{array}{l}\text { Vuyo } \\
\text { Leslie }\end{array}$ \\
\hline & Natural Sciences & Mathematics & 1 & Fred \\
\hline & Natural Sciences & $\begin{array}{l}\text { Biodiversity and } \\
\text { Conservation Biology }\end{array}$ & 1 & Tony \\
\hline \multirow[t]{4}{*}{ Stellenbosch University } & Education & Curriculum Studies & 1 & Edward \\
\hline & Education & $\begin{array}{l}\text { Educational } \\
\text { Psychology }\end{array}$ & 1 & Gail \\
\hline & Arts & Design and Fine Art & 1 & Sheila \\
\hline & Arts & Psychology & 1 & Nadia \\
\hline
\end{tabular}




\begin{tabular}{|c|c|c|c|c|}
\hline $\begin{array}{l}\text { HIGHER EDUCATION } \\
\text { INSTITUTION }\end{array}$ & FACULTY & $\begin{array}{l}\text { DEPARTMENT/ } \\
\text { CENTRE }\end{array}$ & $\begin{array}{l}\text { NUMBER } \\
\text { OF PEOPLE } \\
\text { INTERVIEWED }\end{array}$ & PSEUDONYMS \\
\hline \multirow[t]{7}{*}{ University of Cape Town } & $\begin{array}{l}\text { Centre for Higher } \\
\text { Education }\end{array}$ & Languages Group & 1 & Candace \\
\hline & Humanities & Anthropology & 1 & Susan \\
\hline & Humanities & Media Studies & 1 & Ben \\
\hline & Humanities & Psychology & 1 & Thembi \\
\hline & Health Sciences & $\begin{array}{l}\text { Obstetrics and } \\
\text { Gynaecology }\end{array}$ & 1 & Beverley \\
\hline & Health Sciences & Occupational therapy & 1 & Lerato \\
\hline & Engineering & Electrical Engineering & 1 & Robyn \\
\hline \multirow{3}{*}{$\begin{array}{l}\text { Cape Peninsula } \\
\text { University of } \\
\text { Technology }\end{array}$} & N/A & Fundani & 1 & Renee \\
\hline & Engineering & Geomatics & 1 & Zayan \\
\hline & $\begin{array}{l}\text { Informatics \& } \\
\text { Design }\end{array}$ & Visual Arts & 1 & Maria \\
\hline & & Total interviewed & 27 & \\
\hline
\end{tabular}

\section{Interview schedule}

All interviewees were asked the same set of questions, which had been developed in a previous project examining socially just pedagogies in various South African and international HEIs. Interviews were conducted in the academics' offices or in public places, such as coffee shops, and lasted from 30 to 150 minutes. In cases where academics were not available face-to-face, interviews were conducted over Skype. All interviews, but one, were conducted by one of the authors, after initial e-mail contact to gain permission and arrange the time and place for the interview. The following questions were asked in each interview:

1. What are your perspectives on social justice? And on critical, compassionate citizenship?

2. What pedagogical approaches do you use for teaching about/for social justice?

3. What are your notions of critical citizenship/social justice education; how do you practise this in your classrooms; and to what effect? What are you trying to achieve in your own practice regarding critical citizenship/social justice/social inclusion? What is your perspective and/or practice in relation to emotional reflexivity?

4. What sort of knowledge/qualities/dispositions/values are you wanting to develop in your students, and why?

5. What are the achievements and joys you encounter when implementing your pedagogical approaches and how do you explain this?

6. What are the challenges or obstacles you encounter when implementing your pedagogical approaches and how do you account for these? 
These questions form the basis of the data that was obtained.

The rest of the chapter deals with the findings from the interviews. The research questions that guided our analysis were:

(a) How do higher educators understand the concept of "social justice"?

(b) How do higher educators understand critical, compassionate citizenship and the role of higher education institutions towards cultivating this sort of citizenship?

(c) How do higher educators practise social justice in their pedagogies?

For the purposes of data coding, we worked first with a smaller sample of data in order to identify the main emerging themes. These themes developed under three main areas, which largely corresponded to the research questions: higher educators' understandings of social justice; higher educators' understandings of critical, compassionate citizenship; and, higher educators' socially just practices.

\section{Findings of the interviews}

\section{Higher educators' perspectives on social justice}

The perspectives emerging from higher educators' views on social justice confirm not only the multidimensionality of the term "social justice" but also its contextual complexity and the meanings attached to it in light of contemporary social and political developments in South African higher education. For example, most interviewees made some reference to social equality/inequality, discrimination, power relations. Many also referred to social inclusion/exclusion, having one's voice heard, and how to address these in relation to higher education. There was also reference to a fair distribution of resources, opportunities and privileges in society; of maximising students' ability to flourish; and to being responsive to the particularity of students' needs, rather than treating everyone the same. Social justice was also conceived of as the freedom to be able to pursue significant priorities in one's life, with higher education being one such priority. Interviewees also mentioned the power relations that shape higher education and the impact of this on students, in addition to distributive justice or legal mechanisms. The quotes from the interviews that follow demonstrate this contextual complexity and show how important it is to clearly understand how higher educators are calling upon the idea of social justice, and the range of priorities and visions they hold. Without acknowledging these differing perceptions, it would be impossible to evaluate their contributions and limitations in terms of the larger goal of developing socially just pedagogies. 


\section{Discipline-related and institutional views of social justice}

Interviewees from different academic disciplines perceived social justice differently; perhaps unsurprisingly, their views seemed to be influenced by the disciplinary discourse of their fields. Tony from Biodiversity and Conservation Biology, for example, saw injustice in global terms, where poorer nations suffered because of the avarice of rich countries, thus highlighting the notion of interconnectedness that was foundational in biodiversity:

[... ] excessive greed by a few selective societies at the expense of a multitude of poorer countries, citizens, in the world. So we push very hard the idea of justice across the different nations of the world. (UWC, Faculty of Natural Sciences, Biodiversity and Conservation Biology)

Beryl from the Writing Centre saw social justice as providing students with ontological and epistemological access to discipline communities, as did Hannah in Physics, who saw it as important to give students access to what might be invisible or taken-for-granted knowledge in a discipline such as Physics. These views are consistent with a Bernsteinian view of social justice in higher education, which holds that if students gain access to "powerful knowledge" - by which they mean disciplinary knowledge - they will be able to use this to change their circumstances (Wheelahan, 2010).

Sheila, in Design, regarded social justice in art as moving beyond just exhibiting a concern for societal issues:

[...] for me it's very important for students leaving this department to not only think about 'how am I going to exhibit in the best gallery', instead of thinking 'how can my art contribute to society, or how can it make society better'... the way we are indoctrinated basically with a capitalist system where you have to exhibit in these galleries, you have to be a successful artist, and a very individual process very often because it's so much promoted that you could become famous when you exhibit in this gallery. (SU, Arts Faculty, Design and Fine Art)

Maria, from a design discipline, but from another institution, CPUT, also saw social justice from her disciplinary perspective, and saw her role as conscientising students about the sort of work that they would do. For Maria, the discipline is more than the technical aspects of learning, but the contribution that this would make to improving people's lives:

So for me the big question facing designers - which is what our students are becoming - in the twenty-first century, is: what does design do, what work does design do, what work do designers do, to create or respond to the need, the social needs - locally but globally as well? So at every point I try and raise that consciously, so it's not simply learning about form and function as much 
as understanding the context and how it's going to, I guess, improve people's lives in an inclusive and empowering way. (CPUT, Faculty of Informatics and Design, Design)

Shafiek in Business and Finance also expressed the desire that students should be developing the ability to improve their own and their clients' life circumstances. He also saw it as important to be generous and give of one's own wealth to share with those who don't have - thus seeing social justice in material terms.

Gail from Educational Psychology in a historically advantaged institution had thought deeply about social justice in her teaching and had written academic papers about this. She saw it as important to think about social justice in relation to where she was located, particularly with regard to pedagogy. She emphasised that social justice has to do with the educator's relationship to who the students are. She had to adapt her teaching and think about the students at the institution where she was teaching, what their prior experiences had been and what exposure they had had to social justice debates:

If one is working with students, for example, who have been through a history of oppression - who have experienced in many, many ways a social justice conscientisation - one works at a very different level with students pedagogically; so one can use a lot more radical kind of social justice approaches. But if one works, like I do most of the time, with groups of students who have had little exposure to even debates around social justice, and who, for a large part come from very privileged environments, one cannot use those very same approaches in thinking about pedagogy because it will just push them away. And I have had those experiences where I taught about community psychology in a much more radical way - they didn't hear any of it. And so I think in those kinds of situations one may need to think about where are students at; what for them constitutes social justice, and how does one move them from that towards a more radical understanding and structural understanding of social justice. And so for me, of course, social justice really covers a whole number of components, so to speak. It's about redistribution, it's about cultural justice, it's about people having a voice. But I think it's not only at an objective level; it's also at a subjective level and the interaction between those. And so for me that's what social justice is. (SU, Faculty of Education, Educational Psychology)

As this strand of thinking about social justice is primarily disciplinary and institutional, it relies heavily on offering broad ideas and principles at a level that takes into consideration the epistemological and sociological context in which higher educators work. The contribution of this strand of thinking is that it helps us to get greater clarity about the contextual assumptions, terms and visions that are made about social justice from discipline to discipline and from institution to institution. 


\section{Philosophical/theoretical conceptions of social justice}

In contrast to the above contextual understanding of social justice, some academics interviewed regarded social justice from more abstract and theoretical perspectives. Kathy from Engineering referred to Amartya Sen and saw injustice as "inequality with regards to not only material but other resources in society, the freedom to do the things you want to do and what matters to you in life" - which refers to Sen's notions of freedoms, and of valuable beings and doings (Deneulin \& Shahani, 2009; Sen, 1999, 2009). Carl, an academic teaching constitutional law, saw social justice in a similar way to Nancy Fraser, foregrounding participation rather than access to resources:

$[\ldots]$ if you look at socio-economic rights, many people think of socioeconomic rights as welfare or as poverty alleviation. To me that's a sideshow - the injustice is not that people are poor; the injustice is that they can't participate and therefore they are excluded from this possibility of a transformative civic identity and belonging in that sense. And so participatory parity is all about achieving that - and so it has an economic basis, it has a recognition basis, but it also has a voice basis. (UWC, Law Faculty, Constitutional Law) [our emphasis]

Ben, an educator in Media Studies, referring to the \#RhodesMustFall student protests which were occurring at UCT in 2015 , also emphasised participation through recognition, representation, voice and student agency in his view of social justice:

And the big thing for students - \#RhodesMustFall right now this year - being here is not enough; the actual value of participation is significant: What is the actual quality of our life here? How visible are you? How audible? Are we able to set the agenda? Are we able to debate the merits of the curriculum as opposed to just worrying about assimilating? So all of those things link to social justice; it's about not just being present but being recognised as such and actually being able to speak on your own terms - exercise agency. And the big thing for students - \#RhodesMustFall right now this year - being here is not enough; the actual value of participation is significant: what is the actual quality of our life here? How visible are you? How audible? Are we able to set the agenda? Are we able to debate the merits of the curriculum as opposed to just worrying about assimilating? So all of those things link to social justice; it's about not just being present but being recognised as such and actually being able to speak on your own terms; exercise agency. (UCT, Faculty of Humanities, Media Studies)

Susan, an educator in Anthropology, thought that justice should be extended beyond the human to the non-human, and that the emphasis should not only be on the social of social justice. This perspective is consonant with a critical posthuman perspective on justice (Bozalek \& Zembylas, 2016):

I think social justice for me has got to do with the human condition whereby we just have so much suffering in the world on so many different levels and 
that anything we can do to eliminate the gap or lessen the gap between the haves and the have-nots, would be something that's socially just. But I also think it extends to non-humans - you're thinking about the environment, possibly other actors. I must say Latour, I think, has really influenced me in thinking about what he calls 'actants' and thinking about how it is that ... living, non-human living beings and also just other objects have their own agency and a will; and how [we can] actually think about protecting those. So I was fascinated in New Zealand when they issued a river with full rights, so it's a river and its given the kind of agency that we would give to human rights; and I thought that was just such an interesting ontological shift in the way that we value and understand what it means to be a being on this planet. So social implies that it's possibly only humans but I guess I want to extend that to non-humans as well. (UCT, Faculty of Humanities, Anthropology)

Some interviewees articulated philosophical stances regarding the notion of social justice. Edward from Curriculum Studies in Education, for example, expressed his views in the following way, showing an inclination towards a relational ontological view of social justice:

My approach to social justice is informed by the Neo-Aristotelian view that you do things in association with others in a deliberative spirit, listening attentively to what others have to say; and others in turn should oblige - taking [under] critical scrutiny one another's views and recognising vulnerabilities [in] making changes. (SU, Education Faculty, Curriculum Studies)

Similarly, Rebecca from Teaching and Learning, expressed a relational and feminist new materialist view of social justice, drawing on the work of Karen Barad (2007) and Donna Haraway (2016):

[... intra-acting responsibly and being part of the world. They talk about 'worlding'; and Haraway and Barad also talk about human flourishing, but [they] very much [see] human beings as being entangled with non-human and other matter. (UWC, Teaching and Learning in Higher Education)

The higher educators' thinking in the theoretical or philosophical strand seemed to foreground the meaning of social justice from a few different perspectives. Common theorists to which references were made included Amartya Sen, Nancy Fraser, and Karen Barad. As this strand of thinking was primarily theoretical or philosophical, it relied heavily on offering theoretical principles and constructs for application in thinking about social justice. This reminds us of the importance of being cognisant of the richness of existing theories and of taking care to articulate them in relation to the realities of each context in which we find ourselves.

A few interviewees were motivated by spiritual beliefs in their ideas about what should be done to act in a just manner. Shafiek from Business and Management Science saw generosity and charity to be important, stemming from his Islamic 
spiritual beliefs, while Fred from Maths also has beliefs regarding social justice which stem from, amongst other things, spiritual or religious convictions:

[...] driven by ... your conviction that all people deserve - I don't know if love [laughter in voice] is the starting point ... I suppose mine would be informed to a large degree by morals, by faith, by experience of course as well. (UWC, Faculty of Natural Sciences, Mathematics)

\section{Uneasiness with the concept of social justice}

While the majority of interviewees were quite definite about their views of social justice and saw it as a useful and necessary concept, others were more tentative about it. One interviewee saw the concept as a meaningless one: it means nothing as it means so many things to so many people, changing from context to context. Another interviewee, Jane, expressed her concerns regarding the term, critically examining her own positionality and that of her students:

I'm wary of the term 'social justice' because far be it for me from a privileged background to preach to my students. I think they probably know more about it than I do - so I'm very wary. (UWC, Faculty of Arts, History Department)

Candace, from the Languages Group at the Centre for Higher Education also expressed an uneasiness with the concept of social justice regarding herself - seeing the concept as having many layers. She firstly locates injustices in the South African society and the effects that these have on her. She also reflects on her own institution which she regards as privileged, and difficult to access for students, and then, more generally again, on different forms of discrimination. She prefers to locate herself within the disciplinary field of academic literacies rather than a personal position when she considers how she responds to the notion of social justice:

I think that's also what makes it hard to easily say, to use a term like 'social justice' at the forefront of what I do. I can talk about it [more] in the collective $[\ldots]$, when I'm thinking about the work we do in the language development group or the bigger academic literacies project - then I can say when I'm talking about the 'we'. But when I'm talking about the 'I', I find it much harder; and I think it's something about that as well. (UCT, Centre for Higher Education Development, Language Development Group)

The different strands identified in this section on social justice include disciplinespecific and institutional; philosophical/theoretical; and also demonstrate some dis-ease with the concept of social justice). All in all, it is useful to develop some kind of organising framework to make sense of the various kinds of perspectives and visions that higher educators hold in their respective institutions when they claim to ground their pedagogies in social justice. What was also fascinating in our sample, for example, was how the perceptions of social justice differed between 
those in similar disciplines or faculties at the same institution, with some being more responsive to where students were starting from and working from there; and others being more provocative and challenging towards students. Despite the progress that has been made in South Africa regarding efforts to promote social justice, one of the pieces that seems to be missing is a genuine and critical dialogue across disciplines and institutions: this would help us to build on each of the contributions of each strand of thinking (such as those identified in this study, but also others that may emerge), as well as to better acknowledge the contextual challenges of each institution.

\section{Perspectives on critical, compassionate citizenship}

One might wonder why we include in this study an investigation of the notion of critical and compassionate citizenship, or how it might be relevant to social justice. In recent years, there have been growing discussions about citizenship as compassionate and empathetic understanding of "the other" (Fortier, 2010; Johnson, 2010; Mookherjee, 2005); namely, how citizens can be encouraged to develop compassionate feelings and actions as part of efforts to promote social justice. In the context of education, for example, the notion of critical and compassionate citizenship emphasises the interrogation of how individuals and groups are taught to feel certain emotions about themselves and others and examine the consequences of those emotions (Zembylas, 2014). In addition, a broad concept of critical and compassionate citizenship cultivates emotions of compassion and empathetic understanding of the other rather than monolithic emotions of loyalty and attachment - to the nation, or to those who are considered "citizens" in a narrow legal sense. Therefore, the notion of critical and compassionate citizenship is very relevant to social justice and we included its investigation in this study in order to explore how higher educators make sense of this notion as an element of their work in terms of social justice.

Unsurprisingly, many of the interviewees had not heard of the term itself, nor of the combination of critical and compassionate citizenship, and had to think very hard about what this meant, although they had some ideas about each separate notion, or about critical citizenship. With regard to the notion of criticality, many of the interviewees saw it as being an important attribute for students to develop, for example about their own disciplines, as Leslie conveys in her wish for her physics students to develop a view of the world that is more transdisciplinary and fuller, rather than only a narrow scientific view:

I've been very aware of scientists or students not being aware of science in the broader context, of the social and ethical dimensions of science. I try in my teaching to undermine that whole scientism - which is that idea that science is the best or the only way of knowing the world. From my own experience as an undergraduate, the science community can be quite 
smug - I remember as an undergrad myself, this snide [way of] referring to arts students - that science is somehow a better way of knowing about the world. And so I actively try and resist that with the students; to [make them] aware that science is just one way of understanding the world; and [that] to be more [fully] human beings they need to engage with literature and with other ways of understanding. And also contesting this idea that science is going to solve all our twenty-first century problems ... clearly it's not - it's actually climate change and inequality and all those problems that science alone cannot solve - it has to be science in relation to sociology and human understanding. (UWC, Faculty of Natural Sciences, Physics)

Other interviewees, however, applied the notion of criticality to themselves and their own practices as teachers in higher education. Shafiek, for example, regarded it important to interrogate what he did in class to see if he could inadvertently be perpetuating injustices towards students:

[...] critical for me is looking at how what I'm doing perpetuates injustices so in other words if I teach poorly or if I don't empower some of the students that come from a different cultural background in my class, if I don't do that then ... I am keeping them behind and I'm perpetuating this. So the critical part would be my awareness of what I do, that inadvertently without me knowing perpetuates injustice - and that's the critical dimension: in thinking about your own involvement or your own role in the perpetuation of injustice. (UWC, Faculty of Economics and Management, Business and Finance)

Another example of criticality towards oneself as a teacher is Renee, from Fundani Centre for Higher Education who finds it difficult to empathise with students who are defensive in her classroom, particularly about their privileges:

I think this is one of the things that I struggle with - [it's] to feel empathetic for all students, also for those for whom it's much more difficult to open up and to understand what I'm trying to do or where I'm going, and who react very defensively. For me that is my biggest challenge - [it's] how to be with those students who act understandably defensively because they are being put immediately in a position of the oppressors or the ones who are guilty or who are painted guilty because of where they are coming from. (CPUT, Fundani Centre for Higher Education)

Although not initially au fait with putting together the concepts of critical and compassionate citizenship, most interviewees had thought about this and provided some of their understandings of how these were related, and would play out, in their views relating to social justice and higher education. Susan from Anthropology was very committed to the notion of critical citizenship, which she saw as a graduate attribute and also believed that anthropology assists with the development of all three of these concepts:

Critical citizenship for me when I think about what it is that I want our undergraduates to exit with; the ability to see the world as complicated, messy; to feel a degree of comfort in that messiness and to therefore start 
to unpack it and not try to put it in boxes. I guess one of the things we do a lot of in anthropology is deconstructing just about everything, including our own discipline. We do cast a critical eye on ourselves constantly; others do it for us. I think compassion for me would be the ability to see the world from another's eyes; but that's also really anthropology of course also, and my job is to be able to translate the world in another so that people can in a sense talk to each other. So, ja, I guess in presenting a worldview of another, you hope to develop the compassion. (UCT, Faculty of Humanities, Anthropology)

Thembi, a Psychology academic, was critical of the notion of compassion from a sentimental or patronising perspective, of doing good, but found it acceptable from a relational and political perspective, to understand the perspectives of others:

As long as compassionate doesn't mean being nice; I think being nice is what's caused us a lot of problems - and so the point is not to be nice. I think perhaps compassion should be about trying to understand the perspective of others and trying to take on the perspective of others in our lives, in our lives as citizens, in our relationships. So then in that case it would make sense to me. Often compassion means charitable type of thing, and that I think is not helpful. (UCT, Faculty of Humanities, Psychology)

Generally in the interviews, compassion was seen as an affective rather than cognitive response (felt rather than thought), and as the ability to reach out and have a nuanced understanding of the other. One interviewee went back to the original meaning of the word compassion as with passion, which led to a more active notion of compassion - acting on one's understanding with passion and empathy rather than coldness, as can sometimes be the case with academics putting another down in debates or reviews. Compassion was also seen as the ability to give and receive, to show fallibility as a teacher to students, and to indicate that students have affective impact on the teacher too. Zayan from Geomatics expressed it this way:

$[\ldots]$ being able to give of yourself to your students, also being able to receive graciously - not because I think that I'm a martyr - I don't pretend to know. It's important for me to show that I am fallible also, to my students, and I can be wrong. And I like to show that it affects me, whatever they do does affect me, $[\ldots]$ whether it's positively or negatively. (CPUT, Engineering, Geomatics)

Citizenship was seen to be about participation, belonging, and for some also being human - as Gail expressed it:

$[\ldots]$ for me citizenship, the core of it is - what is it that makes us human? For me that is the core of citizenship: the kinds of things that make us actually at the personal, individual, interpersonal and structural level that makes us feel that we belong or don't belong. (SU, Education Faculty, Educational Psychology)

A few interviewees were more critical of the notion of citizenship in its conventional conception. For example, the nation-state view of citizenship, which could lead 
to "othering" (Jensen, 2011:63-78) and on the concentration of "human" that citizenship could imply, which could lead to anthropocentric views:

But I think that to be a citizen of a place means that - I suppose it gives people a sense of belonging. But it is something that I'm finding a little bit problematic in a sense because citizenship of a nation ... for example: nation-states and hierarchies that are built up imply 'othering. But after having thought about global citizenship for a bit I realised that it's also anthropocentric. So again, there's that species hierarchy that's kind of implicit in there. (CPUT, Engineering, Geomatics)

Carl from Constitutional Law had given much thought to all three concepts critical, compassionate, and citizenship - and how they worked together. He came to conclusions similar to those of Fraser $(2008,2009,2013)$ and Zembylas (2014) in the notion that citizenship is not equivalent to nationality:

So citizenship in the classical sense would be overlapping with nationality and would entail an element of patriotism towards the nation and nation building. My understanding of citizenship is subversive of that, it's completely not that; it is to try and resist framing of issues in terms of nationalism. One of the pre-conditions of forming a civic identity, participating democratically as a citizen, is this kind of empathy and openness towards difference and the ability to look across and beyond your own interests. So compassion in that sense I think plays a key role; but compassion in the sense of reflective compassion, a judgement - it's seeing the world from your perspective, understanding your plight, your position and your framework and then feeding that into a reflective judgement where other perspectives are also taken into account. So to me one should separate citizenship and nationality. Nationality is a legal technical concept that you carry a passport: that doesn't make you a citizen, it makes you a national and [you] can claim international benefits and [sanction of] international law and then you go for your passport - it's got nothing to do with citizenship. And the same with an identity document. Citizenship involves something different - so it's a new citizenship, which involves this critical compassionate dimension - then you become a citizen. (UWC, Law Faculty, Constitutional Law)

This is similar to Francis Nyamnjoh's (2016) view of flexible citizenship in his writing about the \#RMF movement in South Africa. He regards open-mindedness as crucial in encounters and relationships in order to be and become citizens. His view is that citizenship should not be bounded by "race, ethnicity, class, gender or geography", and that one must be "both conscious and critical of hierarchies that make a mockery of the juridical-political regime of citizenship provided by the coercive illusion of the nation-state" (Nyamnjoh, 2016:232). As well as seeing citizenship as broader and more fluid than the nation-state, and foregrounding criticality, similarly to Carl, Nyamnjoh sees citizenship as relational, as resulting from social action, as establishing balances between competing interests of collective groups, and as a means that privileges are "claimed and contested, sought 
and maintained" (Nyamnjoh, 2016:233). The notion of conviviality is important to Nymanjoh when thinking about citizenship from a relational and interdependent positionality and could perhaps be a useful addition to the concept of compassion, with regard to citizenship.

All in all, with regard to the interviewees' responses to critical and compassionate citizenship, although many of them had not thought about the three concepts together, they offered insightful ideas about these three concepts, as can be seen in the excerpts in this section. These notions offer a useful critique of the normative ways in which citizenship has been defined so far, because they acknowledge not only some neglected aspects of citizenship (e.g. conviviality, compassion), but they also enrich discussions about socially just pedagogies by empowering students to become more hospitable to others. The investigation of these ideas, then, in conjunction with socially just pedagogies, suggests the need for a more complex discourse of social justice and citizenship education at the higher education level.

\section{Practising social justice in teaching}

In this chapter, the last section in reporting the findings of our interviews with higher educators pertains to how they practised social justice in their teaching. In contrast to the more abstract and philosophical orientation of the previous two themes, this one is more practical, offering criteria and ideas for what socially just pedagogies in higher education look like in the interviewees' work settings. Scholars have pointed out that socially just pedagogies are about the content of what is being taught; the way in which the teaching is happening (Moje, 2007); and the mechanisms and social arrangements which are put in place by institutions to arrange pedagogical practices (Leibowitz \& Bozalek, 2015). Therefore, it is a valuable experiment to identify precisely what sort of content and mechanisms are used in higher educators' everyday practices for promoting social justice.

\section{Content and strategies used in socially just pedagogies}

Kate, from Women's and Gender Studies, thought that for socially just pedagogies, both content and pedagogical approaches were important for developing student agency:

I mean, obviously the content is important - that we attempt to shift [from] the kind of dominance of Eurocentric models, Eurocentric theories, Eurocentric examples, Northern examples; but what we have not given enough attention to is the actual practices in the classroom and how we continue to model an expert, dominant, authoritative voice of the Lecturer a didactic model of teaching and learning, which - I think - is not conducive to ... Social Justice Pedagogy. [We need to think] very critically about what we do in the classroom, and outside the classroom; and [find] ways in 
which we get students to be agents and to develop scholarly identities and participatory kinds of active education. (UWC, Faculty of Arts, Women's and Gender Studies)

Like Kate, Thembi in Psychology regards a socially just pedagogy to be a combination of a critical stance towards the discipline, a consideration of who your students are, and an interactive approach to teaching:

[... ] a critique of the discipline and a critique of society. So both of those things kind of come into the classroom or the curriculum of what I prescribe [for reading]. And how, for instance, psychology is also very gendered, it's a very male discipline - so it's led us to believe certain things about the differences between men and women and fixes people in particular identity categories. So my approach is really to offer a critical reflection on mainstream forms of psychology. I try to make the curriculum also relevant to people's experiences in my classroom. So we'll talk a lot about issues of race, class and gender, sexualities. And then in terms of experience, like day-to-day experiences, I also link those experiences to perhaps broader issues around ideologies; how does capitalism fit into it, how ... the ideologies around racism or ... the past fit into the historical context of apartheid, colonisation and what they've led us to believe.

The classes are very interactive. I try and get colleagues from different departments to come and present so that it's more interdisciplinary. I get my students to present. (UCT, Humanities Faculty, Psychology)

Rebecca referred to the significance of modelling democratic practice in one's teaching, rather than just focusing on social justice in the content of the curriculum:

For me it's going beyond the content. If you are talking democracy and you are behaving in a very autocratic or dictatorial way towards students, for me it doesn't make much sense. One needs congruency [in] what you're actually doing - because I think it's in the doing that people would learn more than in the actual saying. Ja. It's not only modelling - modelling is also important but it's how you give people spaces to express themselves as well. And I suppose also what you would hope for for your students, and how you try and grow people rather than diminish them. (UWC, Teaching and Learning in Higher Education)

Following on from the conviction that both the content and what we do in the classroom are significant, the relationship between lecturer and students is a crucial consideration for socially just pedagogies, as Fred from Mathematics explains, indicating how his modesty and egalitarian stance is important for teaching mathematics:

Teaching is about a relationship between the teacher and the learner, and like any relationship the openness of that relationship will hinder or encourage the person to learn - so to be absolutely fair and open and non-judgemental at a human level is crucial, even whatever your subject is. But I think [it's] in 
mathematics in particular where it does have an emotional effect on people. I certainly try to convey to the class, if I've got a class, that I am approachable, that I listen, that I am there for them, that I don't laugh at them, make them feel small; that I'm not there to lord it over them - that kind of attitude for me is really important to get across - that I am fortunate that I have knowledges that I can share with them, but not that I'm better than them. (UWC, Faculty of Natural Sciences, Mathematics)

Carl, from Constitutional Law, emphasised the methodology that he used in teaching, which he saw as pertaining to social justice. His approach is unusual in a discipline like Constitutional Law, in that he uses novels and storytelling to teach it, which he relates to poetic justice and to transformation. He also tries to convey to students that knowledge is contested - that there are no right or wrong answers. However, he is unsure of the impact that his course makes on the large groups of students he teaches:

The method that comes close to that is this method of storytelling, the storytelling methodology; because there are some people that write and say when you apply/interpret legislation or apply rights, [they] are getting that poetic justice idea, to act as a poet, that you'd need those poetic skills and literary skills to be able to be a judge in the first place. So the methodology that I try and teach in that course is one that is open to this kind of transformative effect and would not allow a judge to say, well, I'm just applying the law - it's about law and not about justice. So it's a methodology in which justice is the central focus. So, I don't accept that there's a right or wrong answer first of all - it's all contestable. It's what values you bring to the table - and right and wrong on whose book? The legal test for right and wrong is too limited. (UWC, Faculty of Law, Constitutional Law)

With regard to the sorts of arrangements that would assist in promoting social justice in higher education pedagogies, Tony from Biodiversity and Conservation Biology had some ideas of how higher education institutions should change to accommodate difference and spend less funding on infrastructure. He makes reference to the dissatisfaction that is being experienced more generally in South African society and which is being manifested in higher education:

I think we in South Africa are going to have to really rethink how we do our education - big time. You're going to see a political change - you have a ruling government that has certainly in the local elections got bruised. We are seeing a lot of discontent. At the moment the education is the target, though I think it goes far deeper than the education. The real challenge is: should we still be investing in big concrete structures at university or should we have the idea of [a] sort of distributed university - a series of fairly simple buildings, very connected to the internet - and we start to run virtualisations across. First of all, environmentally it will be sound because there will be so much less transport. We could get education to communities that are disadvantaged. We don't necessarily need to pull students out of their family to be in residence. 
It might also help the idea that students can also still get an education but support their family. So I would like to see the idea of a sort of distributed university rather than these kind of corporate structures. Universities are starting to try to resemble big corporate buildings with shiny facades. (UWC, Faculty of Natural Sciences, Biodiversity and Conservation Biology)

What emerged as interesting from the interviews, and which was alluded to in the previous section on conceptions of social justice, was the extent of the differences in the views of people from the same faculty and the same institution. In their conceptions of socially just pedagogies, two academics from the same institution and faculty completely differently saw their roles in changing how students think. The one was more interested in getting to know the students and proceeding to work with where they were coming from and use participatory techniques where the students reflect on their own experiences to come to a more structural understanding of discrimination and injustice:

How do I practise it? I think there are a couple of ways. Firstly - and [it] has taken me quite a while to get to this place, and certainly from 2004 onwards - it became quite important for me to really recognise where my students are coming from, because most of them come from very, very different backgrounds from the one that I come from, and some have very different views as well: often very conservative views. And I realised - long before I had read stances towards critical pedagogy or critiques of critical pedagogy - that adopting a political soap-box stance was just not going to work with students and that in fact I was going to cut them off completely and actually not create opportunities for them to engage with work in community psychology. So I tried different ways of working with them. So that [was] like thinking about who my students were. And I think that is still very, very important for me to know a little bit more about my students. (SU, Education Faculty, Educational Psychology)

In contrast to this more conciliatory approach, which starts from where the students are, Edward in Curriculum Studies uses a more confrontational approach - what he calls a provocative or belligerent encounter, which is disruptive and provokes students by asking questions and providing spaces for alternative imagining:

$[\ldots]$ so you can throw into a pedagogical relation - or insert into a pedagogical relation - what I would call a belligerent encounter, something that is more provocative; and in that way it's about opening the minds of students and yourself, and you connect with one another. For me, a provocative encounter will just open up - and often [a] complex pedagogical situation is messy - [in this way] disrupting the pedagogical encounter, which is really an encounter whereby students are free to speak their minds. And there are some students who are very responsive to the kind of work that I've been doing - no, but not overwhelmingly. The encounter is not about your intellectual engagement only; the encounter is where student and I bring to the encounter our own cultural orientations - and that's vast and diverse. So you cannot 
overwhelmingly use destructive teaching as a way to include; then you have to act more responsibly towards students, I call it compassionately. I think our work in education should remain to ask questions - because if we are not going to ask questions then we are not going to let anybody - and ourselves think. So even - you don't have to be so disruptive - but even asking a question in a particular way can be a form of disruption because you're making the other person think, and creating that opportunity to see things differently. (SU, Faculty of Education, Curriculum Studies)

An important consideration, then, that seems to be relevant to compassionate teaching in socially just pedagogies is paying attention to affect. Some of the interviewees saw the inclusion of affect as central to thinking about socially just pedagogies:

Ja, for me you can't think about education without thinking about affects and emotion. If students aren't emotionally engaged, I don't think they will learn. And it is a more inclusive way of engaging with education because it's something that everyone can respond to. (UWC, Teaching and Learning in Higher Education)

The necessity of thinking about emotions as political (Zembylas, 2007, 2008) was also stressed by other interviewees, who made specific reference to the pedagogy of discomfort, which was deemed necessary for learning about issues of social justice:

I want them to reflect back on the emotional responses they have both in writing and hearing their stories and when listening to other stories. And so it's one way of showing that what's happening in the classroom is political ... That's one of the things I want to try this year - for example, ask them on a piece of paper to draw a story and say how do you feel, and then have each of them tell the first thing that came to mind - and some might feel angry, some might feel pity - and then start a conversation, why is it that you felt angry and the student next to you felt pity? And those are uncomfortable conversations, but I see if I get something ... But there are raw emotions and one has to handle those raw emotions and they have to be handled in a safe space, otherwise I think it would be extremely unethical - because our students do not go there completely voluntarily. (CPUT, Fundani Centre for Higher Education)

By drawing on these emotions and enacting "critical emotional reflexivity" about socially just pedagogies (Chubbuck \& Zembylas, 2008), educators in higher education may take up the call to engage in interrupting their teaching practices as part of the struggle to improve the learning opportunities of their marginalised students. Critical emotional reflexivity could serve as the basis for educators' work, eventually bringing about changes in themselves, in their relationships with students, in their conceptualisation and practice of socially just pedagogies, and in their activism/advocacy at the institutional level. This point of engaging and reflecting on emotion as political is precisely where an exploration of socially just 
pedagogies advances our understanding, as educators in higher education, of how to prepare students better to be compassionate and critical citizens. By engaging in practices of critical emotional reflexivity in their teaching, educators in higher education can begin to create spaces for interrogating unjust and exclusionary teaching methodologies or policies.

\section{Issues of privilege and disadvantage in socially just pedagogies}

Many of the interviewees were people who took a different and more critical perspective on their own disciplines and tried to get students to think about issues of privilege and disadvantage in relation to that. What is significant in Shafiek's case is that he actually brought these issues into the summative assessment tasks in Business and Finance, so that the students were obliged to think about and respond to these issues:

I put a question in the supplementary exam to ask the student: what would you say to a young white male if he said, why must I pay for the sins of my father's support and my grandfather's supports of the Nationalist Party, why must I pay for it, what did I do? So I gave a question like that. I expected two answers. The one would be to say people are continuing to be privileged because they have a particular wealth advantage that perpetuates, and that affirmative action is a positive discrimination. And then the other answer would be to say, no, but this is discrimination between the same thing to what they did to the black students and the non-whites, and there has to be some other way. It's the owners of the capital that must pay, not the young child. So in other words Rembrandt, all these big groups - they've gotten the money out so they should be paying. In the final exam I put questions like, why do you think executives pay themselves - three executive salaries [are] equivalent to [the combined income of] all the miners? What makes people accept that? What makes executives do that? So I ask those kinds of questions, which I don't think [have] ever been asked in the first year course. (UWC, Economic and Management Sciences Faculty, Business and Finance)

Susan, in Anthropology, had come to South Africa from another country, and was very conscious of the failure rates of black students. She initially felt hopeless about it, but then saw how she could use her influence as a teacher in the classroom to be an advocate and activist for these students' educational trajectories, particularly their paths into postgraduate education. She decided to focus specifically on black students, in order to promote participatory parity, leaving white students to fend for themselves, as they had had previous privileges and still had access to resources. She welcomed the initiative of the \#RhodesMustFall movement, seeing it as an opportunity for conversations in her classroom:

I think to me teaching in South Africa is a real wakeup call; when I first got here you could put a line through your marks and go: here [go] your black students, here [go] your white students - and I found it so despairing. 
Look, for me that's where my activism lies, it lies in the classroom. So I realise that one can't just be nice; I can't be nice to all in the same way, I don't have the capacity to change all lives and so I realise what my job is, the target above others, and I do - so my activism is student learning and trying to establish a kind of parity among my students. I also have a further goal, which is to take any student who wants to get into postgraduate and get them there, get them ready. I do quite a bit of deconstructing my whiteness through demonstration, to try and get students to actually start to think about their own whiteness. On the whole I neglect my white students; [but] I'm not criticising whiteness. But my sense is they've got the resources.

One time I was teaching them Foucault and someone asked the question, are you not just an agent of the state then? Given everything I've said, I was absolutely floored, and I went home practically in tears; I just kind of displayed it. I came back the next day and I said, you guys really upset me yesterday. I said, I've had to think about why I'm so upset because what you've said is the truth and it really is; in many ways I am an agent of the state or something, an agent of societal denial which is to be productive workers. (UCT, Faculty of Humanities, Anthropology)

While Susan shows sensitivity to the lack of participatory parity between black and white students, it could be possible that white students may still need different kinds of intervention in a socially just pedagogy.

An important element of this differential kind of intervention needed for white students is providing space to recognise the consequences of white privilege that are still prevalent nowadays. Maria from Visual Arts found that in the discussions of the removal of the Rhodes statue at UCT and the statues which were destroyed by ISIS, it was the white female students who dominated the discussions in her classroom. As a white female herself, she attempted to interject in these conversations by alerting them to their privileged positions by using herself as an example:

So my first question [to the students] was: so what did the ISIS militants and the UCT students have in common? So the one white student said they both want to destroy art. And then there was a response saying, no, the one removed and the other destroyed. And so then a comment came back, well, at least they got education, why did they want to mess it up? And so this very complex, I think very real, conversation ensued. The challenge for me obviously was to contain it and to participate. So what I found was also very interesting, is that I said, 'Look, where I come from my children go to fantastic schools, I was on the governing body and I speak English; I can help them with language, with the homework, I can fetch them from extramurals, I can attend the extramurals - you cannot begin to' ... So that position of privilege is one that I think so many of the white students take for granted. So one of the women in the group, an African student who went to a former Model C school, said, 'My parents forced me to go, and they said just bite your tongue, just go and get the education.' But at every turn she was excluded in the most subtle [or] obvious and overt ways ... Okay, this is about me, more within 
me - within the white community - to be able to say, 'Well, I believe this' and feeling safe enough to say what I believed. So from that point of view - so I often try and set projects to get them to talk and to force them to see, or firstly to formulate their own opinions and then to share them. (CPUT, Faculty of Informatics and Design, Visual Arts)

The issue of recognising white privilege, then, seemed to be a fundamental pedagogical challenge in the teaching practices of these higher educators. This challenge, our participants seemed to be telling us, was not addressed merely by providing space for students to discuss provocative questions in the classroom; it had to go beyond that, because it demanded that higher educators - especially white ones - put themselves on the line and expose their own privilege and its consequences. This was clearly not an easy task for higher educators, yet students needed their instructors to actually live by the lessons they taught.

\section{Students' material circumstances and neoliberal university structures}

Finally, many of the interviewees, particularly those working at UWC and CPUT, made reference to the impact of students' material circumstances on their learning and how these circumstances affected the teaching process. Maria spoke about students as parents, their transport challenges and lack of access to funds; and of the administrative inefficiency of the HEI and the impact that this had on pedagogy, for example:

[...] public transport is a nightmare. A number of our students are parents, young women [who] have got children and they have asthma and all sorts of [health problems]. You've got children, you know about that. Money, students can't afford to come to the school and they spend hours trying to secure their bursaries for next year. So I feel in a way that the institution doesn't support the students; it kind of sets them up - and it makes me mad because they can't afford to miss out on a day at our art courses - they really can't because it's so intense. And they can't help it, they have to go through these interminable queues. I'm sure they could streamline those processes. (CPUT, Faculty of Informatics and Design, Visual Arts)

Leslie from Physics at UWC found that teaching students who come from rural and poor backgrounds was very meaningful and motivating for her as a teacher in higher education and gave her a lot of pleasure in her pedagogical practice:

$[\ldots]$ at UWC there's that sense that you can really make a difference. And I think the inspiring part of seeing students who ... have taught themselves maths and science in a rural school in Transkei, where there was no teacher - and those kind of students [come] into an environment where suddenly there's support and interest, they are just flourishing, and it's so gratifying. And it's so inspiring; so often I've felt so inspired by the students' determination. Ja, I just felt quite humbled, like I'm not sure I would have had the drive to do what you're doing. (UWC, Faculty of Natural Sciences, Physics) 
Another UWC academic from the Natural Sciences Faculty was less optimistic about how students' needs were understood and how they were being met:

We've actually failed to fully understand many of the students' problems which are outside of the curriculum. And the one thing that keeps hitting me in the face is many students are actually hungry. They are hungry - they do not have access to food.

One of his recommendations regarding the position of students who are hungry is to start food gardens and involve the students in that:

I think that one of the problems is the university is still operated a bit as an ivory tower. They are not as - shall we say - accountable to the public as I think they could be. And if we think of our own grounds here; we've got students hungry, why can we not have a food garden and then use the food garden to feed back into various education programmes? Yes, there's a lot of management, and also it does take some sort of financial investment. But I believe from this active learning you could be a lot more efficient. (UWC, Faculty of Natural Sciences, Biodiversity and Conservation Biology)

Another challenge in trying to implement socially just pedagogies is that one is not supported by one's peers in the department/faculty/university/discipline and one is a lone voice. Some of the interviewees spoke about the limitations of the impact that they could make in a neoliberal world, which rewarded particular sorts of values and behaviours:

$[\ldots]$ so it becomes this big corporate legal world, and they want to access that because then they get international mobility and all of that. And so to do that - to do an advanced course in corporate and mercantile law, or company law, tax law - they feel will be [more] worth their while, than to do an elective in refugee law. So I'm afraid I think the days when UWC and the students here were driven by social consciousness and social conscience - that's not the case anymore, not in the law faculty in any case. A further problem in doing this on an individual course basis is that the LLB is very, very structured - it's four years, 40 courses - so you can imagine if you do 40 things and it's all broken up into those 40 things, 40 different subjects really - to now have one or two here at the end, or anywhere, in which you want to bring in certain themes, it falls flat. (UWC, Faculty of Law, Constitutional Law)

Edward from Curriculum Studies in the Faculty of Education at SU was also conscious of the impact of managerial performativity and its impact on teaching. Furthermore, he felt doubtful that his provocations and encounters with students always panned out in the ways that he had hoped they would - what he considered a provocative encounter could end up alienating student or lecturer instead of leading to more inclusive teaching:

Look, obviously the biggest thing is performativity, that we have to comply with particular managerial constraints. And it's really out of our hands also to do as we think best for our pedagogical encounters, because often as, 
I just think practically, a lesson which I thought was highly provocative and I would categorise as one of my best encounters with students; they didn't see it as a best encounter, they saw it as quite debilitating. So for me that's the biggest constraint - that sometimes we think that we connect with them but I think with this kind of provocative disruptive way of encountering the other, we actually become alienated. So that's for me the biggest obstacle: if we imagine what is good for the other and how you can establish a more inclusive classroom, you might just alienate yourself further from students. (SU, Education Faculty, Curriculum Studies)

All in all, students' material circumstances and neoliberal university structures constitute major challenges in higher educators' efforts to enact socially just pedagogies in their institutions. Having a vision for socially just pedagogies in higher education, then, is not enough, no matter how progressive or transformative it is. This vision can be idealistic if it fails to consider the pragmatic obstacles emerging in each context. The gulf between rhetorical claims about socially just pedagogies and university realities are wide.

\section{Discussion and implications}

What can we learn from these interviews with 27 academics from different disciplines in differently positioned Western Cape HEIs? First of all, what has become clear from these interviews is that it mattered where these interviewees were located in terms of their discipline, faculty and higher education institutions. The HEIs had different access to resources, different historical legacies, and attracted different sorts of students, and this impacted on the sorts of issues picked up by academics in terms of their notions of socially just pedagogies. It also mattered what sort of national and international imperatives, which affect higher education globally, were in operation. Academics were also influenced by the sorts of theoretical, philosophical and spiritual perspectives from which they envisaged social justice and pedagogy. Depending on these varying perspectives, very different forms of socially just pedagogies were described and different views of themselves and students were presented in the interviews. From a participatory parity perspective, economic, cultural and political issues (and how they were experienced and accommodated by the institutions and the academics), played a significant role in how socially just pedagogies were enacted.

The \#RMF and \#FMF student movements of 2015 and 2016 were significant events in higher education in South Africa, and were perceived in affirmative ways by most interviewees during those periods. The movements were perceived as opening up spaces for dialogues in the classroom and as providing the potential for curriculum and pedagogy changes; and changes more generally in the higher education sector. The cultural issues of subjugated knowledges not being 
recognised were very significant for those at HAIs, whereas economic issues of resources and the lack thereof were foregrounded in HDIs in the study. The student movements of \#RMF and \#FMF had profound impacts on the content of what was being taught in class and in the ways that discussions were facilitated between differently placed lecturers and students, as well as between students themselves. A more nuanced concept of citizenship, which incorporates compassion and criticality was alluded to in the interviews. Francis Nyamnjoh (2016) in his analysis of the \#RhodesMustFall movement writes about the importance of embracing the complexity and the unfinished nature of citizenship, rather than starting from the position of the autonomous and fixed. Many lecturers were interested in students' flourishing and were thinking carefully about the best ways to achieve that. An important component of socially just pedagogies was the quality of the relationships that developed between students and lecturer and amongst students - the attempts of lecturers to make themselves vulnerable to students was one of the ways in which more egalitarian relationships could be developed (Leibowitz, Bozalek, Carolissen, Nicholls, Rohleder, Smolders \& Swartz, 2011). Another important element for developing socially just pedagogies was lecturers' attentiveness and responsiveness to their students' needs, and the rendering of each other's capabilities (Tronto, 2013; Haraway, 2016). Therefore, rather than seeing a socially just pedagogy as a one-way process, it is necessary to regard both academics and students as becoming-with as mutually benefiting and changing through the interactions with each other. In this last part of the chapter, the potential implications for higher education in South Africa and beyond raised by this analysis are explored.

First, it is important to note that socially just pedagogies at the higher education level begins with the acknowledgement that socially just educators understand the multiple complexities - e.g. emotional, political, economical - in the unjust systems and practices that inform our everyday lives. Participants in this study demonstrated this understanding by constantly coming back to their core beliefs and understandings about fighting injustice in society. Yet, it is important to emphasise that it is not enough for educators as individuals in higher education to have the intention and will to enact just teaching practices: these efforts have strong implications for them as educators and for their students at many levels emotional, institutional, societal. Their efforts to engage in socially just pedagogies might be threatening to normative politics and practices. Coping with these challenges requires strategic responses from the higher education institutions as such. An important implication, then, is that educators in higher education need to address how to contribute to sustaining or dismantling structures of power, privilege, racism, and colonisation - both individually and collectively.

Second, there need to be systematic and sustained explorations from HEIs on how students' experiences affect the practice of socially just pedagogies in specific 
contexts. The participants' enactment of socially just pedagogies, as seen from their narratives, required them - fundamentally and personally - to recognise and challenge the ways that disillusionment, denial, or hopelessness (both in themselves and in their students) are used to reproduce existing unequal structures. Thus, the struggle to engage both students' and educators' experiences, perceptions and emotions in specific settings seems to be a productive component of socially just pedagogies. Educators in higher education, then, need to confront themselves, as well as to help students to enact critical emotional reflexivity, compassion, and critical citizenship, so they can analyse and take a critical stance towards everyday unjust practices that are perpetuated in HEIs and the community (see Chubbuck and Zembylas, 2008).

This process has to be carried out strategically and patiently, institution by institution. Higher educators working in each institution are likely to create their own versions of socially just pedagogies, in formats useful for them. Despite this work though, we want to highlight that one of the pieces that seems to be missing is a dialogue across various versions and manifestations of socially just pedagogies: this could help us build on each of their strengths, as well as to recognise challenges better, and to reflect on the complexities of enacting socially just pedagogies in different institutions. We don't see it as the goal of this dialogue to come up with a consensus or definition of socially just pedagogies in South African higher education, but rather we see this as an important aspect of the wider decolonisation process, namely of engaging in the difficult work of challenging taken-for-granted epistemological frameworks, and making alliances that may help us to become more effective in foregrounding social justice in the higher education sector and the society. As Santos (2014) highlights, the struggle for social justice is inseparable from the struggle for cognitive justice, namely, the recognition of epistemic diversity. Further, we also emphasise that the struggle for decolonisation in higher education is inextricably connected with inventing and enacting socially just pedagogies that consider contextual diversity. Speaking in particular about creating pedagogical practices that are empowering and socially just, bell hooks (hooks, 1994) writes that is it crucial that critical thinkers and educators "who want to change our teaching practices talk to one another, collaborate in a discussion that crosses boundaries and creates a space of intervention" (hooks, 1994:129). Ultimately, we hope that outlining here the different strands of socially just pedagogies can help us to better build bridges across disciplines and institutions and create openings for more sustained dialogue amongst higher educators in South African universities. Better understanding of what we mean by socially just pedagogies within and across each institution can hopefully contribute to opening up new possibilities, commitments and agendas in the process of decolonising higher education. 


\section{Conclusion}

In conclusion, we would like to suggest how our analysis might further assist socially just pedagogies in higher education. First, studying multiple perceptions and experiences of socially just pedagogues in higher education can provide a deeper understanding of how transformation in higher education can emerge in the context of seemingly few opportunities; and perhaps even in counterresponse to the wider social and political context of HEIs. Our study examined the experiences of educators in a few HEIs in the Western Cape; the experiences of other educators all over South Africa also need to be studied to understand applications of socially just pedagogies relevant to their experience. Second, our analysis suggests the important and ongoing role that multiple components play in "translating" perceptions about socially just pedagogies into practices. Scholars in higher education need to look beyond their own institutions to see how other educators conceptualise and enact socially just pedagogies. On the other hand, the particular discipline, the type of HEI, and historical and contemporary context were seen to play a major role in how academics conceived of and performed social justice and socially just pedagogies.

An analytical focus on socially just pedagogies in higher education raises new questions and modifies those that already dominate the field: how are educators in higher education enabled to handle teaching for social justice in the face of substantial institutional or societal obstacles? What mechanisms at the institutional level are necessary to promote socially just pedagogies so that those who enact these pedagogies are not fearful of having to take huge risks? What do educators in higher education need to change when they move from one context to another? Would educators benefit from exploration of alternative venues for pursuing socially just pedagogies? In what ways can tools, such as compassionate teaching or critical emotional reflection, further deepen educators' knowledge about socially just pedagogies? The explicit attention to these and other relevant questions in the future could certainly create new openings for rethinking and renewing the project of socially just pedagogies in higher education. 


\section{References}

Ayers, W.; Hunt, J.A. \& Quinn, T. (eds). 1998. Teaching for Social Justice. New York: New Press.

Banks, J. 2007. Approaches to multicultural curriculum reform. In: J. Banks \& C. Banks (eds). Multicultural Education: Issues and perspectives. Hoboken, NJ: Wiley.

Barad, K. 2007. Meeting the Universe Halfway: Quantum physics and the entanglement of matter and meaning. London: Duke University Press. https://doi.org/10.1215/ 9780822388128

Bozalek, V. \& Boughey, C. 2012. (Mis)framing higher education in South Africa. Social Policy \& Administration, 46(6). https://doi. org/10.1111/j.1467-9515.2012.00863.x

Bozalek, V. \& Zembylas, M. 2016. Critical posthumanism, new materialisms and the affective turn for socially just pedagogies in higher education. South African Journal of Higher Education, 30(3).

Brand South Africa. 2017. South Africa's Population. https://bit.ly/2O4KFwK [Accessed 18 February 2019].

Carlisle, L.; Jackson, B. \& George, A. 2006. Principles of social justice education: The Social Justice Education in Schools Project. Excellence and Equity in Education, 39(1):55-64. https://doi. org/10.1080/10665680500478809

Carolissen, R.; Canham, H.; Fourie, E.; Graham, T.; Segalo, P. \& Bowman, B. 2017. Epistemological resistance towards diversality: Teaching community psychology as a decolonial project. South African Journal of Psychology, 47. https://doi.org/10.1177/ 0081246317739203

Casey, K. 1993. I Answer with My Life: Life histories of women teachers working for social change. New York: Routledge \& Kegan Paul.

Chubbuck, S. \& Zembylas, M. 2008. The emotional ambivalence of socially just teaching: A case study of a novice urban schoolteacher. American Educational Research Journal, 45(2). https://doi. org/10.3102/0002831207311586
Cochran-Smith, M. 2004. Walking the Road: Race, diversity, and social justice in teacher education. New York: Teachers College Press.

Cooper, D. 2015. Social justice and South African university student enrolment data by "race", 1998-2012: From "skewed revolution" to "Stalled Revolution". Higher Education 2uarterly, 69(3). https://doi.org/10.1111/hequ.12074

Council on Higher Education. 2017. Higher Education Monitor 14: Learning to teach in Higher Education in South Africa. https://bit.ly/2Fg0NZH

Darling-Hammond, L. 2004. Learning to teach for social justice. In: L. Darling-Hammond, J.C. French \& S.P. Garcia-Lopez (eds). Learning to Teach for Social Justice. New York: Teachers College Press.

Delpit, L. 1995. Other People's Children: Cultural conflict in the classroom. New York: New Press.

Deneulin, S. \& Shahani, L. 2009. An Introduction to the Human Development and Capabilities Approach: Freedom and agency. London: Earthscan. https://doi. org/10.4324/9781849770026

Department of Education. 2008. Report of the Ministerial Committee on Transformation and Social Cohesion and the Elimination of Discrimination in Public Higher Education Institutions. Pretoria: Government Printing Works.

Department of Higher Education and Training. 2013. White Paper for Post-School Education and Training: Building an expanded, effective and integrated post-school system. Pretoria: Government Printing Works.

Fortier, A-M. 2010. Proximity by design? Affective citizenship and the management of unease. Citizenship Studies, 14(1). https://doi.org/10.1080/1362102090 3466258

Fraser, N. 2008. Reframing justice in a globalizing world. New Left Review, 36. 
Fraser, N. 2009. Scales of Justice: Reimagining political space in a globalizing world. New York: Columbia University Press.

Fraser, N. 2013. Fortunes of Feminism: From state-managed capitalism to neoliberal crisis. London: Verso.

Freire, P. 1970 [1955]. Pedagogy of the Oppressed. M.B. Ramos (transl.). New York: Continuum.

Giroux, H. 1988. Teachers as Intellectuals: Toward a critical pedagogy of learning. Westport, CO: Bergin \& Garvey Publishers.

Haraway, D. 2016. Staying with the Trouble: Making kin in the Cthulucene. Durham, NC: Duke University Press. https://doi.org/10.1215/9780822373780

hooks, b. 1994. Teaching to Transgress: Education as the practice offreedom. New York: Routledge.

Jensen, S.Q. 2011. Othering, identity formation and agency. Qualitative Studies, 2(2). https://doi.org/10.7146/qs.v2i2.5510

Johnson, C. 2010. The politics of affective citizenship: From Blair to Obama. Citizenship Studies, 14(5). https://doi.org/ 10.1080/13621025.2010.506702

Irvine, J. 2003. Educating Teachers for Diversity: Seeing with a cultural eye. New York: Teachers College Press.

Kincheloe, J. 2005. Critical Pedagogy. New York: Peter Lang.

Kincheloe, J. \& Steinberg, S. 1998. Addressing the crisis of whiteness: Reconfiguring white identity in a pedagogy of whiteness. In: J. Kincheloe, S. Steinberg, N.M. Rodriguez \& R.E. Chennault (eds). White Reign: Deploying whiteness in America. New York: St. Martin's Press.

King, J. 2005. Black Education: A transformative research and action agenda for the new century. Mahwah, NJ: Erlbaum.

Ladson-Billings, G. 1994. Dreamkeepers: Successful teachers of African American children. San Francisco, CA: Jossey-Bass.
Leibowitz, B. \& Bozalek, V. 2015. Foundation provision: A social justice perspective. South African Journal of Higher Education, 29(1). https://doi.org/10.20853/29-1-447

Leibowitz, B. \& Bozalek, V. 2016. The scholarship of teaching and learning from a social justice perspective. Teaching in Higher Education, 21(2). https://doi.org/10.1080/ 13562517.2015.1115971

Leibowitz, B.; Bozalek, V.; Carolissen, R.; Nicholls, L.; Rohleder, P.; Smolders, T. \& Swartz, L. 2011. Learning together: Lessons from a collaborative curriculum design project. Across the Disciplines, 8(3). https://bit.ly/2TUihme [Accessed 8 February 2017].

Leibowitz, B.; Bozalek, V. \& Kahn, P. 2017. Introduction. In: B. Leibowitz, V. Bozalek \& P. Kahn (eds). Theorising Learning to Teach in Higher Education. New York: Routledge.

Leibowitz, B. \& Naidoo, K. 2017. The potential for posthuman insights to effect socially just pedagogies. Education as Change, 21(2). https://doi. org/10.17159/1947-9417/2017/2020

Luescher, T.M. \& Klemenčič, M. 2016. Student power in twenty-first century Africa: The character and role of student organising. In: R. Brooks (ed.). Student Politics and Protests. Research into Higher Education series. London: Taylor and Francis.

McLaren, P. 2003. Life in Schools: An introduction to critical pedagogy in the foundations of education. Boston, MA: Allyn \& Bacon.

Moje, E. 2007. Developing socially just subject-matter instruction: A review of the literature on disciplinary literacy teaching. Review of Research in Education, 31. https://doi. org/10.3102/0091732X07300046001

Mookherjee, M. 2005. Affective citizenship: Feminism, postcolonialism and the politics of recognition. Critical Review of International Social and Political Philosophy, 8(1). https://doi.org/10.1080/ 1369823042000335830 
National Research Foundation. 2016. Education Research in South Africa, Grant No. 90384, entitled "Participatory parity and transformative pedagogies for qualitative outcomes in higher education". https://bit.ly/2UBDZZn

Nicolson, G. 2016. "Fees Must Fall: Reloaded." Daily Maverick, 12 January. https://bit. ly/2XVHHzn [Accessed 4 February 2017].

Nieto, S. 2000. Placing equity front and center. Journal of Teacher Education, 51(3). https:// doi.org/10.1177/0022487100051003004

North, C. 2006. More than words? Delving into the substantive meaning(s) of "Social Justice" in education. Review of Educational Research, 76(4). https://doi.org/10.3102/ 00346543076004507

Nyamnjoh, F.B. 2016. \#RhodesMustFall: Nibbling at resilient colonialism in South Africa. Bamenda, Cameroon: Langaa Research \& Publishing Common Initiative Group.

O’Donnell, J.; Chávez Chávez, R. \& Pruyn, M. 2004. Situating the discourse of social justice in these times. In: J. O'Donnell, M. Pruyn \& R. Chávez Chávez (eds). Social Justice in These Times. Greenwich, CT: Information Age Publishing.

Osman, R. \& Hornsby, D.J. (2017).

Transforming higher education: Towards a socially just pedagogy. In: R. Osman \& D.J. Hornsby (eds). Transforming Teaching and Learning in Higher Education: Towards a socially just pedagogy in a global context. Cham, Switzerland: Palgrave Macmillan. https://doi.org/10.1007/978-3-319-46176-2
Pillay, S. 2016. Silence is violence: (Critical) psychology in an era of Rhodes Must Fall and Fees Must Fall. South African Journal of Psychology, 46(2). https://doi.org/10.1 177/0081246316636766 [Accessed 18 February 2019].

Santos, B de S. 2014. Epistemologies of the South: Justice against epistemicide. Boulder, CO: Paradigm Publishers.

Sen, A. 1999. Development as Freedom. New York: Knopf.

Sen, A. 2009. The Idea of Justice. London: Allen Lane Penguin.

Tronto, J.C. 2013. Caring Democracy: Markets, equality, and justice. New York: New York University Press.

Wheelahan, L. 2010. Why Knowledge Matters in Curriculum: A social realist argument. New York: Routledge.

Zembylas, M. 2007. The power and politics of emotions in teaching. In: P. Schutz \& R. Peckrun (eds). Emotions in Education. New York: Academic Press. https://doi.org/ 10.1016/B978-012372545-5/50018-6

Zembylas, M. 2008. The Politics of Trauma in Education. New York: Palgrave Macmillan. https://doi.org/10.1057/9780230614741

Zembylas, M. 2014. Affective citizenship in multicultural societies: Implications for critical citizenship education. Citizenship Teaching \& Learning, 9(1). 

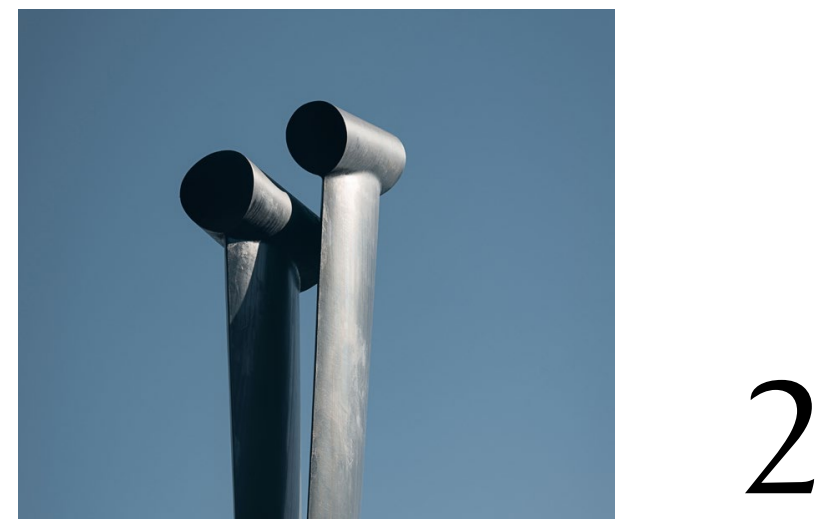

\title{
EXPLORING BEING HUMAN TODAY
}

Equipping teachers for diversity

\author{
Janet Condy, Lena Green \\ and Daniela Gachago
}

The research described and discussed in this chapter was located within the broader framework of the "Being Human Today" initiative carried out by Fellows of the Stellenbosch Institute for Advanced Study (STIAS), to explore racialism and racism, and strategies to address racist attitudes and behaviour. As pointed out in the Manifesto on Values, Education and Democracy (James, 2001), the Education White Paper 6 (Department of Education, 2001:11), and many other policy documents and guidelines, the Ministry of Education in South Africa is committed to a system that promotes the values of human dignity, equality and the advancement of human rights and freedoms as enshrined in the South African Constitution (Act 108 of 1996). Since the late twentieth century, policy has endorsed a critical anti-racist approach to teaching about and dealing with issues of diversity at all levels of education.

Over the past 20 years, schooling and higher education in South Africa have experienced rapid and deliberate racial integration. However, schools remain complex contexts, dogged by racial, class and privilege discrimination (Soudien, 2013). 
In higher education institutions, social integration and cohesion amongst lecturers and students are less developed than was hoped for since 1994 (Pattman, 2010). While students of different social backgrounds may now learn together in classroom spaces, their friendships and relationships are still often formed on the basis of common social backgrounds, and shared language and culture; their social discourse is often still fuelled by deeply rooted beliefs and assumptions that impact on their conscious or unconscious choice of social engagements (Jansen, 2004; Soudien, 2013). It is more than a decade since Christie (2008:64) wrote that promoting social cohesion in the face of difference had become increasingly important and was a crucial issue in education. Society looks to teachers, not only to increase the knowledge and growth of learners, but also to transform education in ways that support and develop a democratic and inclusive nation and contribute to healing the educational wounds of the past (Smith \& Fritz, 2008).

Current practice in education, however, predominantly promotes decontextualised celebrations of multiple identities and difference, without addressing critical issues of power and social forces (Desai, Giliomee, Jordan, Krog, Kulati, Lehoko, Leibowitz, Tlakula, Gevisser \& James, 2004). Critics argue that this practice in higher education is not critical or transformational enough to bring about change in student teachers' attitudes and behaviours, and consequently in their own teaching practices (Alexander, 2001; Carrim, 2000; James, Ralfe, Van Laren \& Ngcobo, 2006; Mentz \& Van der Walt, 2007). The Declaration of the Stakeholder Summit on Higher Education Transformation (Department of Higher Education \& Training, 2010:23) recommends "a curriculum oriented towards social relevance and which supports students to become socially engaged citizens and leaders". As Gumede (2013) argues, to establish an appropriate curriculum we need to design and implement innovative pedagogical interventions aimed at transforming social relations in teacher education and consequently in schools.

This chapter reports on a research project that explored the effectiveness of an innovative pedagogical intervention with final-year education students at a South African university. The intervention, carried out with successive intakes over three years, consisted of three compulsory modules, which in different ways addressed the transformation of social relations in educational settings. The sequence in which they were offered changed during the period. The first module employed digital storytelling as a means of raising student teachers' awareness of systemic inequalities inherent in South African society and explored with them how they may intentionally or unintentionally reproduce social injustices. The second module, Philosophy for/with Children (P4C), involved students in a specific form of philosophical enquiry in order to equip them with a form of classroom discourse that enabled respectful, reasoned engagement with difference, as a collaborative 
enquiring community. The third module introduced the students to academic literature that in various ways addressed human difference and encouraged them to locate their own lived experiences within a wider societal and international context.

A common theoretical framework, which ran explicitly throughout the three modules, was Lave and Wenger's (1991) notion of "communities of practice". Sampson and Condy (2016) state that communities of practice are "everywhere and that we are generally involved in a number of them: whether at work, school, home, or in our civic and leisure interests. Communities of practice are formed by people who engage in a process of collective learning in a shared domain of human endeavour". In all three modules, the intention was to encourage students to perceive themselves as a community engaged in exploring their personal and professional beliefs. This practice involved the "interplay between the physical setting of the institution of learning, its curriculum ... and the practice of teaching and learning within the community" (Wenger, 1998:45).

We begin by describing the context of our specific intervention. Thereafter, we describe the intervention programme and provide details of each module before outlining the specific aims of our research and explaining the research process. The second part of the chapter consists of our research findings, followed by a discussion of the project. We conclude by offering a tentative model of the relationships between the three modules and argue for the importance of providing prospective teachers with experiences of learning as a respectful and reasoning community, aware of their own perspectives and biases.

\section{Context of the intervention}

The intervention, anchored in a course entitled Professional Studies, was conducted over a period of three years with final-year pre-service teachers at a South African university. The basic purpose of the Bachelor of Education Degree is to provide competent and responsible qualified beginner teachers. The Minimum Requirements for Teacher Education Qualifications (Department of Higher Education and Training, 2011:4) stress that teaching is a complex activity that requires teachers to be not just technicists, but individuals able to integrate and apply knowledge and respond to different contexts. As contexts in schools and in higher education become increasingly diverse, engagement with human differences and different knowledges becomes essential. Prospective teachers need to be well prepared for this challenge. More recently, Rusznyak and Masinire (2018) expanded on this notion by suggesting that newly qualified teachers need to be "agents of change" who "will teach in culturally responsive ways" by making schools increasingly responsive to all learners. 
The invitation from STIAS to submit a proposal - for research that would explore strategies to address racist attitudes and behaviour - prompted the crystallisation of ideas emerging from our previous teaching experience. We had become aware that the individual modules within the Professional Studies course might complement and enrich each other and the project offered a framework in which to develop these conceptual connections, experiment with variations in the practical presentation of the modules, and explore in greater depth student teachers' responses to each module, as well as to the three modules as an integrated experience. Our pedagogical aim remained to facilitate students' active and positive engagement with the range of socially and politically constructed differences to be found in most educational settings in South Africa, including, but not limited to, issues of class, gender, cultures, sexuality, able-ness, age, religion, language and race. Since student autonomy remains an important dimension of the course, we could not guarantee that students would choose to engage directly with the topic of racial difference. Our previous research (Green, Condy \& Chigona, 2012; Gachago, Condy \& Ivala, 2014) suggested, however, that "race keeps bubbling to the top", framing many of the stories told by the students, and that the awareness and sensitivities generated, the discursive "tools" acquired, and engagement with relevant literature had the potential to influence race-related attitudes and practices.

If education in South Africa is to play a role in changing society, teachers need to be able to understand and engage positively with the forms of human diversity they are likely to encounter in schools. Our pedagogical aims, therefore, were to:

increase students' sensitivity to a range of human differences, including, but not limited to, gender, class and race;

raise students' awareness of issues of social justice related to difference;

explicitly equip students with thinking and reasoning skills and strategies that facilitate critical thinking;

model practical strategies to explore and engage with difference in schools and classrooms; and

$\square$ facilitate students' meaningful entry into the ongoing conversation about human differences carried on in the academic literature.

\section{Aims of the research}

The research aimed to explore the development and integration of three existing modules, to be described in greater detail. We were interested in tracking student teachers' personal and professional growth in order to inform the development of a higher education pedagogy that optimised students' understanding of diversity and their ability to engage with issues of "difference" with critical insight and sensitivity. 
Hence, the three guiding research questions for this study were:

1. Was there any change in students' attitudes to difference as a result of these modules?

2. How, if at all, did these modules develop students' personal and professional attitudes and skills to equip them to address issues of difference in the classroom?

3. How could we adapt and improve our pedagogy in ways that would make a focus on difference more explicit, and optimise the links between modules?

\section{How the data were collected}

The student participants were final-year education students attending a compulsory course entitled Professional Studies. This fourth-year class grew in size from 77 in 2015 to 114 in 2017. These pre-service teachers were aged between 21 and 55, with a female to male ratio of $75: 25$. In 2016, the racial mix was approximately $55 \%$ coloured $^{1}$ students, $29 \%$ African students, and $16 \%$ white students, proportions that have remained relatively constant. English is the language of instruction at this university, although Afrikaans and isiXhosa were sometimes used in our classes in small group discussions.

The collection of data became extremely difficult due to the continued student protests over the period forming the focus of this study. Qualitative data were collected in order to access students' insights and perceptions into issues of difference, and to discover to what extent the project enhanced students' learning and teaching. We collected data in 2015 and 2016 and added to this in 2017. Each year the pre-service teachers experimented with philosophical enquiry in classrooms and wrote a three-page $\mathrm{P} 4 \mathrm{C}$ reflective assignment, composed and presented a 300- to 500-word digital story script and produced a threepage literature review. In 2015 and 2016, we reflected on the P4C and Digital Storytelling (DST) modules by conducting whole class communities of enquiry which were tape recorded and transcribed. In 2015, classes were interrupted by the \#FeesMustFall campaign, when feelings ran high on campus. Nevertheless, we were able to conduct and record a collaborative enquiry during the final lesson of the academic year, in which students employed their discursive skills to reflect on the protest action. Some of the students' voices are included in excerpts in this chapter. In 2016, the same \#FeesMustFall protests prevented us from holding our final review of the year with the students and, consequently, from establishing the reliability of

1 "Coloured" is a term introduced and formalised in South Africa to refer to those South Africans loosely bound together for historical reasons rather than by common ethnic identity (Erasmus \& Pieterse, 1999). 
a draft questionnaire. The academic project was halted on campus and engagement with students was only possible via alternative channels such as social media. This was not the same as having open discussions, debates and focus-group meetings with small groups of students, which had proved successful in 2014. In early 2017, during the P4C module, we collected additional data by means of a student questionnaire. The lecturers met as often as possible to discuss the project.

\section{The intervention programme}

\section{The Digital Storytelling module}

The way we designed the Digital Storytelling module was influenced by the model developed by the StoryCenter (formerly the Center for Digital Storytelling) in Berkeley, California. Originating from a history of critical theatre, the Center's digital storytelling model had as its main objective to fight for social justice by giving marginalised groups a voice. The StoryCenter showcases many stories from marginalised groups who are often silenced through the hegemony of public discourses. At the core of their stories is an "act of self-discovery, and a means to localise and control the context of their presentation" (Lambert, 2009:82).

Foregrounding the communal sharing of stories, the StoryCenter sees digital storytelling (DST) not as an individual process, but as a collective process of developing stories in what they call the "story circle" (Lambert, 2010). Their model of creating digital stories is quite specific and involves a workshop running over several days, in which participants collaboratively develop their stories. The communal sharing of stories is the main element in the process of digital storytelling (Lambert, 2010:v).

There is growing interest in the use of DST to explore issues of difference amongst students (Benick, 2008; Kobayashi, 2012; L.M. Walters, Green, Wang \& T. Walters, 2011; Sleeter \& Tettegan, 2002). Of even more interest for us were attempts to modify and expand the typical DST process to include a more critical engagement with issues of difference when engaging with the "other". We allowed our students to enter a space of discomfort, primarily through sharing their life stories, using the community of practice approach (Gachago, Ivala, Condy \& Chigona, 2013).

Coventry (2008:200) states that not only do marginalised students gain from this process, but privileged students also experience transformation, allowing them to understand their realities in more meaningful ways: "[T] he collaborative practices in DST deepen understanding across social categories of identity and difference in ways that I have not experienced in any other course over my more than 30 years of teaching". He argues (2008:207) that the unfamiliar medium of multimodality afforded students opportunities to reach a deeper level of learning and reflection: 
Working in multimedia brings something to the student's learning that would otherwise not be possible: speaking and explaining through relatively unfamiliar modes of communication helps enforce a deeper engagement with ideas.

The DST project in this course was introduced in order to allow students to reflect on their diverse backgrounds and to develop a heightened understanding of their own and their peers' social positioning vis-à-vis personal, institutional and systemic structures. It was set up in response to the Department of Education's policy to prepare future teachers for diverse classrooms (Department of Education, 2001; Desai et al., 2004). It was hoped that the nature of a DST project focusing on new media technology and innovative practices would help decrease students' usual resistance to engaging with difficult topics, such as race, class, gender and sexuality in today's South Africa (Gachago et al., 2013; Gachago et al., 2014).

For this project, we adapted the original 3- to 5-day workshop model developed by the StoryCenter into a 5- to 8-week module. Students met every week for a series of half-day workshops, in which they developed their digital story following a step-by-step process. They worked in small communities of practice of about six students each. These groups were purposively arranged so that students worked with people with whom they would not normally have collaborated. At the beginning of each year, approximately 12 students volunteered to be trained as facilitators for this DST programme and each facilitator worked with one community of practice.

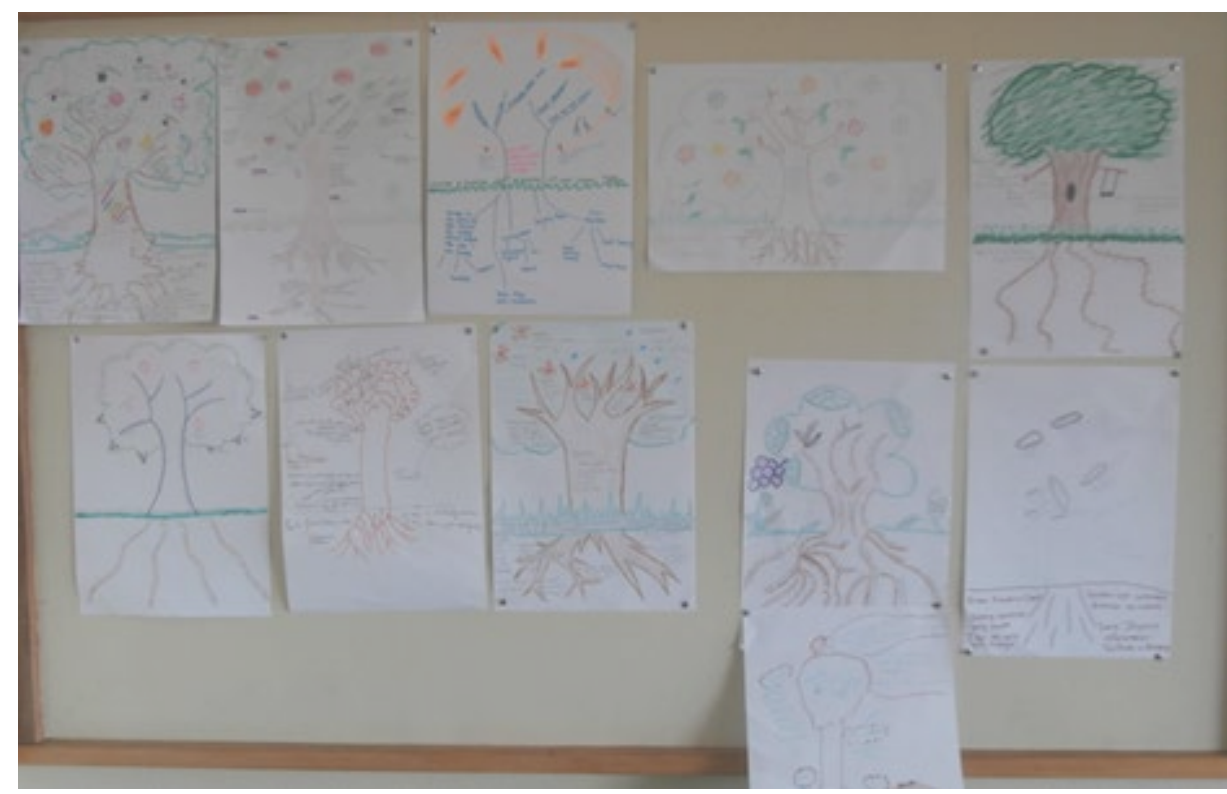

Figure 2.1 "Trees of Life" created during the research project exploring effectiveness of a pedagogical intervention with final-year education students 
In order to help students with writing their stories, we introduced a Participatory Learning and Action (PLA) technique, "Tree of Life" (illustrated in Figure 2.1). The practice allows differently positioned students to share their perspectives and to engage with one another's backgrounds (Bozalek \& Biersteker, 2010:554). This visual PLA technique is not only less daunting for students whose academic literacy skills vary widely, it also starts the process of their being able to position themselves as vulnerable, which is one way of opening up opportunities to connect deeply across difference. From past experiences, we have seen that this is a first moment of discomfort for many students. Opening up to their peers about their personal lives, which they have often kept apart from their academic space, is difficult; and some resist this process more or less openly.

\section{The Philosophy for/with Children module}

Philosophy for Children (P4C) consists of a set of materials and a prescribed pedagogy created by the philosopher Matthew Lipman and his colleague, Ann Margaret Sharp, in the late 1970s and early 1980s (Lipman, 2009). P4C has subsequently become a generic term for philosophical work with children, although there are some differences in the way it is practised. Despite these differences there is broad consensus regarding the need to create and sustain a community of enquiry. Lane and Burroughs (2016:11) describe a classroom community of philosophical enquiry as "an educational space that prioritises dialogue and student engagement", in which participants may acquire "important philosophical skill-sets". The purpose of introducing such skill sets is to equip students of all ages to think for themselves and to make reasoned judgements within a dialogic community.

Lipman based his ideas about education on the work of two American pragmatist philosophers, John Dewey and Charles Peirce. Dewey (1916) believed that participatory enquiry-based learning was the most appropriate form of education for any democracy. In 1877, Peirce (1997) proposed that the scientific community could be thought of as a community engaged in shared enquiry, from which Lipman developed the notion of the classroom as a community of enquiry where children would seek answers to questions that genuinely interested them (Splitter \& Sharp, 1995). The teacher's role in a philosophy lesson is to create a respectful, democratic classroom climate and facilitate constructive and reasoned collaborative enquiry. In other lessons, the teacher may contribute expert knowledge to an enquiry, but when "doing philosophy" she or he is a co-inquirer, because philosophical questions are as perplexing to adults as they are to children. Philosophy lessons as conceived by Lipman and his colleagues model a social and cognitive learning climate very different from that experienced in conventional classrooms. The social context is one of respect and democratic collaboration. 
The cognitive context is one of reasoned enquiry employing a repertoire of thinking moves to explore difficult and puzzling issues. Critical and creative thinking are not, however, divorced from emotions and caring thinking.

Lipman believed that it was important for children to be able to think for themselves. $\mathrm{He}$ argued that engaging in dialogic enquiry about philosophical questions would not only allow them to experience democratic collaborative dialogue, but also to develop their ability to think carefully and reasonably. Through regular experiences of philosophical enquiry with the teacher as a model, he claimed, children would acquire a conscious awareness of what Gregory (2002:11) calls "the standard tropes of good thinking", often referred to as "thinking moves". These include, but are far from limited to, asking a question, agreeing or disagreeing, giving a reason, giving an example, classifying, comparing, and making inferences.

Lipman's view that thinking is "a skill capable of being perfected" (Lipman, Sharp \& Oscanyan, 1980:14) is highly consistent with current theories of cognitive development (Vygotsky, 1962, 1978; Feuerstein, Klein \& Tannenbaum, 1991), which emphasise the active teaching of thinking "skills", "tools", or processes, sometimes referred to generally as "critical thinking". The practice of philosophical enquiry (with university students or with classroom learners) is, therefore, a means of developing critical, creative and collaborative thinking as specified in the South African national curriculum (Department of Basic Education, 2011). In addition, the pedagogical practices it introduces create a space for the respectful and reasonable sharing of different perspectives instead of overt conflict or a refusal to confront difference.

The students attended a Philosophy for Children (P4C) module of between 4 and 6 three-hour sessions, depending on timetable constraints. Students experienced community of enquiry dialogues in various formats, setting ground rules that structured the social and cognitive dimensions of their dialogic enquiries, consciously employing thinking moves, and evaluating the quality of their thinking and reasoning. They observed recorded enquiries in schools, experimented with the pedagogy in classrooms and completed an assignment about their experiences. 


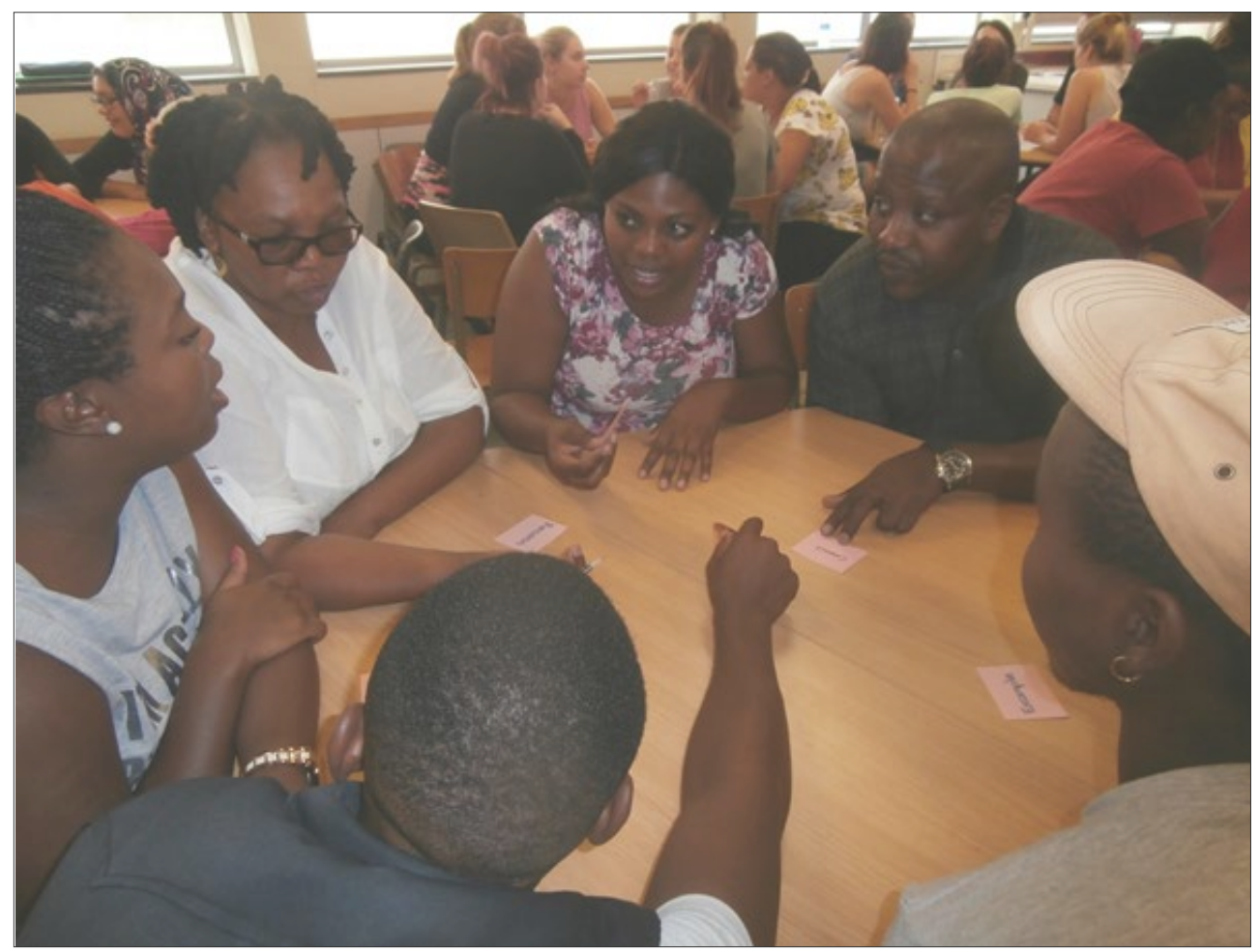

Figure 2.2 Students practising thinking moves during a dialogic enquiry

Students' experiences of “doing philosophy" were based on Lipman's curriculum. For their experimentation in schools, they were provided with various readings and resources, including story texts created by local teachers (Green, 2012). Lipman's story texts are intended to provoke philosophical questions and model how schoolchildren might enquire together. The local texts have the same purpose, but reflect the realities of local, rather than North American classrooms. A feature of this pedagogical approach is that the questions to be explored during an enquiry should come from the participants themselves. The question to be explored during an enquiry is selected democratically by the students, and not by the teacher or facilitator. We could not, therefore, ensure a focus on race or "difference" but were successful in nudging students in this direction by making use of a local text that raised questions about respect. 


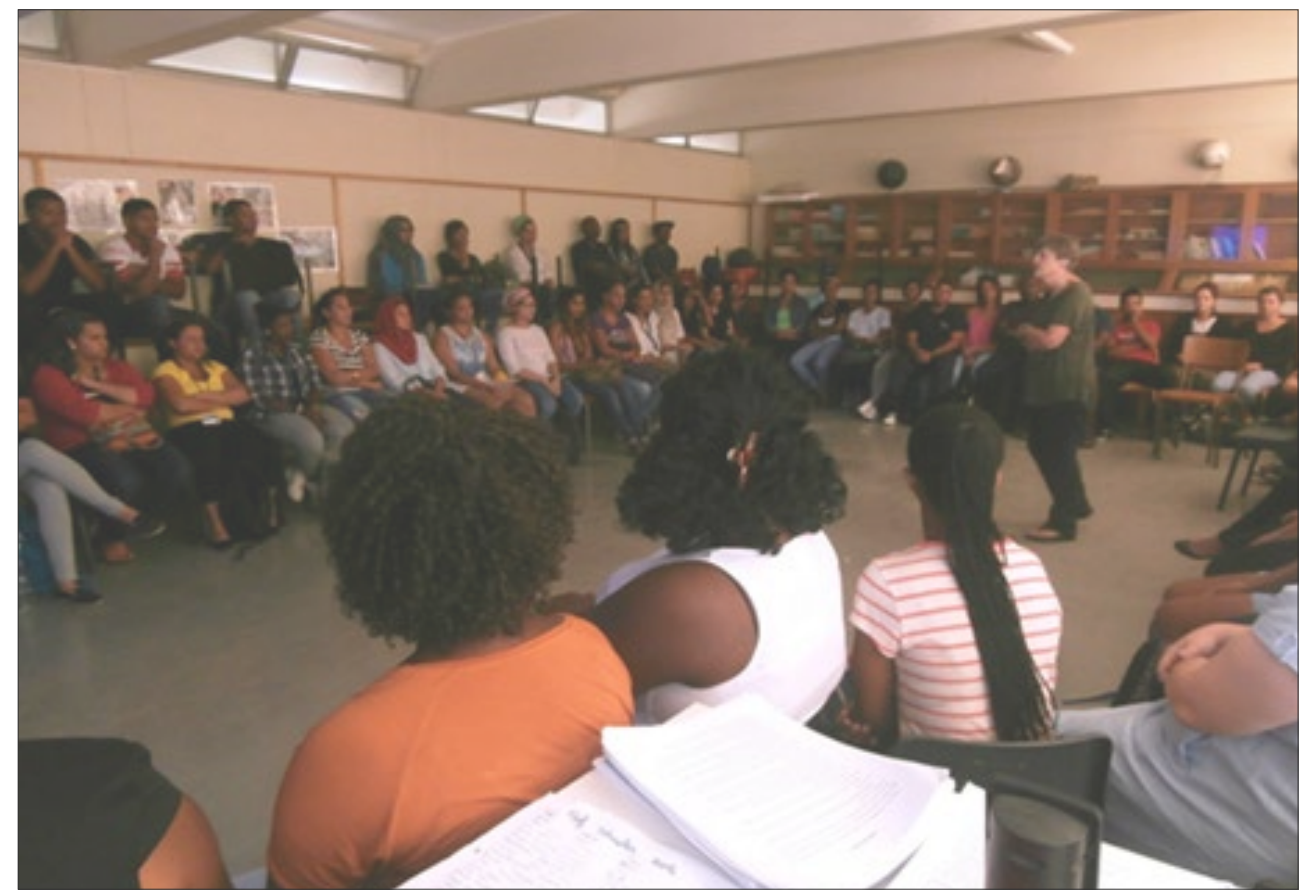

Figure 2.3 Large group community of enquiry

\section{The Literature Review module}

Paradoxically, in the normal research process it is the literature reviews that are most often published at the introductory section of a research article (Okoli \& Schabram, 2010). In this research project, the literature review came at the end of the academic year. The students had the year to develop and explore their topics of interest related to the issue of "difference", gather informal data, through participating in the P4C and the DST modules as well as having the opportunity to become more aware of issues of social injustice during their final teaching practice experience.

The purpose of writing the literature review at the end of the year was to add a broader dimension to students' emotional and cognitive engagement with their chosen topic related to "difference"; and to explore the international breadth of their topic of interest (Okoli \& Schabram, 2010). This process encouraged the students to elaborate, evaluate, assess and integrate existing national and international literature within the theoretical framework of Bronfenbrenner's (2005) bio-ecological model. It gave them an opportunity to review their topics, identify challenges, contradictions or controversies (Wallace, 2013), and engage in what Benmayor (2008) calls "talking back to the literature". Gachago, Clowes and Condy (2016) suggest that to disrupt dominant 
narratives in the literature is "difficult but not impossible". The students were encouraged "not to simply regurgitate" the international literature, but rather offer a "scholarly critique" of their topics of interest (Okoli \& Schabram, 2010:2), both "inside and outside the literature" (Gachago et al., 2016), using the reasoning skills practised in the $\mathrm{P} 4 \mathrm{C}$ module. Finally, the students offered recommendations to support their own professional practice of addressing issues of "difference" in their classrooms. As Petticrew and Roberts (2006) suggest, conducting literature reviews can be "true paradigm shifters".

In the DST module, topics emerged out of students' own lived experiences of "difference/otherness". In the P4C module, the students acquired the mental tools for exploring "difference/otherness" and developing their own "voice". Through this process they began to perceive the value of reasoning about concepts such as "respect, difference and otherness" The final module - the literature review required them to engage with the depersonalised "other" described by research, whose stories, they found, often resonated with their own experiences and to make meaningful connections (Rusznyak \& Masinire, 2018). They also engaged with the "other" as authors, whose voices represented yet another conversation about human difference that students could join.

\section{Results of the research}

In this section, we address the three research questions by providing evidence from the collected data over the past few years.

\section{Was there any change in students' attitudes to difference as a result of these modules?}

We wondered how, if at all, these modules contributed towards students' development as open-minded, critically aware individuals who were sensitive to diversity.

The data, from each of the three years and modules, strongly suggested that the student teachers perceived themselves to have become more understanding and respectful of difference and more aware of their common humanity despite differences such as gender, race and class at an interpersonal level. This involved both understanding of persons perceived to be "different" and an awareness of the mutuality created by sharing the self. The following excerpts are responses from individual participants, arranged according to the themes identified in the data.

\section{Seeing the self in the other}

But now I understand you better. I can sit now and listen to you because I saw your story ... because I judged you on how you behaved. But, ja, I understand 
you now and I'm glad you shared your story because I think I would try to have a better bond with you and not just cut you out. [DST]

I could say I had a revelation about our group and the dynamic of the group that has changed from the beginning of the year to where we are now. I think we're more patient with each other, I think more understanding. [DST]

And you see where they lived and what they went through and what their friends and family look like and were they together or were they drawn apart ... it's almost like you get a sneak peek into their life and it's a place that gives you respect for that person. [DST]

It made me look at life in a different way ... I opened myself up more to people. I speak to people that I've never spoken [to] before ... this process made me open myself up to people that I never would have even spoken [to]. [DST]

We're all human. We all have emotions and I think we've gotten closer on an emotional level. We all realise we get sad, we get emotional, we get angry - so it makes us human. [DST]

It happened that especially with us African people, when you look to someone like a coloured or a white person you think that he or she doesn't face the problems that you're dealing with and now we realise that we all have problems. [DST]

\section{Seeing the "bigger picture"}

If there is conflict occurring in one of the systems, i.e. the micro- or mesosystem, this results in a child looking for solace in the wrong places, which often are gangs. [Lit Review]

I believe that in order to prevent students from joining gangs there needs to be a collective effort made by factors that greatly influence the exosystem, mesosystem and microsystem such as families, schools, peers, community and students themselves. [Lit Review]

We're able to speak about all these other topics [that are] usually just swept under the carpet in South Africa. So we create this platform to talk about our issues and not just hide it away from everyone. [DST]

[...] many of us have been through similar things and in opening up to people, people that you've never spoken to before, you actually start speaking to them - so instead of being divided you're actually bringing people together in opening up. [DST]

In the article which I read, it says that teenage pregnancy poses a challenge to global society. [DST]

\section{Becoming more open-minded}

$[\ldots]$ for me it's just opened me up on how I look at people. I'm more open to talking and not only that, I'm more into the whole single story, single story ... Maybe look at it from another perspective, from another side and not just 
be focused in your own little ... the process has made me look at people in general a bit differently. [DST]

People who don't normally talk to each other can get the opportunity to mingle with people who don't necessarily think the same, which opens them up to a whole new perspective. [DST]

I've learned to be open-minded and [a] critical thinker because I thought that there is one answer to every question but I have learned that in philosophy there are different answers depending on one's perceptions. [P4C]

When doing activities where we need to listen to the opinions of others, we learn to be open-minded about it, not judgemental. You learn to express yourself without being emotional about it, and by hearing others' opinions you tend to agree with things you never thought you'd agree with, but you now do, because someone explained it better. [P4C]

When referring to Bronfenbrenner's macrosystem, teachers should keep in mind and understand that people and individuals live in different cultures and family set-ups. [Lit Review]

$[\ldots]$ just because we are from different backgrounds doesn't mean that we don't go through the same things ... these stories, you know, they're common, and we're not actually that different. [DST]

\section{Becoming more/less vulnerable}

This subject created a space where students became aware of their own abilities to think differently and began to understand disagreement, thereby becoming either more or less vulnerable.

$[\ldots]$ my own story ... you feel exposed and vulnerable and you feel like I don't know. Not that people are judging you but more that a part of your privacy will never be private, especially if you are a private person. And you need to acknowledge the fact that that privacy might help someone else internalise their own struggle. [DST]

And then when I watched their stories, I also see that they are - they have been vulnerable and they have faced a hardship, trying to stay strong. [DST]

Some people will say things that you disagree with but their reasoning will force you to think differently. [P4C]

I understand that everyone thinks about things in their own way and it's not an insult when someone doesn't agree with me. [P4C]

We saw evidence of students disagreeing and becoming vulnerable within a safe environment when we observed the 2015 class engaged in a collaborative dialogue about a highly sensitive and potentially divisive issue: student protest action related to the \#FeesMustFall campaign, which had disrupted the campus. One student said:

I think there's one rule - especially now with what we're going to discuss:

Be open-minded, be very open-minded with whatever people are going 
to say. Understand where everybody comes from and why they are saying what they are saying and how it affects them. It's not a personal attack on anybody. [P4C]

After some time, another student who had until then remained silent said:

I know I wasn't going to say something but I can see that this is going in a peaceful way and it's not getting out of hand. What I wanted to say was that I've been listening to everyone's responses. [P4C]

\section{How, if at all, did these modules develop students' personal and professional attitudes and skills to equip them to address issues of difference in the classroom?}

\section{Professional development}

Professional development was facilitated by the insights that students reported as a result of their engagement in this project:

Being part of this has opened me up to view and be able to question the world. [P4C]

I don't just read what I see on the page - I am now able to open my mind and think more abstractly. [Lit Review]

This course has given me the opportunity to think critically, which I had not really done in the four years attending this university. It really made you think before answering a question. [P4C]

From this experience I have learned to put ideas in order of importance. [Lit Review]

The module has taught me how to create a classroom where all learners can feel included and not be scared to ask questions. [P4C]

Much as I thought I was well equipped with these skills honestly I wasn't because I can now reason better than before ... and I get to question things I thought aren't important. [P4C]

In each year of the project, students reported changes in their attitudes to their professional role:

I always thought that teaching was all about the content and writing ... I now realise that it is more about facilitating learners, helping them to become critical and creative thinkers. [P4C]

I have experienced that it is not always the duty of the teacher to stand in front of the class and explain things. [P4C]

I have realised that being a teacher does not require of me to stand in front of a classroom and demand learners to listen and follow my instructions. [P4C] 


\section{Critical thinking}

If students have become critical thinkers, as some of them claimed, they may be less likely to accept stereotypes. This was reflected in the reasons why they selected the topics they chose to research in their literature review:

$[\ldots]$ before I enter my field as a teacher, I think it is necessary for me to be acquainted on how to address the issue of poverty. [LitRev]

[...] I wanted to explore and describe the experience of boys with absent fathers in order to gain a deeper understanding. [LitRev]

[...] I want to prevent my learners from making the same mistakes that I made, not that I regret having my son. [LitRev]

We as teachers need to stand against racial discrimination in all forms by use of education. [LitRev]

As a teacher I am going to be there for the underprivileged student for guidance and support. [LitRev]

\section{Stress and support}

All three modules, some to a greater extent than others, assisted our students with the skills of facing their daily stresses as future teachers. They learnt the significance of creating a supportive environment in their classroom:

It's also about therapy ... You need to actually get this off your chest to kind of take away that stress that's building up inside. That's building up and it's going to just lash out at those that you love ... This is one way to do it. [DST]

Personally, for me, it's a healing process because you are so stuck with these negative things inside of you. You can't make any progress because you come across so many stories. You will be an outsider ... For me it's healing inside and outside, so really, that's what is important. To be able to be human. [DST] [...] we're able to speak about all these other topics that's usually just swept under the carpet in South Africa. [DST]

I felt like they were supporting in a way because they were sharing some sort of connection or emotion with me. So that for me was showing enough support. If people could get something out of your story. So that's how I felt supported. [DST]

\section{Listening and connecting}

A personal/professional skill, developed each year, reported by many students in the past three years, was the ability to listen attentively and connect with each other:

And for me, it was just hearing, like listening to everybody's story, really, it made me look at, like, life in a different way. I opened myself, I opened myself up more to people. [DST] 
Thinking moves enabled me to listen carefully before answering a question. What is more, having the opportunity to engage in community of enquiry [dialogue] enabled me to put aside my bias. I am no longer suppressing my opinion, instead I am guided to use it in a respectful manner. [P4C]

We as the up-coming, rising leaders in this nation need to learn to listen to people better and change the nature of the conversation. [P4C]

The programme requires learners to interact with each other without getting angry or mad at each other ... it teaches learners to agree and disagree without feeling that one is right and the other one is wrong. [P4C]

$[\ldots]$ usually arguing or interacting would not have worked with a classroom situation but since then [classroom experimentation], my view has completely changed. $[\mathrm{P} 4 \mathrm{C}]$

\section{How could we adapt and improve our pedagogy in ways that would make a focus on difference more explicit?}

In early 2015, we began this research project with the following title: "Exploring being human with final year pre-service teachers: Designing a teaching intervention to engage with difference in a critical, anti-racist and reconciliatory way". Two-anda-half years later, and after reflecting on the results of the three modules, we find that there are some aims that have been achieved and others that still need attention.

The following were our pedagogical aims.

A. Increase students' sensitivity to a range of human differences, including but not limited to gender, class and race;

B. Raise awareness of issues of social justice related to difference;

C. Explicitly equip students with thinking and reasoning skills and strategies that facilitate critical thinking;

D. Model practical strategies to explore and engage with difference in schools and classrooms;

E. Facilitate students' meaningful entry into the ongoing conversation about human difference carried on in academic texts.

Table 2.1 shows the pedagogical aims that were addressed across the different modules.

Table 2.1 The overlapping of knowledge and emerging gaps in this complex research project

\begin{tabular}{|l|c|c|c|c|c|}
\hline AIMS AND MODULES & A & B & C & D & E \\
\hline DST & $\sqrt{ }$ & $\sqrt{ }$ & & & $\sqrt{ }$ \\
\hline P4C & $\sqrt{ }$ & & $\sqrt{ }$ & $\sqrt{ }$ \\
\hline LR & $\sqrt{ }$ & $\sqrt{ }$ & & & $\sqrt{ }$ \\
\hline
\end{tabular}


After analysing the data, four themes emerged that have helped us to reflect on adapting and improving our pedagogy in ways that could make a focus on difference more explicit. These include: structural integration, sequence, social integration, and ethical considerations.

\section{Structural integration}

Although each module had its own focus, there were many issues which overlapped. After constructing Table 2.1, it became evident that certain gaps existed where it is possible to increase the ways in which the different modules inform each other and address the overall aims of this project.

Digital Story module - we plan to challenge the students to take their learning [DSTs] into their classrooms as they teach the curriculum. Although the focus of our research was on exploring issues of social justice, this would often not be applicable in the primary school environment. However, students could recognise and use the power of individual stories within the curriculum, even if they do not have access to digital resources. We will encourage students to think about how their positive experiences of the DST module might be modified for classroom use.

Philosophy for Children - we plan to identify and use sources of initial stimulus for enquiry that raise, but do not resolve, issues of social justice. We would like to introduce texts that raise awareness of issues of social justice although we cannot guarantee that students will choose to engage with the issues they raise.

Literature Review - we plan to highlight and extend the connection of thinking and reasoning more explicitly into academic writing. To assist students to engage more with academic journal articles, we plan to introduce short but appropriate journal articles in the other two modules throughout the academic year. We will also draw attention to the practical recommendations in the literature and connect them with the practical skills developed in the previous modules.

We believe it would be beneficial to set the students a task to brainstorm what they perceive the connections and disconnections of the year have been for them. This task will provide us with further rich data which we can not only publish, but use to improve the content and process of the course for following years.

\section{Sequence}

In the past, we have experimented with the sequence of presentation of the three modules. In the course of reviewing our pedagogical practices, it became clear that the sequence DST-P4C-LitRev is the most appropriate. Students moved from speaking about and sharing personal experience/stories to reasoning together 
about personal opinions, in each case learning to do so effectively. The final module involved the sharing of opinions with an absent "other" using text rather than speech as a medium.

\section{Social integration}

Throughout the two-and-a-half years the students have infrequently made open references to "race", although there has been considerable interest in the notion of "difference, social injustices, social cohesion and respect". Nevertheless, we observed that, except in the DST module when groups were intentionally mixed, the students instinctively sat in their racial and language groups. This contradiction is an issue that needs further exploration. One challenge for us is to encourage conversations and enquiries about race while respecting student autonomy within the course.

\section{Ethical considerations}

When broaching sensitive issues such as race in diverse classrooms and opening up spaces for students to share stories of the trauma of their daily lives, often characterised by gangsterism, crime, drugs, abuse and neglect, there are a myriad of ethical questions and tensions that educators have to consider. The more we engage in this critical work, the more we encounter ethical dilemmas. Some critical issues that we experience, although there are more, include:

the seeming impossibility of creating safe spaces in a society characterised by stark inequality;

$\square$ the difficulties of supporting spaces that students perceive as therapeutic or cathartic without being trained counsellors;

$\square$ our own positionality as white middle-class female academics and the impacts of that on how we read and respond to our students' stories; and

the tension that arises from the need to assess these often highly personal narratives.

Engaging in these practices requires continuous self-reflection/reflective practice, an openness to critique, and most importantly, listening carefully to our students' voices.

\section{Discussion and conclusion}

The main focus of this final-year Professional Studies course was for students to be challenged to understand and become more sensitive to issues of difference. We hoped that they would develop personal/professional attitudes and skills to address difference when they became novice teachers with their own classrooms. 
Our findings suggest that, through the intentionally initiated influences of this programme, students developed socially, emotionally and professionally. The journey through the three modules led to an increased sense of "belonging" in students and boosted their confidence. The students saw the "other" as human and similar to themselves, and this established an affective connection in class. Benmayor (2008) calls this a "social pedagogy", where - beyond learning about ourselves - we also learn from and about the "other". Students every year formed and supported each other in a community of practice that allowed them to connect with people and ideas. After negotiating the "rules of engagement", the students risked being vulnerable and allowed certain sensitive issues to emerge, and the rules for thinking together encouraged reasoned reflection. These experiences provided students with the knowledge that contextual and learner responsiveness are necessary as they begin to embark on their own teaching profession.

The Digital Storytelling module, using affect and discomfort as a pedagogical device, allowed the students' vulnerabilities into the classroom. In their mixed groups, each with a trained facilitator, they were challenged to identify their biases and disrupt their stereotypical views of their single stories. This focus on shared emotions and lived experiences established connections across language, gender, racial and religious groups, which had been absent in their first three years at this pre-service teacher education institution, and in some cases, promoted personal healing.

Learning to listen to one's own story and that of the "other" can be a transformative process, which may last a lifetime, facilitated and mediated by many encounters and engagements with the "other" within and out of the classroom. This transformation is part of an ongoing reflective and critical journey that acknowledges the importance and entanglement of both knowing and feeling when working towards social change - and indeed in all learning situations. The Philosophy for/with Children process empowered the students to develop and practise specific thinking and reasoning skills. Although these students had been together for the previous three years, it appeared that they had had few experiences where they reasoned together about their opinions in a safe environment where disagreement was valued. If our students are not thinkers themselves, how can they encourage thinking skills in the children and young people with whom they work (Green et al., 2012)? The community of enquiry process empowered the students to select topics of interest to themselves and they learnt how to explore their own and others' beliefs and arrive at judgements about difficult topics using both reason and imagination. In the community of enquiry groups, everyone mattered: they were encouraged to raise questions and contribute to the learning and development of the whole community. They saw each other as teachers and learners and worked as a team. 
This process was conducted in both small and large groups, and the students practised facilitating similar dialogic enquiries during their teaching practice.

The Literature Review module enabled students to connect their own individual stories to a collective narrative, through linking their personal stories to academic readings. They began to engage emotionally with their topic of interest both within and outside the literature. This critical engagement with their own story and the broader societal issues helped the students to place personal narratives vis-à-vis dominant narratives, as they continued the process of challenging and disrupting dominant discourses when they felt these were in contradiction with their own lived experiences. Since this was the third and final module, the students knew how to work effectively in communities of practice. They took the content knowledge and professional skills they had learnt from the previous two modules and integrated it into their literature reviews. By now, they could comfortably challenge their peers' thought processes and rely on the collaborative nature of the group to support their writing.

This integrated process may have facilitated the seemingly impossible: feeling close enough to the "other", feeling emotionally invested while keeping the necessary distance to challenge their own and others' assumptions and beliefs. It may lead to what Young (1997:360) called "an enlarged thought", being able both to relativise our own assumptions and views in relation to others, and to learn from others "how the world and the collective relations they have forged look to them" (Young, 1997:360). This includes an imagination that reaches beyond common sense and dominant narratives, to envision a new space, moving students from an individualised to a systemic understanding of difference. Figure 2.4 below represents the journey from personal experience to a systemic understanding of difference. 


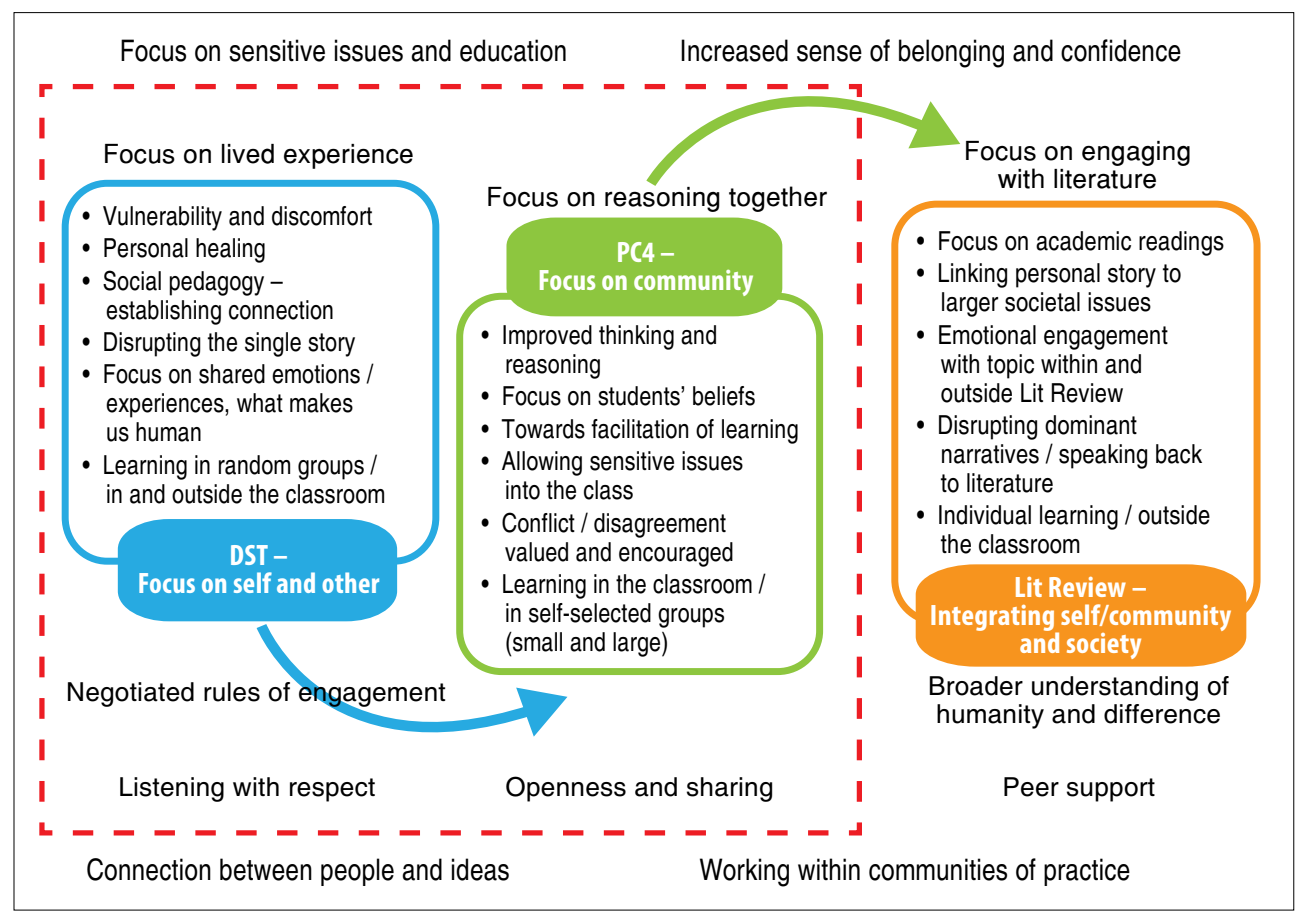

Figure 2.4 A journey from personal experience to a systemic understanding of difference

For the students, we attempted to create a twenty-first century classroom, where the modules, pedagogies and instructional practices challenged them to become agents of change: to understand and become more sensitive to the broader issues of difference. We attempted to provide varying experiences where the layered learning allowed the students to grapple with social issues of difference. In the communities of practice, all students, independent of power and equity, became co-constructors of more culturally responsive learning, where everyone's thoughts were heard, appreciated and valued.

At the beginning of this chapter, we referred to Gumede's (2013) recommendation that innovative pedagogical interventions are necessary in teacher education. We argue that the Professional Development course has created a platform where teachers are encouraged to not only think deeply and systemically, as the Minimum Requirements for Teacher Education Qualifications specify (Department of Higher Education and Training, 2011:4), but to also transform social relations. If we can achieve this in teacher education, schools may become different places. We acknowledge, however, that further research is necessary to establish the sustainability of the changes we observed. 


\section{References}

Alexander, G. 2011. Dealing with the complexities of integration in cultural diverse rural school communities in South Africa. New Horizons in Education, 1(1).

Benick, G. 2008. Digital storytelling and diasporic identities in higher education. Collected Essays on Learning and Teaching, 5:147-152. https://doi.org/10.22329/celt. v5i0.3360

Benmayor, R. 2008. Digital Storytelling as a signature pedagogy for the new humanities. Arts and Humanities in Higher Education, 7(2):188-204. https://doi.org/10.1177/ 1474022208088648

Bozalek, V. 2011. Acknowledging privilege through encounters with difference: Participatory learning and action techniques for decolonising methodologies in southern contexts. International Journal of Social Research Methodology, 14(6). https://doi.org/ 10.1080/13645579.2011.611383

Bozalek, V. \& Biersteker, L. 2010. Exploring power and privilege using participatory learning and action techniques. Social Work Education, 29:551-572. https://doi.org/10.10 80/02615470903193785

Bronfenbrenner, U. 2005. Making Human Beings Human: Bio-ecological perspectives on human development. London: Sage.

Carrim, N. 2000. Critical anti-racism and problems in self-articulated forms of identities. Race Ethnicity and Education, 3(1). https://doi.org/10.1080/713693013

Christie, P. 2008. Changing Schools in South Africa: Opening the doors of learning. Johannesburg: Heinemann Publishers.

Coventry, M. 2008. Engaging gender: Student application of theory through digital storytelling, Arts and Humanities in Higher Education, 7(2). http://doi.org/10.1177/ 1474022208 [Accessed 23 October 2016].

Department of Basic Education. 2011. National Curriculum Statement, Curriculum and Assessment Policy Statement: Intermediate Phase Grade 4-6. Pretoria: Government Printing Works.
Department of Education. 2001. Education White Paper 6: Special Needs Education, Building an Inclusive Education and Training System. Pretoria: Government Printing Works. http://www.info.gov.za/ whitepapers/2001/educ6.pdf [Accessed 24 October 2016].

Department of Higher Education and Training. 2010. Report on the Stakeholder Summit on Higher Education Transformation Called by the Minister of Higher Education and Training, Dr Blade Nzimande, 22-23 April. Johannesburg: DHET and the Centre for Education Policy Development.

Department of Higher Education and Training. 2011. National Qualifications Framework Act (67/2008): Policy on the minimum requirements for teacher education qualifications. Government Gazette, 583. Pretoria: Government Printing Works.

Desai, Z.; Giliomee, H.; Jordan, P.; Krog, A.; Kulati, T.; Lehoko, K.; Leibowitz, B.; Tlakula, P.; Gevisser, M. \& James, W. 2004. Manifesto on Values, Education and Democracy. Ministry of Education. Pretoria: Government Printing Works. http://www.info.gov.za/view/Down loadFileAction?id=70295 [Accessed 3 February 2014].

Dewey, J. 1916. Democracy and Education. New York: Macmillan.

Erasmus, Z. \& Pieterse, E. 1999. Conceptualising Coloured identities in the Western Cape Province of South Africa. In: M. Palmberg (ed.). National Identity and Democracy in Africa. Cape Town: HSRC Press.

Feuerstein, R.; Klein, P.S. \& Tannenbaum, A.J. (eds). 1991. Mediated Learning Experience: Theoretical, psycho-social and learning implications. London: Freund.

Gachago, D.; Clowes, L. \& Condy, J. 2016. "Family comes in all forms, blood or not": Disrupting dominant narratives around the patriarchal nuclear family in a South African family. Gender in Education, 30(8). https://doi.org/10.1080/09540253.2016.1 259464 [Accessed 18 February 2019].

Exploring being human today | 
Gachago, D.; Condy, J.; Ivala, E. \& Chigona, A. 2014. "All stories bring hope because stories bring awareness": Students' perceptions of digital storytelling for social justice education. South African Journal of Education, 34(4). https://doi.org/10.15700/201412052108

Gachago, D.; Ivala, E.; Condy, J. \& Chigona, A. 2013. Journeys across differences: Pre-service teacher education students' perceptions of pedagogy of discomfort in a digital storytelling module in South Africa. Critical Studies in Teaching and Learning (CriSTaL), 1(1).

Green, L. 2012. Adjusting the wheel: Philosophy for children in a different context. In: C.S. Lee \& J.W. Parks (eds). Moral and Multicultural Education through Philosophy. Seoul: Korean Academy of Teaching Philosophy in School.

Green, L.; Condy, J. \& Chigona, A. 2012. Developing the language of thinking within a classroom community in inquiry: Pre-service teachers' experience. South African Journal of Education, 32(3). https://doi.org/10.15700/saje.v32n3a583

Gregory, M. 2002. Are children and philosophy good for each other? Thinking, 16(1).

Gumede, V. 2013. Public sector reforms and policy-making: A case of education in an emerging developmental South Africa. In: Y. Sayed, A. Kanjee \& M. Nkomo (eds). The Search for Quality Education in Postapartheid South Africa. Cape Town: HSRC Press.

James, A.; Ralfe, E.; Van Laren, L. \& Ngcobo, N. 2006. Reacting, adapting and responding to change: Experiences of multicultural and anti-racism teacher education post 1994. South African Journal of Higher Education, 20(5). https://doi.org/10.4314/sajhe. v20i5.25707

James, W. 2001. Manifesto on Values, Education and Democracy. Pretoria: Government Printing Works.

Jansen, J. 2004. Race and education after ten years. Perspectives in Education, 22(4).
Kobayashi, M. 2012. A digital storytelling project in a multicultural education class for pre-service teachers. Journal of Education for Teaching, 38(2). https://doi.org/10.1080/ 02607476.2012 .656470

Lambert, J. 2009. The center for digital storytelling in California. In: J. Hartley \& K. McWilliam (eds). Story Circle: Digital storytelling around the world. Chichester, UK: Wiley-Blackwell.

Lambert, J. 2010. Digital Storytelling Cookbook: Elements. Berkeley, CA: Center for Digital Storytelling.

Lane, J.M. \& Burroughs, M.D. 2016. Philosophy in Education. Lanham, MD: Rowman \& Littlefield.

Lave, J. \& Wenger, E. 1991. Situated Learning: Legitimate peripheral participation. Cambridge, UK: Cambridge University Press. https://doi.org/10.1017/CBO978 0511815355 [Accessed 18 February 2019].

Lipman, M. 2009. Philosophy for children: Some assumptions and implications. In: E. Marsal, E.T. Dobashi \& T.B. Weber (eds). Children philosophize worldwide. Frankfurt am Main: Peter Lang.

Lipman, M.; Sharp, A.M. \& Oscanyan, F.S. 1980. Philosophy in the Classroom. Philadelphia, PA: Temple University Press.

Mentz, K. \& Van der Walt, J.L. 2007. Multicultural concerns of educators in the Western Cape province of South Africa. Education and Urban Society, 39(3). https://doi.org/10.1177/0013124506297963

Okoli, C. \& Schabram, K. 2010. A Guide to Conducting a Systematic Literature Review of Information Systems Research (5 May). https://doi.org/10.2139/ssrn.1954824 [Accessed 18 February 2019].

Pattman, R. 2010. Investigating "race" and social cohesion at the University of KwaZulu-Natal. South African Journal of Higher Education, 24(6).

Peirce, C.S. 1997 [1877]. The fixation of belief. In: L. Menand (ed.). Pragmatism: A reader. New York: Vintage Books. 
Petticrew, M. \& Roberts, H. 2006. Systematic

Reviews in the Social Sciences: A practical guide. Oxford, UK: Blackwell. https:// doi.org/10.1080/14733140600986250 [Accessed 18 February 2019].

Rusznyak, L. \& Masinire, A. 2018. The role of developing pre-service teachers' pedagogical reasoning to support contextually responsive teaching. In: E. Walton \& R. Osman (eds). Teacher Education for Diversity: Conversations from the Global South. London: Routledge.

Sampson, C. \& Condy, J. 2016. Teaching reading under challenging conditions of an urban multi-grade Foundation Phase class. Perspectives in Education, 34(2). https://doi. org/10.18820/2519593X/pie.v34i2.7 [Accessed 18 February 2019].

Sleeter, C. \& Tettegan, S. 2002. Technology as a tool in multicultural teaching. Multicultural Education, 10(2).

Smit, B. \& Fritz, E. 2008. Understanding teacher identity from a symbolic interactionist perspective: Two ethnographic narratives. South African Journal of Education, 28.

Soudien, C. 2013. The change balance sheet in South African education. In: Y. Sayed, A. Kanjee \& M. Nkomo (eds). The Search for Quality Education in Post-apartheid South Africa. Cape Town: HSRC Press.

Splitter, L. \& Sharp, A.M. 1995. Teaching for Better Thinking: The classroom enquiry. Melbourne: Acer.

Vasudevan, L. 2006. Making known differently: Engaging visual modalities as spaces to author new selves. E-Learning, 3(2). https://doi.org/10.2304/elea.2006.3.2.207 [Accessed 18 February 2019].
Vygotsky, L.S. 1962. Thought and Language. E. Hanfmann \& G. Vakar (transl.). Cambridge, MA: The MIT Press. https://doi.org/10.1037/11193-000

Vygotsky, L.S. 1978. Mind in Society: The development of higher psychological processes. M. Cole, V. John-Steiner, S. Scribner \& E. Souberman (eds). Cambridge, MA: Harvard University Press.

Wallace, J.E. 2013. How to write a literature review? Graduate student writing workshop. 7 November. Unpublished course notes. https://bit.ly/2Ji0AsP [Accessed 21 November 2016].

Walters, L.M.; Green, M.R.; Wang, L. \& Walters, T. 2011. From heads to hearts: Digital stories as reflection artifacts of teachers' international experience. Issues in Teacher Education, 20(2):37-52.

Wenger, E. 1998. Communities of Practice: Learning, meaning, and identity. (Learning in Doing: Social, Cognitive and Computational Perspectives). Cambridge, UK: Cambridge University Press. https://doi.org/10.1017/CBO978 0511803932

Young, I.M. 1997. Asymmetrical reciprocity: On moral respect, wonder, and enlarged thought. Constellations, 3(3). https://doi. org/10.1111/j.1467-8675.1997.tb00064.x 
Appendix A Respect Questionnaire

\section{BEING HUMAN TODAY: ENGAGING WITH THE OTHER}

SCALE: $\quad 1=$ Strongly Agree; $\quad 2=$ Agree; $\quad 3=$ Uncertain; $\quad 4=$ Disagree; $\quad 5=$ Strongly Disagree

1. People should respect my beliefs.

2. People have the right to try to change my beliefs.

3. People should have the right to live how they wish.

4. People should keep quiet about their personal views.

5. It is important to show respect for other people's practices and beliefs.

6. It is important to show respect for other people's practices and beliefs, even when I disagree with them.

7. It is possible to respect other people's practices and beliefs even if one believes they are wrong.

8. All ways of living are equally valid.

9. It is good to be challenged to think about the world in a different way.

10. Society benefits from a diversity of traditions and lifestyles.

11. People should act respectfully towards others even if they do not feel respected.

12. All human beings are entitled to have their human dignity respected.

13. Respect has to be earned.

14. Genuine respect for others implies willingness to engage in dialogue about difficult topics.

15. Genuine respect implies being prepared to disagree with that person.

16. Reciprocal trust is necessary for genuine engagement.

17. I need to trust people before I am open about my beliefs.

18. It is hard for me to trust people who are different from me.

19. I trust people with my thoughts until proved otherwise.

20. When other people trust me, I find it easier to trust them.

\begin{tabular}{|l|l|l|l|l|l|}
$\mathbf{1}$ & $\mathbf{2}$ & $\mathbf{3}$ & $\mathbf{4}$ & $\mathbf{5}$ & $\begin{array}{c}\text { OFFICE } \\
\text { USE }\end{array}$ \\
\hline & & & & & RO \\
\hline & & & & & RO \\
\hline
\end{tabular}

CR Conditions for trust 
Appendix B Open-ended Questionnaire

1. How did the digital storytelling (DST) project influence your choice of literature review topic?

2. How could you use the $\mathrm{P} 4 \mathrm{C}$ experience to help you plan and organise your literature review?

3. How did the experiences of the P4C and the DST projects influence your final teaching practice this year?

4. Did either or both of these projects influence you in any other way? 

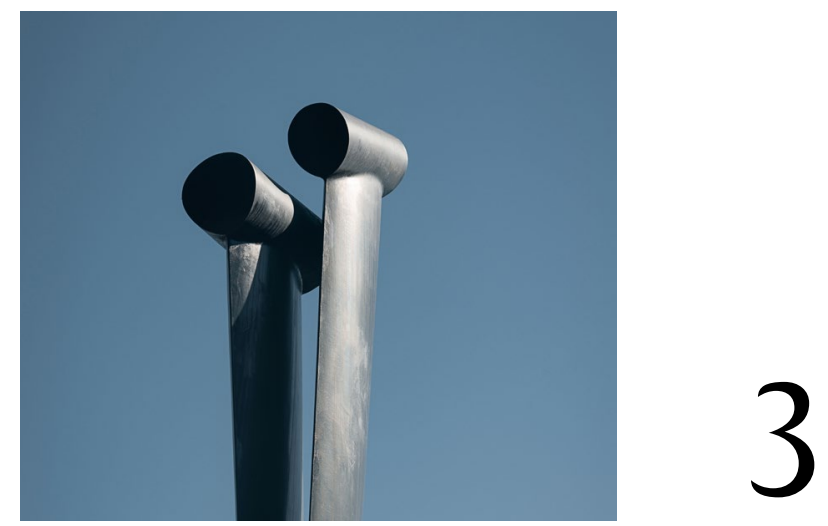

\title{
NON-RACIALISM, RACIALISM, RACISM \\ The power of youthful dreams
}

\author{
Kira Erwin and Kathryn Pillay
}

Dreaming is a profoundly human experience. Dreaming with our eyes open, associated with either daydreaming or imagining desired ideals, mixes the present with multiple other possibilities to concoct something both familiar and, as yet, unknown. Evoking the imagery of dreams is particularly powerful when the dream is presented as a collective one, a social ideal for a better society. Martin Luther King Jr's speech, "I Have a Dream" (28 August 1963), is perhaps the best-known of these. But here in South Africa, in the struggle against colonialism and apartheid, we too had a powerful collective dream that spoke of freedom, liberation and unity. Non-racialism, amongst other ideals such as non-sexism, formed an important part of this dreaming, and is a founding principle in the current democratic constitution of the country. Indeed, the South African dream (no matter how ambiguously defined) continues to resonate with our social imagination. Take, for example, popular political commentary such as Mark Gevisser's (2007) book, titled Thabo Mbeki: The dream deferred, or Abebe Zegeye and Julie Maxted's (2002) similarly titled book, Our Dream Deferred: The poor in South Africa. Politicians also evoke the sentiment of the South African dream. In 2008, Helen Zille, the then leader of the 
opposition Democratic Alliance party, delivered a speech entitled "Delivering the South African dream: One nation one future" (Zille, 2008). In her brief foray into politics, Mamphela Ramphele announced the launch of her political party, Agang, at Constitutional Hill in 2013 with a speech titled "Rekindling the South African Dream” (Ramphele, 2013). Recently, in April 2016, cabinet spokesperson Phumla Williams gave a speech assuring us that the African National Congress (ANC) ruling party was "On track to realising the South African dream" (Williams, 2016). As these titles reveal, the South African dream appears to be in trouble, a dream that, more than two decades after the end of apartheid, remains unrealised. As Crain Soudien (2012) explains in his book, Realising the Dream: Unlearning the logic of race in the South African school, this dream, and its lack of materiality, has much to do with race, racialism, racism and non-racialism.

Our study is also interested in the dream of a better, more equal and just South African society, but less in how actors in the state or academic institutions believe it should be defined. Public imaginings must extend beyond the state. This study explores how groups of Grade 11 students (approximately 17 years old) from five different schools in the city of Durban, imagine this future. In this project, it is the young participants who take responsibility for and agency in imagining a new social order, and the issues we would need to address in the present to get there. It uses a methodology called Dreaming Workshops designed specifically to answer the questions posed in this study: whether and how these young people imagine race and non-racialism in this future; and what present day obstacles to obtaining this dream they identify. Their dreams and what they think about them are complex and, at times, contradictory, but deeply insightful. As we will discuss, they do not articulate these dreams as non-racialism, although the meanings they attribute to these ideals often mirror the diverse broader understandings of non-racialism in the country. They offer, we feel, some inroads into making sense of how some young South Africans understand, and choose to take agency within, an unequal but democratic society, in which both race and class are being reproduced and reconstituted. In addition, the findings in this study raise questions about the obstacles, as identified by the students and by the researchers, to achieving a more equal and just society.

\section{Non-racialism}

Non-racialism in South Africa is a somewhat ambiguous concept. Despite its rich and contested history in various struggle movements, and being a founding principle in our constitution, there has never been an organised effort to give it definitional substance (Posel, 2015:2168). Unpacking the intellectual history of non-racialism is outside the scope of this chapter (see Zinn, 2016; Everatt, 2009; 
Frederikse, 1990). However, a brief outline of how non-racialism is understood is useful for the context of this research. Certainly, regardless of whether students in this study are conscious of this history or not, many of their dreams converge with the various ways in which non-racialism is conceived in the broader society.

Non-racialism during the struggle against apartheid was used as a pragmatic mobilising strategy to bring about solidarity between divergent activist movements. For many activists, it was "something that we had to learn in practice" in organising and mobilising across organisations with membership bases that consisted of different "race groups" (Kathrada, 2012:11). Ideas associated with non-racialism, what Julie Frederikse calls the "unbreakable thread" (1990), can be found in liberation organisations from the 1930s onwards. It was not, however, a unanimously accepted ideal. Even within the ANC it has an uneasy history (Gillespie, 2010), with the movement's policy decision of non-racialism contributing to the breakaway of the Pan African Congress. Notions of non-racialism also created tension between Black Consciousness activists and the non-racial United Democratic Front (Kathrada, 2012:10). In the 1970s, Steve Biko saw non-racialism as a mechanism through which "white" liberals maintained privileged positions while fighting the "good fight" (Biko, 1987:20). Writing more recently, Xolela Mangcu states that non-racialism is less a common thread and more a consistent bone of contention between the "non-racial modernity of the African National Congress (ANC) and the race consciousness of Black Consciousness and Pan Africanism" (2015:7). These contestations are fundamentally questions of how South Africans understand their humanity in relation to one another. For Deborah Posel, non-racialism rejected the problematic humanism of the enlightenment, and instead started "depicting the human condition as an essentially social one, [where] humanity was defined ethically by its mutuality - rendered as a contemporary retrieval of the long-standing African ethic of ubuntu" (2015:2168).

In its popular form, during the transition from apartheid to democracy, non-racialism was a national ideal that vaguely suggested a way to live together harmoniously in South Africa, an "ideological force to promote reconciliation and nation-building" (Ndebele, 2002:133). More than two decades into democracy, it is unclear what non-racialism means for ordinary South Africans. In 2011, the Ahmed Kathrada Foundation undertook research that addressed this issue through nation-wide focus groups of ordinary South Africans (Bass, Erwin, Kinners \& Maré, 2012). In 2012 and 2013, respectively, they continued to research the meaning of non-racialism but with South African struggle leaders (Ahmed Kathrada Foundation, 2012), and then ANC branch members in Gauteng (Ahmed Kathrada Foundation, 2013). In all three of these studies, non-racialism was equated to a multiplicity of ideas, prevalent amongst them multiracialism, multiculturalism, nation-building, and raceblindness (Erwin, 2017). Commenting on the 2011 national focus group study, 
David Everatt notes that "non-racialism is widely accepted as 'a good thing' - but like so many other virtues, it is fuzzily understood, rarely practised, and more often the recipient of lip service than of action". For him, this is in large part "because it has emotive and symbolic, but no substantive, meaning" (2012:17).

Certainly, leaving non-racialism as a non-defined abstract principle with no "sociopolitical or economic project driving it" has exacerbated frustration with this concept in South Africa (Everatt, 2012:6). As people try to make sense of non-racialism in the continuing context of gross economic disparities within a democratic state, this constitutional principle has come under increasing attack. Having said this, we do not wish to downplay the significant social justice gains in South Africa that began in the early 1990s, in terms of extending state services to all, rejecting racist legislation and entrenching constitutional rights. We are indeed constitutionally, socially and legally speaking in a far preferable context than under apartheid. Yet, despite the significant shift in political power, vast economic and material inequalities remain. In addition, these inequalities continue, in general, to easily map onto racial demographics in ways that highlight significant continuities with the recent past (Gumede, 2015:91). The entanglement of class and race remains a striking contemporary feature of South African society. These structural inequalities fundamentally enable reproductions of racialism and racism in the country.

Given this, it is not surprising that some South Africans feel alienated from the principle of non-racialism. It has also come under academic critique. In 2009, David Theo Goldberg likened non-racialism in South Africa to "the emperor's clothes ... what the state wears to represent itself to the world, how it looks" (2009a:532). Goldberg has been scathing of how anti-racialism (his term for non-racialism) provides a convenient amnesia that dismisses past and present discrimination, which in turn maintains its neoliberal structural enablers (2009b). Goldberg is not alone in his critique: in current popular debates non-racialism has been portrayed as a mechanism through which neoliberal and elite concerns have been safeguarded in South Africa, particularly when used as a form of "colour-blindness", or as Mangcu puts it, "an ideology of non-racial inequality" (2015:16). The \#RhodesMustFall and \#FeesMustFall student movements in 2015 and 2016 levelled similar critiques. For some of these students, government rhetoric of reconciliation through non-racialism "capitulated to the power of white capital", and it safeguards colonial principles and practices that alienate "black" students in higher education institutions (Posel, 2015:2171). Without substantial economic restructuring, unifying national ideals can certainly serve to protect non-transformative agendas (Beall, Gelb \& Hassim, 2005:690; Abrahams, 2012:116). However, there is a concerning trend in some of these arguments that decontextualises non-racialism, and a turn to a popular rhetoric with desired political outcomes that are ambiguous (Posel, 2015). 
Most of the current critiques of non-racialism focus on how it is utilised within the political sphere of government. While they have relevance, they tend to downplay or overlook how, outside of this sphere, non-racialism as an intellectual and philosophical project directly engages with the complexities of building solidarity across difference. In valuing what Posel calls the "precept of human mutuality that exceeded the mere tolerance of difference" (2015:2168), the South African intellectual history of non-racialism contains within it a refusal to discuss only race, or only class, but insists on an analysis that acknowledges both within a particular political context (see Harold Wolpe, quoted in Soudien, 2012:130). Embedded in this intellectual history is a call to destabilise the construct of race, not as an antithesis to fighting racism, but to serve as a necessary precondition in the struggle for liberation from racial oppression (see the interview with Alexander in Gillespie, 2010). Without this, processes of racialisation are normalised and race reproduced as a given descriptor of "who people are" (Maré, 2001). There is a strategic purpose in what Zimitri Erasmus calls "shatter[ing] the lens of race": doing so exposes what "lives behind race ... with a view to disrupting underlying structures of privilege rather than simply tinkering with or compensating for their outcomes" (Erasmus, 2010a:50). Lawrence Blum's (2015) comparative analysis of American and South African struggles against racism acknowledges that it is not possible to simply equate South Africa's ideology of non-racialism to that of America's "colour-blindness". For him, "Americans who say they are colour-blind, or that policy should be colour-blind, do not have the primary commitment to racial justice and equality that I see in 'non-racialism"' (Blum, 2015:43).

We write this chapter at a time in South Africa when race and racism are again at the front and centre of political and popular debates (driven by increasing exposure to racism on social media platforms, and the sensationalism of race as a primary social division in the media). It is a time that simultaneously inspires exciting possibilities for discussing race and inequality in different ways, and a retreat into existing polarised arguments and essentialist identity politics. It is in this context that Suren Pillay asks:

Should non-racialism and Black Consciousness still be the dominant terms of a debate that we are being asked to participate in? Or are they two opposing sides of a 'question-answer' complex that might no longer be useful politically to think with or think against in the present conjuncture? (Pillay, 2015:134)

South Africa is not alone in this conundrum; in many struggle movements there is a frequent return to the "question of the place of history in the present, and how this helps or hinders the opening up of future possibilities" (Bhambra \& Margree, 2010:59).

What non-racialism is, or should mean, in these contemporary debates may well be a question worth pursuing. However, for the purposes of this study we are less 
interested in the popular debates that currently appear to be rehashing (and hashtagging) old positionalities. We are more interested in the idea of non-racialism as a utopian future, and how some of the concepts found in non-racialism may or may not be something that young people imagine in such a future. We agree with Posel that non-racialism during the struggle against apartheid was a "fundamentally more pragmatic, if also principled, engagement with the realities of the present - a critical tool, in fact, in stabilising a precarious transition and performing the conditions of an emergent and fragile national collective". However, we are less convinced when she states that it was "not a Utopian project looking to a future in which race would be erased" (Posel, 2015:2169). In response to the myriad of everyday horrors of apartheid, non-racialism did encompass a future-orientated framework, a desire for a time when race would no longer determine life chances or essentialise our beings. There are many examples of this, one of which is Steve Biko's 1977 BBC interview where he explained his future vision for the country: "We see a completely non-racial society. We don't believe, for instance, in the so-called guarantees for minority rights, because guaranteeing minority rights implies the recognition of portions of the community on a race basis."

Non-racialism as a way to imagine a desired future state of being continues to hold contemporary relevance in thinking about race and racism. Indeed, as Bhambra and Margree remind us:

The raison d'etre of any politicised identity is the bringing about of a tomorrow in which the social injustices of the present have been overcome. But identity politics also needs that tomorrow - today - in the sense that politicised identities need to inscribe that tomorrow into their self-definition in the present, in order to avoid consolidating activity around the maintenance of the identity rather than the overcoming of the conditions that generated it. (Bhambra \& Margree, 2010:65)

Future imaginings are useful. Firstly, they enable the social imagination to escape the confines of present paradigms; dreaming outside of the ubiquitous racial framework means that we may start to imagine other ways of being. Secondly, it is a mechanism through which to recognise and confront the challenges that stand in the way of achieving a utopian future; ${ }^{2}$ herein lies the complex praxis of translating the fantastical into action. Future thinking can spark critical reflection on the present, on how and why race thinking remains so "obvious" and its entanglement and articulation with other systems of oppression (such as gender, religion and class). Here, utopian thinking can be used "to measure and critique life as it is by life as it should be, in order to effect change or even revolution" (Kraftl, 2007:121).

1 This interview can be viewed at http://www.youtube.com/watch?v=6ZHDPTE4TXk

2 We are well aware that "utopia is conceptually as well as substantively contested" (see Levitas, 2003) but use it here as a pragmatic strategy for reflecting on the present. 
In 1972, Rick Turner argued that utopian thinking could be more than an exercise in fantasy if used to recognise and confront the obstacles to the imagined utopia. Utopian thinking offered a solution-orientated move away from the fixed apartheid present through exploring "the absolute limits of possibility by sketching an ideally just society”, where racist and sexist ideas would not make sense (Turner, 1972:3). A future-orientated vision asks us to do the hard work of articulating not just what we are fighting against, in this case racism, but what it is we are fighting for (Alexander, 2013 [1989]:5). ${ }^{3}$ For all its lack of clarity, non-racialism may yet offer such a necessary horizon for the present (Mbembe quoted in Erwin, 2017). This research does not set out to present what a definitive non-racial horizon should look like. Rather, it is interested in exploring how young people in this study may imagine such a horizon, and what this future dreaming tells us about their sense of agency and possibility in the present.

\section{Why talk to young people?}

There is a paucity of research in South Africa on how people imagine a future non-racial society. Existing studies either focus on how non-racialism is not yet practised through examining racial tensions and inequalities, or as in the Ahmed Kathrada Foundation project, investigate South Africans' perceptions (or lack thereof) of non-racialism in the present. The present research therefore develops and extends into areas, and in ways not done before, by implementing a future-orientated theoretical and epistemological framework. Focusing on young people rather than, say, young adults or older people, it is motivated in part by the general propensity to see young people as a "social barometer" to understand "what society might look like in the future" (Heath, Brooks, Cleaver \& Ireland, 2009:1). In South Africa, the popularly termed "born-free" generation - children born into democracy - are often seen as the hope for a better society. For example, Caryn Abrahams' analysis of the Ahmed Kathrada Foundation's nationwide research project on the meaning of non-racialism, using citizen focus groups, noted that "there was one overwhelmingly similar response: the achievement of a South Africa in which race is not the primary way of regarding each other is best left to the next generation" (Abrahams, 2012:118). Romanticising the youth as future heroes who will fix what is broken in the present is not unusual in societies transitioning from traumatic pasts. Indeed, in the global construction of childhood, the young have become "an enormous, permanent repository for hope". Constructed as untainted and innocent, "we can fill them and the very idea of childhood with our hopes and dreams" (Kraftl, 2008:82).

3 See Paul Joshua's (2014) article, which argues for the necessity of a post-racial imaginary for anti-racism work in the United Kingdom. 
Perhaps in societies such as South Africa, with "an uncertain socio-political climate" and deep structural inequalities, seeing children in this way may seem to be the only viable option for change (Abrahams, 2012:116). While we are not completely cynical about this romanticised notion, we are critical about how this discourse burdens young people as primary agents for social change. This is especially problematic, given that young people continue to be socialised into a highly racialised society, and continue to experience gross social and economic disparities. Expecting young people to eradicate racism without adult assistance in tackling the material inequalities that feed these ideologies is a deeply unfair deferral of responsibility onto the young (Erwin, 2017). Admitting that we too are drawn to the idea that young people may be less "jaded" in imagining alternate social worlds, but acutely mindful of this deferral tendency, we have attempted to design this study to listen to young people's ideas, as opposed to looking to them for solutions.

Conducting research in schools is motivated by a number of factors. In South Africa and elsewhere, education is seen as a key strategy to address prejudice and discrimination, as well as being touted as critical to nation-building programmes (Ahmed Kathrada Foundation, 2012:25; Everatt, 2012). Anti-racism educational campaigns targeted at schools and youth programmes are regularly employed throughout the world (Bonnett, 2000; Anthias \& Lloyd, 2002; Nelson, 2015). But schools are also of interest in that they are spaces where, particularly in urban areas, young people of diverse identities spend long periods of time together. Schools, it has been argued, are a microcosm of society, a "space in which the tensions inherent in contemporary South African society are played out" (Dolby, 2001:9). Many researchers have looked to schools to investigate how ideas of race are played out in these (apparently) transforming institutions. Often these studies highlight how race remains central to student-student and student-teacher interactions (Botha, Myburgh \& Poggenpoel, 2012; Bhana \& Pattman, 2010; Dolby, 2001). While we do not necessarily dispute this, it would be interesting to use a different research lens to note how, despite this, young people may still imagine a future where race may not, or at least not in expected ways, mediate personal experiences. Some scholars, such as Jansen (2012:8), have argued that outside of the polarised South African debates on race that insist on depicting division and separation, young people in educational contexts are already practising ways to come together that counter this dominant trope.

\section{Dreaming Workshops}

Taking the above into consideration, the questions that inform this research are around how young people (here Grade 11 learners) imagine a better, more just and equal future South African society. Specifically, we were interested in whether race 
or non-racialism was something they imagined in this future and if so in what ways and why. We also explored what these young people saw as necessary pre-conditions for their utopian future. When we imagine a better future for humans, we must recognise that we are already busy making or dismantling this future. Therefore, more than simply providing a description of this future we analyse where and how experiences of, or obstacles to, non-racialism in the present inspire, or hinder, dreams of the future. Therefore, two further research questions were included in the study: Do experiences of what participants identify as non-racialism in the present inspire these future imaginings? What present obstacles do students identify as preventing or hindering their imagined future?

We designed a specific methodology of enquiry to answer these questions, called Dreaming Workshops. Designing this methodology, rather than selecting one or two traditional methods, enabled us to craft a collaborative and creative space to imagine radical utopian futures, yet also direct the discussions in relation to the focused research questions if necessary. Dreaming Workshops, a form of focus group enquiry/dialogue, encourages participants to engage in future dreaming discussions through incorporating various creative methods. Creative methodologies, as opposed to conventional methods, allow for more participants to be involved in the research process, thereby creating a platform for multiple voices to be heard (Horsfall \& Titchen, 2009). This type of data collection method is particularly appropriate when researching children's experiences and perspectives, as it "acknowledges the participants as experts" and encourages them to view the process as communicating with peers, as opposed to being interrogated by an adult (Greene \& Hogan, 2005:5).

The Dreaming Workshop process was designed to be cognisant of the tensions between inserting direct questions on race that may restrict the possibilities of thinking outside a racialised paradigm, and providing some flexible guidance to ensure a discussion in relation to the project's focus. This is pertinent, since existing research suggests that schools themselves socialise a particular discourse of non-racialism within their student body (Soudien, 2012). The initial broader focus on the utopian future ensured that we did not from the start spark preconceived institutional rhetoric of the concepts that the learners may have felt compelled to share.

Four schools were selected for this study. However, prior to research being conducted at these schools, a pilot study was undertaken at a private school located in a similar ward to the four schools under study. It is important to provide a background and context of the research sites, as we discovered that the school ethos shaped many of the learners' responses. The schools selected to participate in this study are located in a primarily middle-class (with some working-class areas), 
formerly "white", ward in Durban. ${ }^{4}$ The ward boasts a large number of educational institutions. "Middle-class, former white areas have experienced significant increases in inflows of black people", as parents moved children from less-resourced township to suburban schools (Soudien, 2004:107). In some ways, urban schools represent far greater transformation compared to rural schools, which remain under-resourced, and overwhelmingly service similar populations to those under apartheid. The schools selected for this study do not cater only to students who reside in the ward, but also to those whose parents work in the area, and in the case of Greenwood, learners who live in townships a significant distance away. ${ }^{5}$ The schools have a diverse student body, with the exception of Greenwood, in which the Grade 11 class we worked with was comprised almost entirely of learners classified as black. The two private colleges appeared to have a student body primarily belonging to the middle and upper class, whereas Greenwood represents a lower- to middle-class economic group, and the two ex-Model C schools reflect more class diversity, especially in the all-girls school. ${ }^{6}$

The geographic distance between the schools selected in this study is small and they represent a relatively small spectrum of the post-1994 South African schooling landscape (of "good" schools), one primarily determined by the financial capacity of the institutions. It is important to note that only a small number of South African children have the types of schooling experiences of the young people in this study. The more general picture of the South African schooling landscape is that "structural exclusion from educational resources entrenches intergenerational inequality" (McKay, 2015:99), leaving the majority of poorer South Africans reliant on low-performing and under-resourced schools. While private and ex-Model C schools make up a disproportionately small percentage of schools in South Africa, "formerly-white schools, along with private schools, still produce a disproportionate amount of powerful people in South African society ... and the schools help to define what counts as 'prestigious' culture in society, for instance

4 Under the Group Areas Act during apartheid this area would have been designated as a "white"-only residential area.

5 Township areas during apartheid were under-resourced and under-serviced designated residential spaces for "black" people. While the Group Areas Act that legislated this racial segregation was repealed even before the beginning of democracy, township demographics today remain almost unchanged.

6 The term "Model C" refers to an early restructuring of the education landscape in the 1990s, where, in anticipation of the end of the apartheid government, schools no longer used race as criteria for access, but also allowed governing bodies' increased decision making over school fee structures and the hiring of staff. Although this term was abolished when the ANC government came into power in 1994, it is still commonly used to denote former 'whites'only government schools. 
[speaking] English with a 'white' accent” (Hunter, 2015:2). Given this, how young people in these institutions make sense of ideas of race, social justice and equality, is most certainly worth exploring.

The list below outlines the schools selected, from which one class of Grade 11 learners was selected by the school, to participate in the study. We were aware that in at least four of the schools the class selected to take part in the study was considered a top performing class by the school. Schools closely monitor how they are perceived by outsiders and in one way this was an attempt to uphold their reputation as high-performing institutions. The Grade 11 classes in each school were made up of approximately 20 learners per class:

School 1 (Pilot): Ascension College is a co-ed, ${ }^{7}$ well-funded (out of ward) private Christian school which follows the Accelerated Christian Education curriculum, and at the time of the research did not write any of the mainstream exams on school leaving (such as the Independent Examination Board or National Senior Certificate exams). School fees are approximately R55 000 per annum. ${ }^{8}$

School 2: Gardens College is a co-ed, well-funded private school. Private schools in South Africa are not administered or funded by the state but through school fees charged to parents. Fees are often high and, despite bursary schemes, essentially ensure that access to these institutions is overwhelmingly limited to middle- to upper-income families. The annual school fees at this school are approximately R68000 per annum. ${ }^{9}$ This school had achieved a 100 per cent matric pass rate for the three successive years prior to this study. ${ }^{10}$

School 3: Greenwood High School is an ex-Model C co-ed public school, considered a fee-paying school by the Department of Education, and as such receives minimal financial state support per pupil. In reality, it is in dire financial straits as parents are unable to pay fees. Despite this, it still continues to be categorised by the Department of Basic Education as a quintile 5 school, which is the same category as Riverbend Boys' High and Manor House Girls' High.

7 "Co-educational", that is, accommodating girls and boys together.

8 This is an indicator of the approximate cost of registering children at these schools. These fees do not include the cost of uniforms, stationery and extracurricular activities that students are compelled to participate in.

9 Ascension College and Gardens College are not the most expensive of the private school offerings in the area. The fees for one of the top private girls' schools in the Durban Metro area are approximately R89400 per annum.

10 Matric, or Grade 12, is the last year of secondary schooling education in South Africa. Students' results in this year fundamentally determine access to tertiary education programmes. 
Many of the students in this school are residents of Umlazi township in the south of the city, or from working-class families in the surrounding area. In 2009, the school was placed under financial administration in an attempt to get it back on track. In 2012, fees were R7 100 per annum with 50 per cent of the learners exempt from paying fees and 25 per cent being allowed to pay only a portion of the fees. The school had achieved pass rates of 78.6, 84.5 and 85.3 per cent, respectively, for three successive years prior to this study.

School 4: Manor House Girls' High is an ex-Model C girls-only public school. This school is well resourced and school fees, set fairly high at approximately R28 000, are supplemented through the parent body by means of a development levy. Although a public school, it obtains sponsorships and fundraises to upgrade and develop school facilities. The learners at this school are actively engaged in leadership activities and social responsibility programmes run by universities and other organisations. This school had achieved a 100 per cent matric pass rate for the three successive years prior to this study.

School 5: Riverbend Boys' High is an ex-Model C boys-only public school, considered a "brother" school to School 4 . This school actively competes at the highest levels of school sports in the country and has substantial sports grants from outside funders. School fees are set at approximately R39500. The school had achieved pass rates of 96, 96.2 and 100 per cent, respectively, for three successive years prior to this study.

The teaching bodies of Ascension College and Greenwood High are diverse, but Gardens College, Riverbend Boys' High and Manor House Girls' High still have a predominantly "white" teaching body. This is not unusual in schools typified by those in this research, where rapid changes in the student body have not been matched by a similar shift in staff profiles (Chisholm, 2004:21).

Prior to the research initiative in the schools, ethical clearance was granted by the Durban University of Technology for the study to take place. In addition, permission was received from the Department of Education to pursue the research in the selected schools. Parental consent was not required as the young people were all over the age of 16 and could sign letters of assent agreeing to participate in the study. However, both the private schools, Ascension College and Gardens College required students to receive parental consent prior to participation. Only two learners, from Gardens College, chose not to participate in the study, one of their own volition and the other because a parent chose not to give consent.

The Dreaming Workshops were facilitated in these schools over two sessions, with each lasting between 40 minutes and an hour. In most cases, the length of the session was dependent on the class timetable, as the sessions took place during the Life Orientation subject period in the classroom. The first session we referred 
to as the "Dreaming Session" where learners were asked to use their imagination, and to be free to express their ideas, imaginings and vision of a future South Africa that they see as fair, just and equal. The learners were supplied with poster paper and colourful writing tools. While some learners worked in groups during this session, others chose to work on their own. They expressed themselves through drawings, poetry, and statements which gave us insight into their vision of a future utopian South African society (see Figure 3.1). Greene and Hogan (2005) indicate that such creativity is essential when researching young people as it is crucial to maintain interest and focus in the research exercise.

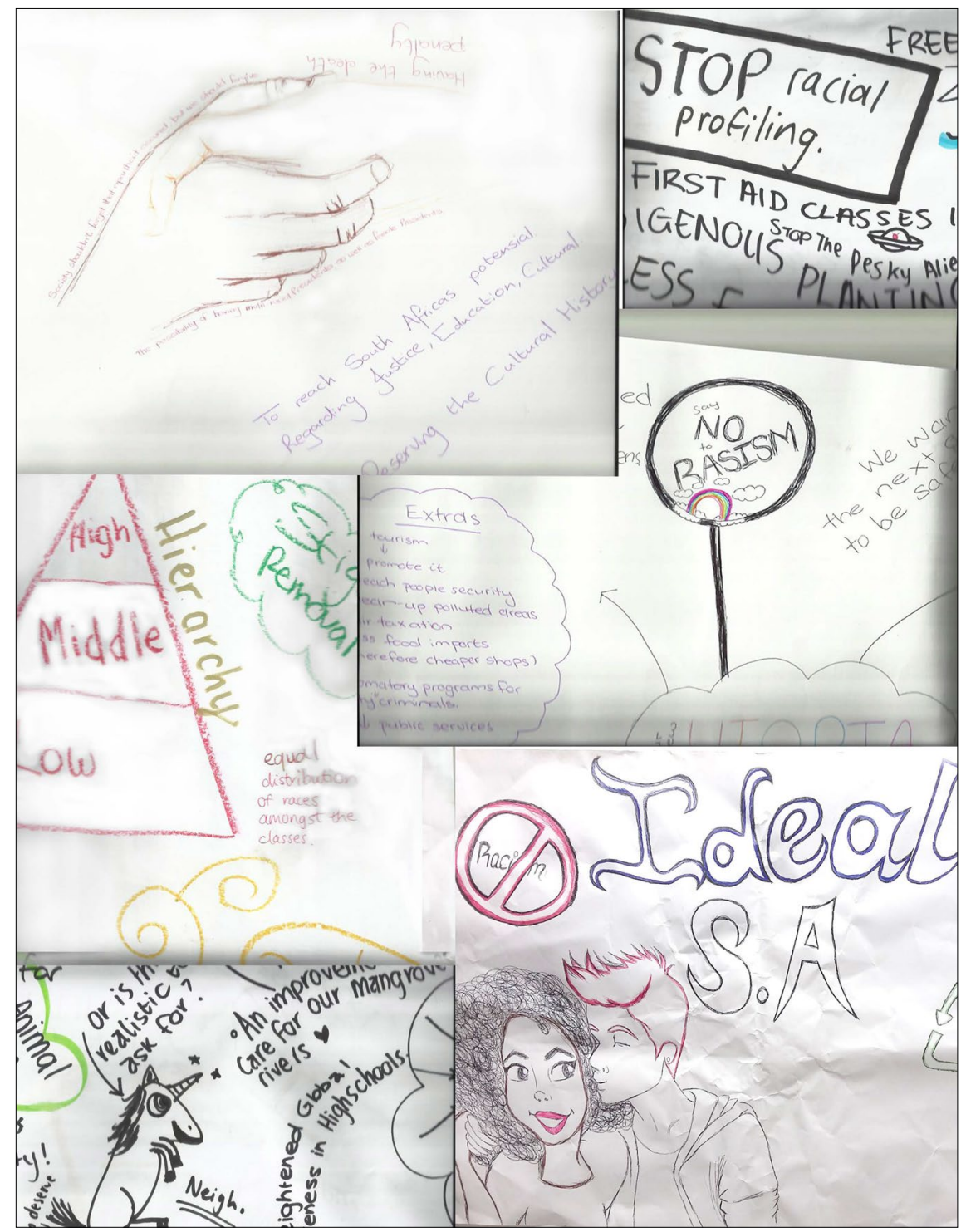

Figure 3.1 Example of the student work in the first Dreaming Session 
After the first session, the ideas/dreams contained within the posters were typed up and organised according to dominant themes that emerged, such as the environment, service delivery, equality, education, and so on. These themes, or collective dreams of the learners, along with specific statements from the learners related to the relevant themes, were arranged into a Dreaming Tree. Each Dreaming Tree depicted an outline of a tree on an approximately A0-size poster, with each theme representing a branch of the tree. An example is presented in Figure 3.2.

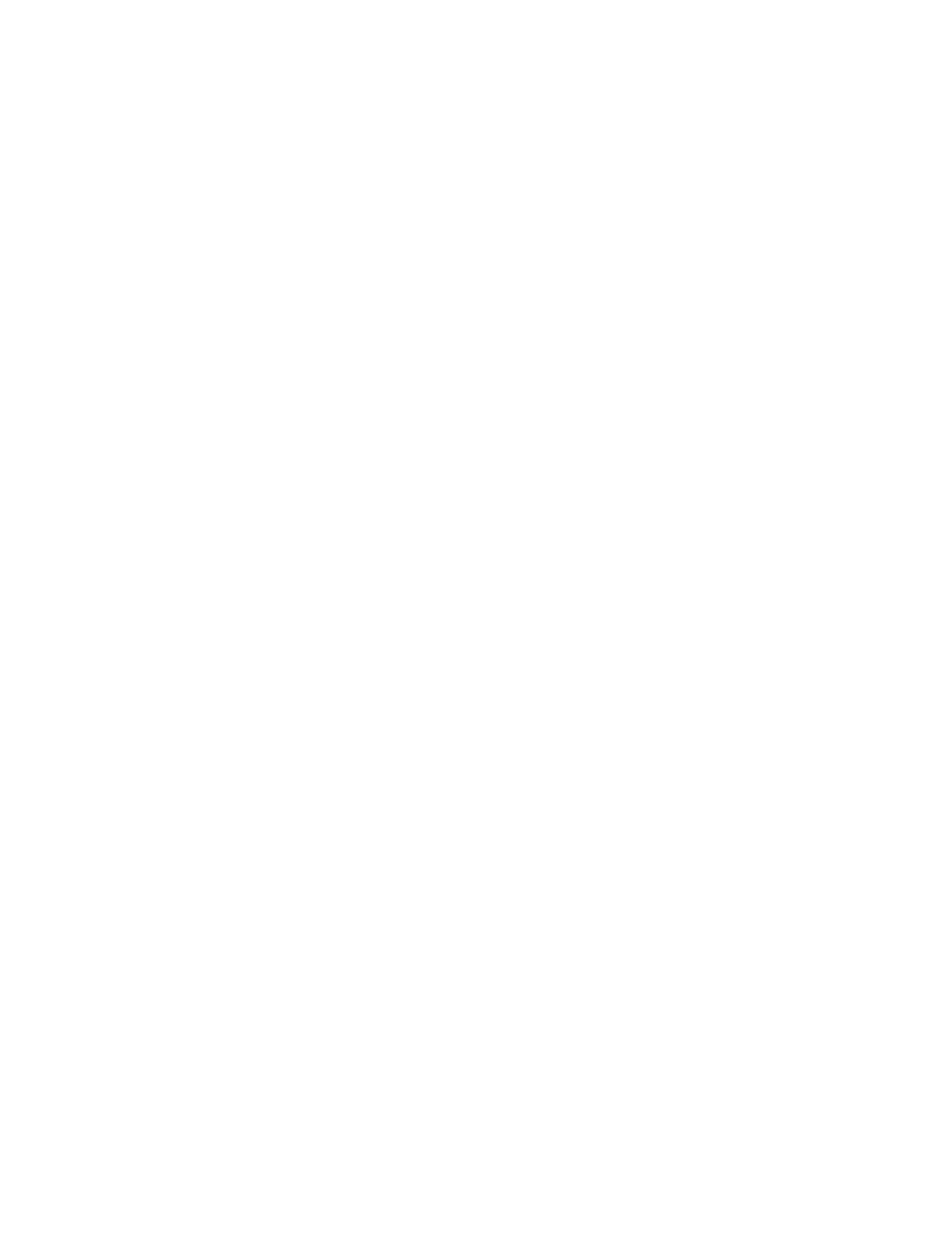

Figure 3.2 Example of a Dreaming Tree 
In session two, this Dreaming Tree was stuck up on the wall at the front of the classroom. Learners were invited to view it and to then vote for the issues that they believed were most important, and which presently needed to be addressed in order for South Africa to become a fair, just and equal society in future. Voting for an issue was done by adding a leaf to a branch which represented the issue that the students felt was crucial. Each student was given three leaves with which to vote. In addition, they were able to take a blossom at any point in the discussion in order to write comments or statements that they did not wish to make publicly, but wanted to include in the conversation. A few students added a blossom at the end of the session. However, these personal comments did not contradict any of the open discussions, and most were statements about enjoying the session or wanting more of this type of classroom engagement. Visual prompts, such as the Dreaming Tree, are an important technique when carrying out focus group dialogues with children as it encourages participation and promote an exchange of views. It also meant that the ensuing discussion was student led, as it started with the issue that most students voted for.

Following this exercise, the researchers engaged in an open discussion and dialogue with the students. During this session, students critically reflected on why a chosen branch was important to a utopian ideal and what we needed to shift or protect in the present in order to make sure the branch's theme was a future possibility. During these discussions, the young people were positioned as "active researchers", interrogating and exploring one another's ideas, and not merely as objects of research (Christiansen \& Prout, 2002). For the most part, the discussions took place amongst the students as they engaged one another on the ideas on the Dreaming Tree. At times, we asked students to elaborate or asked probing questions about their statements.

These discussions were audio recorded and thereafter transcribed. In addition to the audio recording, written notes were taken to capture important details that the researchers wished to pursue, for instance phrases and terminology used by students when discussing race. Once again, themes were identified from the data and these were organised, firstly within each school and, thereafter, the broad themes and patterns common across schools were established. Except in one instance, teachers were not present during the sessions. The presence of the teacher may have been a hindrance for some learners; however, this particular group of learners on the whole engaged in robust discussion with the researchers. 


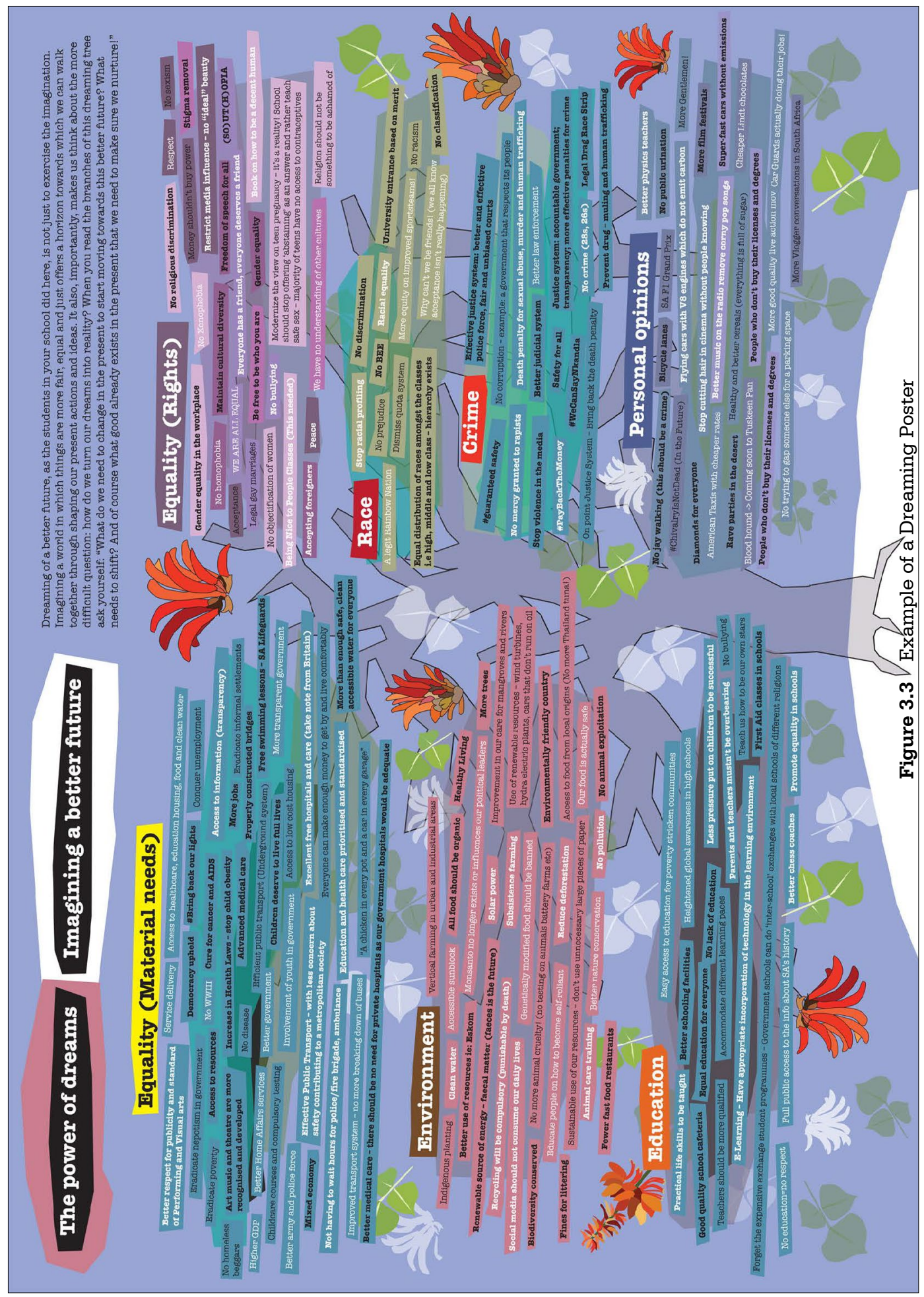


Feedback on the project findings were potentially available to all the schools in the form of a spoken presentation, and the poster designs of the students' Dreaming Trees (see Figure 3.3) were given to all the schools. In two cases, the schools were happy with only receiving the poster; in one, the deputy principal and teachers requested feedback; in another, the feedback was given to the teacher and the class that participated; and in one school we were asked to present the findings to the whole high school body in the school assembly.

\section{Things they dream of ...}

Prominent overarching themes emerged from the five Dreaming Trees. The themes of material and rights-based equality, no environmental degradation or ecological destruction, an equal and fair justice system, and no crime, are strongly shared ideals amongst all these learners. ${ }^{11}$ Young people in this study overwhelmingly desire a society that has no inequality or discrimination. The largest branch on all the schools' trees was what we would loosely call material equality, in other words a society where all people have access to quality healthcare, water, housing, and education (sometimes this last ideal had enough content to warrant its own branch). This is important as it indicates that young people, who in this study mostly come from the middle class, are deeply aware of societal inequalities. For them, reducing inequality is a priority if we are to move towards a better world. How these young people propose to deal with these inequalities, is varied and, at times, fluctuates between advocating for welfare interventions from the state and a defense of privilege and problematic meritocracy where people should not be given "hand-outs". Indeed, what it means to desire social justice and equality but refuse to "give up" anything is one of the pressing questions raised in this study.

It should be noted that the only parameter we gave to them in the first Dreaming Session was that they imagine a more just and equal society, a utopian ideal. That all the schools have large branches illustrating equality, in the senses of both material and rights, may well be a product of this parameter. However, how they gave meaning to these themes was left open; and so it remains, we feel, of importance to recognise that material inequalities are the largest obstacle these young people identify to a better future.

It is also clear that without being prompted to supply such an answer, racial discrimination and racism is something these young people would like to see end. In three of the five schools, there were sufficient texts or illustrations against racism

11 How ideas of environmental justice, and safety and security, may already be forming types of solidarity that cut across the usual divides of race, class and gender is an interesting point for further investigation. 
and discrimination to warrant its own branch on their Dreaming Tree. In the two schools where it did not have its own branch, eliminating racial discrimination and racism were present but incorporated into a more general branch on equal rights. Here ideas of removing racism shared space with other human rights issues such as no gender discrimination, no homophobia and no xenophobia. The lack of any given branch theme in a school's Dreaming Tree does not necessarily indicate the absence of an idea; it simply means that the idea was not prevalent enough to warrant its own branch (so, for example, ideas of equal and accessible education would be included in the Material Equality theme when it did not have sufficient text to start its own branch).

Table 3.1 Prevalence of branch themes in the Dreaming Trees

\begin{tabular}{|l|c|c|c|c|c|}
\hline BRANCH & ASCENSION & GARDENS & MANOR HOUSE & RIVERBEND & GREENWOOD \\
\hline Material equality & $\sqrt{ }$ & $\sqrt{ }$ & $\sqrt{ }$ & $\sqrt{ }$ & $\sqrt{ }$ \\
\hline Environment & $\sqrt{ }$ & $\sqrt{ }$ & $\sqrt{ }$ & $\sqrt{ }$ & $\sqrt{ }$ \\
\hline Equality (Rights) & & $\sqrt{ }$ & $\sqrt{ }$ & $\sqrt{ }$ & $\sqrt{ }$ \\
\hline Justice/Law/Crime & & $\sqrt{ }$ & $\sqrt{ }$ & $\sqrt{ }$ & $\sqrt{ }$ \\
\hline No racial Discrimination & $\sqrt{ }$ & $\sqrt{ }$ & $\sqrt{ }$ & & \\
\hline
\end{tabular}

Table 3.1 illustrates an overview of the branch themes that appeared in at least three or more of the schools. Branch themes not included in the above table, but which appeared in at least two Dreaming Trees, were Education, Government and Politics, and Values and Principles (e.g. love, ubuntu, friendship). Themes that contained ideas related to the Economy, Citizenship and what students called BEE (Black Economic Empowerment) only appeared in one school's Dreaming Tree (although, as will be discussed later, BEE and racial quotas were a topic of heated debate in all the schools in the second Dreaming Session).

\section{What they think about their dreams}

Describing the themes across and within the schools is fairly straightforward. Analysing how these young people make sense of these dreams is more complex. Their debates and discussions in the second Dreaming Sessions form the core data set of this study. Often these discussions focused on issues of race, inequality and politics. Their conversations and debates with one another and ourselves oscillated between being deeply insightful and emancipatory, and radically contradictory and conservative. The fluid way in which race and racism were understood and talked about mirrored the multitude of ways that race is constructed in the wider South African society. In the data are underlying sentiments of humanism, colourblindness, racialism, multiracialism, anti-racism and racism. 
The analysis in this chapter purposefully focuses on the messy, often contradictory, interplay in the ways in which race is called upon, disputed, rejected and accepted. If we wished to, we could purposefully select abstracts from the data that focused on the expected South African narratives of race; how privileged young people remain fiercely defensive of their benefits; or that some young people still socialise according to "race groups". However, such a selective focus dismisses the extracts from the data that point to unexpected counter-narratives. In each school, there are young people who have a deep individual commitment to eradicating racist thoughts, who are ready to openly challenge parents and family members about racism, and who actively refuse to essentialise their peers, through finding ways to come together that appear not to be shaped in any definitive way by racial identities. That contrasting narratives are sometimes told by the same person adds another layer of complexity to the analysis. What is interesting to explore here is how the meanings of race shift depending on the context of the conversation: for example, race when it relates to racial quotas as opposed to race when it relates to identity or politics. It is vitally important to complicate the machinations of racialism and racism within the South African context. Too frequently popular and academic debate on race and racism has fallen into the trap of dogma and "morally defensible" positions that actively choose to disentangle race from its many articulations with other ways of being. As these young people illustrate, we are all somewhat muddling through what it means to be human, as we carry our past into the present and dream of our future.

\section{Non-racialism, racialism and racial stereotypes}

The first question we wished to explore was whether race or non-racialism was something young people in this study imagined in a utopian future, and if so in what ways and why. It is notable that non-racialism is not a concept that is volunteered by any of the students in any of the schools as a future ideal. Not once did it appear in the first, or second, Dreaming Session. Given that it is a constitutional principle, and the attention it has received politically and academically, its absence in the dreams of young people is rather disconcerting. Instead, these participants talk about the end of racial discrimination and racism. This is perhaps unsurprising given that there has been no state-led programme that gives meaning and substance to non-racialism and, as Everatt suggests, "the entire bureaucracy of society, in its state and non-state forms, insists on race as a primary indicator" (2012:12). Yet, despite its absence, many of these young people make statements that equate to the various definitions outlined previously which non-racialism is argued to have in South Africa. 


\section{Racial identities}

Students in this study desired a future without racism. They also acknowledged that racism was something that remained common in the present, where "people are discriminating against each other because of the colours of their skin" (Greenwood High). Students are aware that both race and racism are processes of socialisation in South Africa; the views shared by one young student at Greenwood are found in a few discussions in this study:

It's in the way you're taught from when you grow up because when you're born, you're just a human being. And then when you grow up, they start to teach you things [so] that you know that you're black and you can see it on the skin colour, and then you grow up with this mentality that okay I'm black and that person's white. (Greenwood High)

That this racialisation then turns to racism is also understood as taught since, "you're not born racist" (Greenwood High). Research in educational settings has indicated that parents are frequently seen as an obstacle to shifting students' attitudes in the classroom (South African Human Rights Commission, 1999; Soudien, 2012:233; Pillay, 2014), and our study is no different in this respect. In every school, the older generation is identified as the carrier and transferor of racist ideas and stereotypes. For these young people, a "person's mentality and attitude towards others [is] ... because of their parents" (Ascension College). As we will discuss, this is something these young people feel is a pressing intergenerational tension. But parents are not the only obstacle to reaching a future where race can no longer be used as a discriminatory mechanism. As one student from Riverbend Boys High explains, racism is also entwined with the continuation of inequality:

$[\ldots]$ because the truth is it's passed through generations, and people who aren't white were previously disadvantaged and they still are disadvantaged, and they still have a problem getting out of the continuous loop of poverty and, because of corruption, the government cannot provide them with the same amenities as someone who can pay for them ... it has resulted in a mostly racial idea of inequality. (Riverbend Boys High)

While we do not focus on the negative sentiments towards government in this chapter, we cannot understate their prevalence in these discussions. On the whole, government was seen as corrupt, offering poor service delivery, and maintaining inequality. A hand-drawn poster stuck up in the classroom at Greenwood, in which the then president, Jacob Zuma, was depicted grinning in a top hat and coat dancing a happy little jig, his hands and hat stuffed with money, appeared to sum up these young people's views of government. In this sense, the participants in this study share a common "alienat[ion] from contemporary South African democratic political culture" with the broader youth in the country (Malila \& Garman, 2016:65). 
While students in this study were against racism and desired a future where "what colour you are or what race you are shouldn't be that much of an issue" (Greenwood High), racial identities still played an important role in these young people's sense of self. For the most part, they were spoken about as a given. For example, a Gardens College student tells us that "if you're Indian you're an Indian, I mean if you're white you're white, it shouldn't really matter what you are" (Gardens College). An Ascension College student similarly states, "like it's, we just need to be proud of who we are; that person's black, that person's black, that person's white, that person's white" (Ascension College). Despite some recognition that race was socially constructed, as in Soudien's studies in schools, "their commitments to the racial identities bequeathed to them by apartheid remains powerful" (2012:124). For many people, collective identities are "central to their individual identities" (Appiah, 2005:108); given South Africa's history of creating the collective identities of "races" this commitment may appear obvious. In the long history of racialisation, even violently imposed racial identities may become sites of resistance to oppression, belonging and pride (Blum, 2015:31).

\section{Race and culture}

Much of the rationale for having a pride in racial identities stems from conflating race and culture. Students make comments such as "coloured is as much of a culture as Zulu is a culture" (Ascension College). Although some students may think it is the "weirdest thing ever" (Manor House Girls' High) that you still see a lot of segregation of "race groups" in their school during lunch breaks, they make sense of this through using cultural frameworks. For example, a Manor House student explains that this segregation "it's not subconsciously racist, it's easier to relate to each other because of our cultures, that's why we end up having the majority of the same race". Her peer agrees with her analysis and elaborates, "I don't think it's so much as a racism issue ... you do get people that are more traditionally Indian, or traditionally black or white or coloured and they all stick with their cultures" (Manor House Girls' High).

Using race and culture not just as proxies for each other, but as justifications for drawing lines of difference, is very much part of the South African experience of racialisation. "Cultural rhetoric" as a rationale for apartheid racial segregation was an active political strategy by the ruling National Party from the 1950s onwards (Taylor \& Orkin, 1998:88). This practice seeped into the everyday implementation of policies such as the Population Registration Act of 1950, where all South Africans were racially classified through "readings of bodily differences [that] were closely tied to judgments about socio-economic status and culture" (Posel, 2001:94). Reproducing race-thinking through notions of cultural difference continues in contemporary South Africa (Bass et al., 2012; Bentley \& Habib, 2008:9). Neville Alexander has argued strongly that the national ideal of the Rainbow Nation, what 
he calls "rainbowisation", has legitimised a "new brand of multiculturalism, as opposed to the old brand of 'pluralist' multiculturalism which late apartheid tried to disguise itself as" (Alexander, 2002:101). Alexander's argument is evident in the ways in which these young people make sense of perceived racial difference in this study (although, as we will show, some actively challenge essentialist notions of self and other).

These students are not alone in drawing on this type of racial imagery. Bass et al's (2012) analysis of the large national dataset from the Ahmed Kathrada Foundation's study on non-racialism in 2011 concluded that "it is the numerous ties to thinking about race groups as cultural frameworks that solidifies race as fixed incommensurable difference" (2012:34). In democracies, both here and elsewhere, cultural sensitivity and respect for other cultures is viewed as a protected human right, and young people in this study subscribe to this notion. Yet, as Anne Phillips has skilfully argued, multiculturalism as a state project in many democracies has a tendency to escalate into "a regime of authenticity" in which cultural fluidity is actively eroded (2007:14). ${ }^{12}$ As Phillips states:

When culture is treated (as in much popular usage) as something from which we can predict a whole swath of human behaviour, this edges disturbingly close to the racist treatment of skin colour or physiognomy as predictors of human behaviour. (2007:56)

But what are the more immediate consequences when multiculturalism and multiracialism blend into each other? Certainly, in this study, it serves to provide a commonsense explanation for the desire to "stick with one's own", no matter how "one's own" is defined. This suggests that in some of Durban's "good" schools there needs to be more pedagogical thought in working with students so that they could start to "question every apparently natural easiness in the world around us and look for the work involved in making it easy" (Bowker \& Star, 2000:159). Without this criticality about power relations in racial and cultural constructs, conflation of the two creates a problematic delimiter restricting people's freedom to play with and/or refuse constructed identities. In this paradigm, anyone who openly rejects their racialised identity is by proxy seen as rejecting their culture. As one student accedes, it may be theoretically possible for a person to choose not to identify with a particular racial identity, yet she can only conceive of this as a desperate act of wanting to belong to another racial identity: "if you do feel that you're lost or whatever and you want to say that you're white then by all means say that" (Gardens College). Here the racial-cultural paradigm confines her imagination in relation to agency and identity.

12 She also illustrates that a multiculturalism that focuses on a politics of cultural representation often positions men as powerful gatekeepers of cultural traditions and norms; here multicultural programmes can increase gender inequalities (Phillips, 2007:133). 
We would, however, like to point out that this "commitment" to racial identities is more complex than it first appears. The contemporary multiracialism found in both the state and everyday life is preferable to the past state sanctioned racism of apartheid. Yet, there is an inherent disquiet between accepting and feeling pride in racial identities, and not wanting them to count as measures of social value.

I think it's important to establish a difference between race being a classification and something by which we can discriminate. Because it is, it's nice to be able to say, 'Hi I'm an Indian and it's just a factor of who I am' ... So I think classification is important in your sense of self identity, but not necessarily your worth [group agreement]. (Manor House Girls' High)

Students are vocally opposed to instances when race is used to measure "your worth" - in this study this is expressed as a rejection of racial stereotypes, and a rejection of the use of race in government policies. Perhaps these young people intuitively sense that multiracialism and racism "rather than being oppositional ... are relational" (Bass et al., 2012:37). In racialised paradigms, even if all racial identities are valorised, there is an ever-lurking disquiet that they may yet be deployed for all sorts of violent exclusions.

\section{Racial classification and discrimination}

It becomes problematic when people judge you by the box that you tick and not by your marks. Like you could have a 98 per cent aggregate and they look down and see that you're white or you're Indian, then they say no. (Gardens College)

In each and every school, students take issue with official racial categories when they are linked to state policies. Students are particularly critical of the use of racial categories in what they interchangeably describe as affirmative action, racial quotas, and BEE. Leaving aside the students' lack of understanding of how these policies are implemented in practice, or the differences between various race-based policies, it is notable how unpopular these policies are amongst the majority of students. In South Africa, BEE has come under increasing fire. For the most part, it is seen as opening up the corridors of wealth to a few (already well educated and resourced) "black" individuals, without making any significant shifts in narrowing the broader income inequality in the country (Friedman, 2015:45; Habib \& Bentley, 2008; Alexander, 2007).

For the students in this study, albeit from different standpoints, there is fierce frustration at having to tick a box that denotes one's race. A student at Greenwood explains how this makes him feel:

Why do they have to classify as to we need 20 people who are Indian to do the specific course. There are also black people who actually know very much, very much, also white people. So, I don't see the need for them ticking that box. They look down upon you. They say no it's a black guy, no man let's give 
him a space. It's better to be on the same level there's no need for it. Okay, we see its Andile Thusi - let's take that person. (Greenwood High Student)

Andile explains further that in his view, "whether we're all educated at the same level, the fact that if I wanted to be a doctor [and] they ask my race, it means that it [race] will always be there" (Greenwood High Student). Here this young student picks up the relationship between the use of the state racial categories and how it serves to reproduce racialism. Many students in this study shared similar sentiments, admittedly not with Andile's above sophisticated critique about "why that even matters". This critique is particularly targeted at the use of race as a category when applying for university admission. Government policies that demand the declaration of one's race were viewed as unfair and exclusionary for some people and not others. While many of the students, most likely racialised as white, stated that BEE was initially a good thing in that it was meant to "bring most of the black population back into economic industry" (Riverbend High Student 2), or "to give power to people who were previously disadvantaged” (Riverbend High Student 1), they felt that 22 years into democracy this was an unfair intergenerational penalty for them to carry.

But it is not only students racialised as white who make arguments against racebased policies based on fairness. An Ascension College student tells us:

Like the whole BEE type of situation, it was meant to bring us black people up, like from one level, but now it's like we're putting down other races for another race to strive. I don't have a solution for it but I just think it's wrong. (Ascension College)

Furthermore, it is not only students who are racialised as white that feel they are being excluded through racial quotas. Students in Gardens College told us that many of their parents were already making plans for them to study in other countries as they expected to be denied entry into their preferred degree due to being "Indian". While these fears may be over-exaggerated, there are also real examples of this exclusion that have attracted media attention over the years. Numerous media reports and court cases highlight how high performing "Indian" applicants to the University of KwaZulu-Natal's (UKZN) medical school, the nearest public university to the schools in this study, have been unsuccessful since the racial quotas for "Indian" and "white" students are limited, and they require much higher matric marks for entry than "coloured" and "black" students (Independent Online, 21 July 2016). ${ }^{13}$ In 2016, the media reported that a UKZN syndicate, which included senior managers, had "sold" positions at the medical

$13 \mathrm{UKZN}$ is not the only university in which racial quotas have been contested. See, for example, the University of Cape Town (Independent Online, 21 February 2005). 
school to "Indian" students by classifying them as "coloured" on their application forms (Sunday Tribune, 8 January 2017, page 7; Independent Online, 7 July 2016).

However, in each school, there are students who defend affirmative action policies as necessary for social justice. The exchanges around these policies, such as the one below, make for fascinating reading:

I feel like now everyone should move forward. Everyone should be considered equal ... I feel like that time is over. Especially with us. Like a lot of people in our generation have had opportunities to go to good schools, a lot of people have opportunities to get a fair education. (Student 1, Manor House Girls' High)

I'm not the biggest fan of quotas but I feel like they are necessary especially considering the state of the country we live in, like it's easy for us to sit here and say apartheid is over because we're all sitting together in a classroom, but in the majority of schools every single person I sit next to looks exactly like me and we're all sitting on the ground and the teacher is absent, because they decided not to come to school today and then I feel like, even though I'm excited about learning and I want to be able to get a degree or diploma, I can't and that sort of disadvantage is really, really important ... The same people who were in the workplace, many of the same people who were in the workplace before 1994 are still there, so I think it's so very important to have quotas. (Student 2, Manor House Girls' High)

The overwhelming majority, if not all, of the students in this study recognised that South Africa continues to suffer from gross inequalities, both economic and social. Since "inequality is a large factor in what generates and sustains the salience of racial(ised) identities, ... it is likely to be difficult to get rid of the latter without first, or at the same time, battling the former" (Blum, 2015:44). Yet, these young people do not, in the main, see policies based on racial categories as a means to ameliorate this. Why?

As suggested at the end of the last section, students may resist classification frameworks, because they recognise that they are "powerful technologies" that do the invisible or, in this case, visible work of putting people in place in society (Bowker \& Star, 2000:147). But there are more probable personal drivers of these responses that involve parental and societal expectations. During our time with these young people it became clear that almost all these students (with the exception of some students in Greenwood) carry a heavy burden of parental expectations of attending tertiary education. We should not underestimate the impact of family pressure to perform, and to perform well enough to get into the top universities, and into "high status" degrees such as medicine. As university registration looms for these students the anxiety that no matter how hard you work you may not be able to meet these expectations due to "racial quotas" is daunting. 
Studies such as Bock and Hunt's show that, the fear of exclusion through racial quotas is one shared by university students who identify as belonging to various South African "race" categories (Bock \& Hunt, 2015:10).

Confusingly for these young people these policies appear to contradict the middleclass principles of meritocracy in which individual hard work pays dividends. Critically these values of individual merit are not just established in the family home but actively upheld in their schools. The schools in this study, private and public alike, have within their codes of conduct ideals such as to "aspire to your full potential"; "optimise full potential for life in a multi-cultural society"; and "provide opportunities to realise our dreams, through education and training for all”. Formal schools are important spaces of socialisation; they are also "the terrain on which the forces of domination work out their ideological strategies" (Soudien, 2012:81). Explaining this, Soudien correctly points out that the South African educational model closely follows a global English-speaking system of schooling which "has to manage the contradiction of its message of possibility and even egalitarianism and the insistent urge of elites to mark the worlds they govern through the attributes of race and class" (2012:85). For these young people, there is a confusing tension between the competing democratic ideals of equality and fairness amongst individuals, and, in their view, the unfairness of race-based policies that deny individual merit. The "wiping out" of the individual in favour of a group identity, in this case racial classifications, creates obstacles to the actualisation of these socialised individualistic and meritocratic aspirations. This is true for students racialised as white or Indian, and for some students racialised as black who feel that their classification as black erases recognition of the hard work they have put in to obtain good marks. We will return to the matter of how individualism shapes another aspect of these students' understandings of the world, and how these contradictory ideals enable contradictory and conditional explanations of the world.

There are conceivably a number of trajectories that enable a society in which race no longer shapes our lives in the destructive ways it does currently. Not all of these incorporate aspects of social justice and equality. How class allegiances appeared to dominate many of the ideals of these young people was jarring. Indeed, many of the arguments for meritocracy are problematically delinked from any structural inequality. In this study, class privilege became indiscernible from what in South Africa would usually be thought of as a defence of white privilege.

\section{Defending privilege}

Since we did not specifically ask participants for family income levels, we worked on an assumption that the majority of participants in this study would roughly belong to the middle class (acknowledging the contested nature of this grouping in 
South Africa), although there would be substantial diversity of family wealth within this group. This assumption is based on the need to pay relatively high school fees to access "good schools", which in South Africa include both private and the well-off formerly "white" public schools. When "education is viewed as crucial to intergenerational class mobility" (McKay, 2015:99), there may well be students in all these schools whose parents are making enormous personal sacrifices to ensure that their children receive this mobility opportunity. In this study, Greenwood would be on the lower fringe of family income with a concentration of pupils from working and lower earning middle-class parents. However, here too there is a strong sense of belonging to the middle class, even if not matched in actual financial terms. When we presented the findings of this study to the deputy-principal she told us that even though many of the students did not come from middle-class homes financially, there was a strong sense of social capital associated with the middle class. She said that this primarily came from the students, who despite living in the townships, saw attending a school in the suburbs as being middle class. As Mark Hunter explains, "the advantages these school [sic] offer in addition to high academic standards include prestigious accents, connections to businesses, and social networks that emerge from relatively privileged schoolchildren being concentrated in the same institution" (Hunter, 2015:4).

Class elites, even if they continue to hold onto racialised identities, will collaborate to secure institutional norms and traditions that serve the hegemony of their class interests (Friedman, 2015:45; Soudien, 2012:148). There are glimpses in this study that these schools are indeed "central post-apartheid institutions involved in the deracialisation of privilege" (Hunter, 2015:2-3). At times, the othering of the working classes and the poor appears to be put to active use in building an already emerged multiracial/non-racial upper middle class. The common tropes usually associated with a defense of white privilege, such as "we need to get over blaming the past" (Ascension College), linking poverty with laziness and delinking the accrual of wealth and success from structural inequalities, were present in all the schools. This non-empathetic and detached view of those who have less capital was present in students who would be racialised as belonging to all four of South Africa's "race groups". The prevalence of class privilege "is not a matter of cultural diversity and nor should it be treated as congruent with racial identity" (Bentley \& Habib, 2008:13). In these tropes of privilege, the redistribution of wealth is seen as "taking it from the rich and giving to the poor", and equated to making poor people "believe that everything should be given to them and they won't work towards making South Africa a better place" (Gardens College). Of concern was the opposition to redistribution even through government grants:

$[\ldots]$ because I mean, there's a lot of people that sit on the streets and know that, 'Oh the people or the government will give me grants and what not, so 
why do I actually have to try and make a better future for, not only for me but for my children or what not?' (Ascension College)

The underlying meritocratic sentiments in these statements are particularly problematic given the extensive structural inequality in our country which ensures that there is no equal playing field to justify merit alone. Teaching meritocratic values in these schools, which may well be supported by similar family values, creates a form of ideological blindness to seeing one's own privilege for some of these students. Even when students acknowledge that structural inequality needs to be addressed, as in the quote below, they fundamentally regard the accumulation of wealth as being an outcome of individual effort rather than accumulated benefits from various forms of privileged positions:

It also links back to the whole point of education. You can't take money from someone who works hard and give it to you know, someone because they're poverty stricken. But if you build them up then, those who are poverty stricken, you have to build them up from the beginning. For example, education. So it's basically equal opportunities from the start. (Gardens College)

These students appear to have missed a fundamental irony in their own arguments: they complain about how people they view as poor wait for the government to fix their problems, yet they themselves state that it is the government's responsibility to address social problems, and that this should not be the burden of the well-off. The arguments against redistribution measures in these narratives are a stark reminder that it is not just race-blindness that we should guard against in South Africa; class-blindness too leads to a repetition of grave injustices.

This kind of weight on individualism and success is even evident in Greenwood, which arguably has the less wealthy students. While there most certainly is not the brash defense of class privilege seen in the other schools, responsibility for making a success of one's life still rests on the individual in ways that are problematically divorced from structural constraints on individual agency. As indicated previously, the dynamic nature of the discussions enabled a debate on these types of statements. Even without a prompt from the researchers there was a push back at some point in these discussions against this defense of privilege. A few students argued along the lines that "it's more than just one generation of systemic racism that we have to overcome" (Manor House Girls' High), and that "the people who lived during apartheid still suffer from those consequences” (Manor House Girls' High). A student at Ascension College explained to his peers how forms of capitals are passed on to the next generation:

Imagine knowing that you're born into a world where your father and your mother can't help you go to university and you are black, but the young white guy can because his mother and his father can do that for him, on average. And that's what is happening in our economy and that's why affirmative action is important. (Ascension College) 
There were also some very personal stories of recognising the context of an unequal playing field.

I think it's because, I know my family, my parents, they went through bantu Education so the education wasn't as good as we have it now. Because I'm the first generation in my family to have this type of education, so it still needs to, my dad can't get as good a job as someone who goes to this type of school. My mom can't get a job with this type of standard and I think that also makes it harder for like a lot of adults to get their children into better schools so then when you go into universities, that's why marks are different and, I'm not saying it's okay to have the inequality there [talking about racial quotas], I'm just saying that. (Manor House Girls' High)

While these open challenges in the debates were appreciated by the researchers, this young woman did not yet have the vocabulary to articulate how arguments for meritocracy are offensive in the context of these structural injustices. This more radical vocabulary may emerge as these students enter the university environment, as we have seen in the recent student protests around South Africa in 2015 and 2016. Indeed, the role of institutional culture in schools on these types of debates, where the school ethos seems to "vibrate in the bricks", as opposed to university culture which is far more fluid and contested, would be an interesting area for further research.

\section{Forms of togetherness, anti-essentialism and negotiating difference}

While there are significant blind-spots in how these young people position themselves within a wider structure of power relations in society, they are also doing some challenging self-reflection work on race-thinking and its meaning. While structural change is perceived as the responsibility of the state, or more usually a critique of the state, it is in the realm of the personal that these young people appear to embrace their own sense of agency and change. Stories in which young people realised how restrictive and problematic the racial lens is for making friends and finding peer support were fairly common in this cohort. One young woman explains that "when I was at my primary school, it started then, I knew that my social group were like white girls, they were not very faithful to me and Shanice, you were like one of my proper friends ... I never, ever saw it as race. Shanice and I have been together since pre-school, you know we've been friends" (Manor House Girls' High). Another student in the class has a similar experience of moving out of what is expected when it comes to friendship; pointing to the two girls sitting next to her she explains:

I just want to say that these are my very close friends, 'my crew' [laughter]. Although I do, at break time I sit with a group of Indian girls. It's because when I got here in Grade 8, I was literally so scared of everything, I just decided, and then my mom told me 'get into a group of people' [laughter], 
so I thought okay Indians you know! [laughter] And so last year I got accepted to go to this programme at Wits and, I'm telling you, there wasn't another Indian [laughter], I felt so secluded. That is how I felt. I felt so secluded but they never let me feel that. And since then I've changed the way I think about things so much. I really have. I mean, these two know more about me than the people who sit with me at break. I tell them everything and I feel like I'm not Indian anymore [laughter]. Because I have every race in me. I interact with so many different people and I can't see myself in the future, like me going to work one day and just sitting with Indian people. Never, that's going to be the death of me [laughter]. (Manor House Girls' High)

In all the schools, there was a genuine sense of feeling excited about seeing "each other in our heterogeneity and to deal with, and not disavow, the proclivity within us to 'other' as we socially identify" (Soudien, 2012:132). There were stories of experiences of recognising difference, and yet, rather than feeling this as deeply divisive, finding it a positive process of de-essentialising the self and other. Sometimes this was through observing similarities of behaviour where "white people have gradually become like African people" because in "Riverbend you'll find kids that smoke weed, you come to our school you find kids that smoke weed [laughter]" (Greenwood High). But mostly this is experienced through the process of making friends. A student talked about her ten-year-old brother's best friend who is a "black Jehovah Witness, and we're pagan, and one of my best friends is a pastor's daughter", and explained that experiences of friendship "extend from race and it goes on to religion and into everything ... it really just seeps into everything and you kind of grow and become a more rounded person through that" (Manor House Girls' High). This process of de-essentialising and rejecting racial stereotypes was interestingly, despite admitting that there was still a general segregation of groups during lunch break, associated mostly with spending time at school. In Ascension College, we asked the group at one point whether there were "moments or situations that you suddenly felt the possibility of great change? That you know, the colour of our skins didn't mean particularly much?" (Ascension College transcript). In response, an Ascension College student explained in stark contrast to what he experiences at home: "I experience it when I come to school, because when I look around I'm surrounded by different people completely so that's what's good about it, I don't just have black friends, I have Indian friends, I have white friends" (Ascension College). Seeing the school as a place of learning about the self and other was not uncommon:

I think the public has generalisations, so saying all Indians are like this, and all blacks are like this, and all whites are like that. In some cases they are, and in some cases they aren't, and building your reactions then is, since I've been at this school, not so much in my last school, but since I've been at this school, mixing with other races really helps you learn a lot about both yourself and other races. It helps you build a bigger understanding of different race groups, 
and I think we need to make an effort to mix with other races. Yes, embrace like their cultures because we are drawn to people that have the same interests as us in every aspect of life. But also opposites attract, so I don't know anything about the Zulu culture. But that's why we [talking about a classmate] get on because we can talk about our differences. And I think that if everyone did that it would be such a happier society because we would all feed off each other and know that everyone's accepted. (Manor House Girls' High)

This student went on to explain how she was learning to understand the differences between people she recognised as isiZulu speakers, with a major difference between people who grow up in traditional rural and urban families. By highlighting the above narratives, we are not advocating a glib contact theory, or suggesting that all is well in these schools in relation to race simply because people find themselves sharing a classroom. ${ }^{14}$ We do not, however, wish to be cynical and dismiss these stories as conditional friendships reliant on types of assimilation. Rather than make arguments about whether these friendships are "true" or not (after all who are we to decide this?), we wish to take seriously the challenge to work with the change that is already here. People's imaginings of a better future are intricately shaped by experiences of the present, both "good" and "bad". When researching how people imagine other possibilities we should "instead of only invoking it, [... also] work with it as it is already there" (Soudien, 2012:88).

These narratives illustrate how some young people today are reconstructing and deconstructing forms of social difference in ways their parents would not have been able to. In this study, young people are most certainly not practising the normative non-racialism that Pillay is critical of, that works "towards the erasure of difference and the creation of the abstract serial citizen" (Pillay, 2015:146). There are signs in this study that indicate a comfortableness in negotiating and navigating across perceived difference, although less so in relation to class differences. Theirs is a social world in which there is growing ambiguity around racial identities, where the desire to maintain racial identities as forms of social belonging are juxtaposed against learning the falsity of stereotypes and the desire to have a society free of racism. As Ash Amin suggests "the duracy of race in the present takes many forms, some which have the potential to unpredictably undermine race, and some that direct a strong call back to a 'racial order"' (Amin, 2010:2). While these narratives do not necessarily indicate non-racialism in practice (given the use of racial and cultural identities as explanatory devices within the narratives), they do indicate one necessary precondition of non-racialism, that of challenging racial and cultural essentialism; in seeing the beginnings of realising how little someone's race may actually tell you about them. In this study, there are definitive moments in which

14 See Erasmus (2010b) on the severe limitations of contact theory in South Africa. 
some students express an understanding of how "terms such as 'white' and 'black' work only at the most general level [rather than] capture the complexity that actually constitutes individuals' and groups' lives" (Soudien, 2012:45).

\section{Taking responsibility}

If agency is expressed as learning to navigate difference across friendships, it is also fiercely expressed in taking individual and generational responsibility in rejecting racism. There are discussions in each school about the individual work required to challenge racism and prejudice, often within the family environment, such as in the two extracts below.

When you are raised in a family that has come from staunch racism, it is something that you have been taught to believe. As free-thinking individuals born into a society that is now equal, it is your responsibility to not believe it. And that takes hard work ... and it's our responsibility to ensure that we interact with other races as much as possible because if you don't it's something [segregation] that's subconsciously going to happen. (Manor House Girls' High)

[... ] and I think even I have problems sometimes because I know my parents who have these ideas of racism and they say things about Indians and coloureds and white people and like, I don't believe them. But sometimes I catch myself thinking and I know that that's not true. (Manor House Girls' High)

At times in these discussions, responsibility moved from an individual to a generational level. Indeed, the idea of belonging to a generation group and the responsibility for change, sharply juxtaposed against an older generation, was something these young people held in common.

The only thing we can do is, for us to pass on a better attitude towards our kids so that they know how they feel. Because obviously we, I'm sure a lot of us have parents or grandparents or whatever, that still might have racism or whatever. But now we can change that by telling our children that it's not like ... ja, it doesn't have to be that way. (Ascension College)

So we have to break the chain and be like, it might have happened but it's not like that anymore ... So I think that also falls onto our generation, is leading by example. (Ascension College)

There is little research in South Africa on how people personally conceptualise racism and choose to take individual action against it. In this study, what these young people recognise as racism that needs to be challenged is unclear. Indeed, one could argue that they would be blind to banal institutional racism if it is interpreted as traditional processes or principles of meritocracy. Silva's comparative study of Brazilian and South African professionals indicates that conceptions of racism shape individuals' personal anti-racism strategies. This study revealed that South Africans who believed that racialism and racism were part of "human nature" 
adopted non-confrontational strategies and choose to ignore racism in favour of "working hard and doing your job" (Silva, 2012:514). However, South African professionals who viewed racism as part of a structural competition for economic resources that supported white privilege, were strong supporters of BEE policies, and were more likely to engage in personal confrontations with people they identified as racist (Silva, 2012:514).

We did not set out to implicitly examine the students' concept of racism in this study, yet it is clear that, while most of these young people do not support racebased policies, they are prepared to take on individual actions and responsibilities of fighting racism. This sense of responsibility to "break the chain" raises interesting questions for further research in South Africa. It could be that intense dislike of the formal use of racial classifications to determine an individual's worth, mixed with ambiguity about race as a social divider, underpin this responsibility. It would be difficult to make a strong claim, based on this study alone, that a loosening rather than official fixing of race in South Africa could translate to a social environment, where individuals feel more free to openly challenge racism. But this area is certainly an entry for further research; we agree with Taylor and Orkin that "social research must begin to fully chart and analyse the evidence for the presence and impact of a non-racial outlook, with its alternative interpretation of self-identity which rejects and resists racial politics" (Taylor \& Orkin, 1998:97). However, it would be equally valuable to examine how resistance to racism is shaped where people have an intensely racialised outlook. The data in this study suggests that there is potential to explore how solidarity, which encompasses but is extended beyond resistance to racism, is "generated around the address of injustices rather than the solidarity that is presumed to ensue from being the victim of an injustice" (Bhambra \& Margree, 2010:61).

\section{Concluding thoughts}

The Grade 11 students from all five high schools who participated in this study dreamed of a future without inequality, either material or in relation to discrimination against others. In this utopian future, there should be no racism (or other forms of discrimination), and everyone would have access to good quality healthcare, education, water, electricity and housing, etc. A few students vocalised how material inequality in South Africa continues to racialise society. In the discussions with, and between, students they also dream of a future without formal racial classifications. They do, however, still hold onto racial identities as forms of belonging, and for some young people an identity that one should be proud of. Interestingly, these students did not use the idea of non-racialism to explain this future, despite its long South African history and its presence as a founding principle 
in our constitution. As discussed, some of their ideas equate to the various ways that non-racialism is understood in South Africa more broadly today. The desire to eliminate race as a measure of one's worth is inspired, it would seem, by both negative experiences, such as concerns around how racial categories mediate access to tertiary education and sports teams, eradicate individual academic recognition, and enable racial stereotypes; and positive experiences, where friendships across various types of difference are seen as constructive ways to learn about ourselves and others in the world. These young people identify two primary obstacles to reaching this utopian dream: the older generations, and in particular parents who continue to hold racist ideas; and in their view an inefficient and corrupt government that has not ensured equality and service delivery.

More than simply answering the research questions on non-racialism, this data offers insight into how race is socially constructed through the discourses of these young people. This raises questions for thinking about and researching racialism (and all its typologies) in South Africa. Stressing the importance of context when trying to make sense of how race is thought of, and put to use in society, is to state the obvious. A rich theoretical and empirical literature has argued for the necessity of this, as well as for recognition of the intersectionality of social identities. As Murji and Solomos remind us, "given the importance of context and the continuing and changing formations of racialised ideas and inequalities across the world, any viewpoints that fail to take account of significant changes will probably become irrelevant" (Murji \& Solomos, 2015:17). In 1998, Taylor and Orkin asked two important questions that remain relevant today: they were interested in whether there is "in everyday life, a formal consistency to 'racial' and 'ethnic' thinking or is it marked by contradictions and dilemmas?" Secondly, to gain a better understanding of "where is a belief in 'race' ... at its strongest in present day South Africa?" (Taylor \& Orkin, 1998:96-97). We would expect answers to these questions to have some consistency over time and place, but also to find significant shifts as South Africans negotiate their still relatively "new" democratic nation.

The way these young participants make sense of race-thinking is full of "contradictions and dilemmas", which can best be explained through relating them to the specific conditions in which participants feel race counts, and equally important when it doesn't. In this sense, it is helpful to think of all participants as exercising a form of conditional racialism, rather than presuming that they are all committed to racialism as a stable lens through which to view the world. Equally problematic would be presuming that participants' perceived racial identity gives the researcher sufficient information to imagine how they may use such a lens. Clearly from this study, the importance of race waxes and wanes depending on the context of the conversation, and the conditions that demand its emergence as 
primary identity. Taking as an epistemological stance that race-thinking (and its manifestation as racism) is conditional, as opposed to a constant given, requires engagement with the complexity of the reproduction of race in South Africa today. It also enables recognition of the new spaces of production (Soudien, 2012) in which the usual suspects of race, class and gender may be reconstituted, or discarded, in unusual ways. Just as Philomena Essed debunks the myth that "society can be divided into racists and anti-racists, into those with superior minds versus the others with corrupted minds, into 'goodies' and 'baddies'” (Essed, 2001:496), it is equally necessary to debunk the idea that people are either strictly racialists or non-racialists. An individual may be both, depending on context. This focuses on the broader economic structures and ideological constructs that need to shift, rather than simply a focus on individual change, if we are to create the conditions under which non-racialism becomes a more obvious way of seeing and experiencing the world. Non-racialism here is not a well packaged state of being at which one immediately arrives. Rather, it is a deliberate process of working through complex social relations and structures in strategic ways that one hopes moves closer to a utopian ideal.

Working with conditionality and context assists in understanding the inherent tensions and contradictions in how people use, or refuse, race. For example, in this study, race is seen as being formally reproduced through racial categories in state policies. While these policies and the collection of racial statistics are argued to be measures and necessary monitoring devices for transformation and social justice, it is primarily here that these young people feel unduly racialised; a way, as one of the students in this study tells us, of making sure that race "will always be there" (Greenwood High). As discussed, this dislike is closely linked to the personal impact of racial quotas in fulfilling family educational expectations. But these policies are also seen as conflicting with the principles of individualism and meritocracy taught at these schools. While they may not articulate this as an argument against racialisation, their unease in this regard is justified considering that "codification and institutionalisation are the staples of racial legacy" (Amin, 2010:5). Interestingly, the dislike of formal racial categories appears to translate to a more general rejection of any kind of discrimination based on race, particularly interpersonal racism. Further research would be required to explore whether experiences of exclusion in racial quotas may inadvertently have some positive spin-off in how young people take personal responsibility for challenging racist stereotypes.

However, in the messy everyday production of racial identities, there is a more dynamic process of renegotiating race. Mostly this is in navigating places of ideological tensions where these students feel they have some agency. These young 
people vocalise a generational responsibility to challenge the racial stereotypes they themselves have been socialised into, and to ensure that they do not pass this on to their children. The second place of tension is in not wanting race to count in any form of evaluation of the self, but holding onto race as a form of group identity, often premised on a cultural construct. Here we see some open challenges to racism and racial differentiation which would be important to explore further as they do suggest shifts in how primarily privileged young South Africans think about humanity. Yet, the older discourse in which "races" are constructed as having "distinctive cultures" (Soudien, 2012:129) remains fairly well entrenched in these young people. Constructing race in this way serves to normalise racial divisions and reproduce ideas of racial difference. As Ash Amin states in relation to the obduracy of race, frequently "newness comes temporally freighted" (Amin, 2010:5).

As researchers, we picked up other obstacles to the utopian dream prevalent in the second Dreaming Sessions: that of class privilege and individualism. As is evident in these data, the majority of these young people are socialised into a strong sense of self that is closely linked to ideas of meritocracy. We are not alone in this finding. In his book on "unlearning the logic of race" in South African schools, Crain Soudien (2012:191) notes:

The observation to make about their consciousness is the appropriation of a description of themselves framed in the language of the self. It is this individualising impulse which exceeds the descriptive repertoires of race and class that any rethinking of the narrative of privilege in South Africa needs to engage with.

The consequences of this type of individualism are deeply concerning as it supports forms of privilege that may be rearticulating in regard to race, but actively maintain class hegemony and dismiss mechanisms to redistribute wealth in society. Yet, this "individualising impulse" also appears to open up a sense of agency in these young people. In this study, agency is perceived as belonging to the domain of the individual, with little conception of how it relates and intersects with social structures. As a result, actions that are seen as the individual standing up to racism and discrimination are lauded, but individuals are seldom placed within the systemic context of structural discrimination and power, blinding some of these young people to continuous forms of privilege. Policies and programmes aimed at structural change (race-based policies, taxation scales, social grants, etc.) are equally divorced from power and racism, and similarly viewed as individual penalties or benefits. There are a few alternative voices within this young cohort who do make arguments linking structural inequalities to personal gain and oppression, but they are most certainly not the majority. That this individualism is supported by an individualistic meritocratic school ethos has profound consequences for the work we wish education to do in this country. 
Education everywhere "involves the social production of collective goals" (Appiah, 2005:137). Given South Africa's history of racial oppression, there are strong expectations for education "to challenge the old, the continuing and the new inequalities and injustices" (Chisholm, 2004:24). Most certainly in these wellresourced schools the students have a sense that discrimination against others is wrong, as is inequality. But it is less certain how well equipped they are in working through what it means to achieve these goals; what in other words, one has to "give up", in order to achieve a social goal for the collective. This suggests that at high school level these young people are more than ready for open discussions on the social construction of race and culture, so that they may better recognise the process and practices that work towards solidifying and essentialising these constructs. There are exciting possibilities for educationalists of all kinds to work with young people to "think about the plurality that defines collective and individuated subjectivities" in ways which are not reliant on the reproduction of "the Western standard of individuated freedom" (Pillay, 2015:148). One way of starting these conversations is experimenting with notions of dreaming, and then finding ways to talk critically about the full complexities of what it would take for us to realise these dreams, to dream with our eyes open. 


\section{References}

Abrahams, C. 2012. "We can't really say what the future holds for us": Non-racialism in a transitional democracy. Politikon: South African Journal of Political Studies, 39(1). https://doi.org/10.1080/02589346.2012. 656916

Ahmed Kathrada Foundation. 2012. Rethinking Non-Racialism: Reflections of a selection of South African leaders. https://bit.ly/2T9yrDP [Accessed 18 February 2019].

Ahmed Kathrada Foundation. 2013. The ANC: Still a home for all? Non-racialism and the African National Congress: Views from branch members. https://bit.ly/2VZBCzV [Accessed 18 February 2019].

Alexander, N. 2002. An Ordinary Country: Issues in the transition from apartheid to democracy in South Africa. Scottsville, South Africa: University of Natal Press.

Alexander, N. 2007. Affirmative action and the perpetuation of racial identities in post-apartheid South Africa. Transformation: Critical perspectives on Southern Africa, 63:92-108. https://doi.org/10.1353/ trn.2007.0013

Alexander, N. 2013 [1989]. Language Policy and National Unity in South Africa/Azania. Digital edition. https://bit.ly/2TGa3iy [Accessed February 2017].

Amin, A. 2010. The remainders of race. Theory Culture Society, 27(1). https://doi.org/10.11 77/0263276409350361

Anthias, F. \& Lloyd, C. 2002. Introduction: Fighting racisms, defining the territory. In: F. Anthias \& C. Lloyd (eds). Rethinking Anti-Racisms: From theory to practice. New York: Routledge.

Appiah, K.A. 2005. The Ethics of Identity. Princeton, NJ: Princeton University Press.

Bass, O; Erwin, K; Kinners, A. \& Maré, G. 2012. The possibilities of researching nonracialism: Reflections on racialism in South Africa. Politikon: South African Journal of Political Studies, 39(1). https://doi.org/10.10 80/02589346.2012.656911
Beall, J.; Gelb, S. \& Hassim, S. 2005. Fragile stability: State and society in democratic South Africa. Journal of Southern African Studies, 31(4). https://doi.org/10.1080/ 03057070500370415

Bentley, K. \& Habib, A. 2008. Racial redress, national identity and citizenship in postapartheid South Africa. In: A. Habib $\& \mathrm{~K}$. Bentley (eds). Racial Redress and Citizenship in South Africa. Cape Town: HSRC Press.

Bhambra, G. \& Margree, V. 2010. Identity politics and the need for a "tomorrow". Economic \& Political Weekly, 45(15).

Bhana, D. \& Pattman, R. 2010. White South African school girls and their accounts of black girls at school and cross-racial heterosexual relations outside school. Ethnicities, 10(3):371-386. https://doi.org/ 10.1177/1468796810372302

Biko, S. 1987 [1972]. White racism and black consciousness. In: Aelred Stubbs (ed.). I Write what I Like. Johannesburg: Heinemann Publishers.

Blum, L. 2015. Races, racialised groups and racial identity: Perspectives from South Africa and the Unites States. In: X. Mangcu (ed.). The Colour of Our Future: Does race matter in post-apartheid South Africa? Johannesburg: Wits University Press. https://doi.org/10.18772/22015075690.9

Bock, Z. \& Hunt, S. 2015. "It's just taking our souls back": Discourses of apartheid and race. Southern African Linguistics and Applied Language Studies, 33(2). https://doi.org/10.2989/16073614.2015. 1056196

Bonnett, A. 2000. Anti-Racism. New York: Routledge.

Botha, J.; Myburgh, C. \& Poggenpoel, M. 2012. Peer aggression by secondary school learners in a South African school setting: Effects of race, ethnicity, and gender. Journal of Psychology in Africa, 2(3):409-413. https://doi.org/10.1080/14330237.2012. 10820546 
Bowker, G. \& Star, S.L. 2000. Invisible mediators of action: Classification and the ubiquity of standards. Mind, Culture, and Activity, 7(1-2). https://doi.org/10.1080/10749039.2000.9 677652

Chisholm, L. 2004. Introduction. In: L. Chisholm (ed.). Changing Class: Education and social change in post-apartheid South Africa. Cape Town: HSRC Press. https://doi.org/ 10.1016/B978-155860918-1/50001-6

Christiansen, P. \& Prout, A. 2002. Working with ethical symmetry in social research with children. Childhood, 9(4).

Dolby, N. 2001. Constructing Race: Youth identity and popular culture in South Africa. Albany, NY: State University of New York Press.

Erasmus, Z. 2010a. Reformulating racialised citizenship(s) for South Africa's interregnum. Transformation, 74 .

Erasmus, Z. 2010b. Contact theory: Too timid for "race" and racism. Journal of Social Issues, 66(2). https://doi.org/10.1111/ j.1540-4560.2010.01651.x

Erwin, K. 2017. Anti-racism in post-apartheid South Africa. In: C. Abrahams (ed.). Pathways to Antiracism. GCRO Research Report No. 5. https://bit.ly/2T6E067

Essed, P. 2001. Multi-identifications and transformations: Reaching beyond racial and ethnic reductionisms. Social Identities, 7(44). https://doi.org/10.1080/13504630 120107665

Everatt, D. 2009. The Origins of Non-Racialism: White opposition to apartheid in the 1950s. Johannesburg: Wits University Press. https://doi.org/10.18772/12009065003

Everatt, D. 2012. Non-racialism in South Africa: Status and prospects. Politikon: South African Journal of Political Studies, 39(1). https://doi.org/10.1080/02589346. 2012.656910

Frederikse, J. 1990. The Unbreakable Thread: Non-racialism in South Africa. Johannesburg: Ravan Press.
Friedman, S. 2015. The Janus face of the past: Preserving and resisting South African path dependence. In: X. Mangcu (ed.). The Colour of Our Future: Does race matter in post-apartheid South Africa? Johannesburg: Wits University Press. https://doi.org/10.18 772/22015075690.10

Gevisser, M. 2007. Thabo Mbeki: The dream deferred. Johannesburg: Jonathan Ball.

Gillespie, K. 2010. Reclaiming nonracialism: Reading the threat of race from South Africa. Patterns of Prejudice, 44(1):61-75. https://doi.org/10.1080/00313220 903507636

Goldberg, D.T. 2009a. A political theology of race: Articulating racial Southafricanisation. Cultural Studies, 23(4). https://doi.org/10.10 80/09502380902950955

Goldberg, D.T. 2009b. The Threat of Race: Reflections of racial neoliberalism. Malden, MA: Blackwell Publishers.

Greene, S. \& Hogan, D. 2005. Researching children's experience: Exploring children's views through focus groups. London: Sage. https://doi.org/10.4135/9781849209823

Gumede, V. 2015. Inequality in democratic South Africa. In: X. Mangcu (ed.). The Colour of Our Future: Does race matter in post-apartheid South Africa? Johannesburg: Wits University Press. https://doi.org/10.18 772/22015075690.12

Heath, S.; Brooks, R.; Cleaver, E. \& Ireland, E. 2009. Researching Young People's Lives. London: Sage. https://doi.org/10.4135/ 9781446249420

Horsfall, D. \& Titchen, A. 2009. Disrupting edges - opening spaces: Pursuing democracy and human flourishing through creative methodologies. International Journal of Social Research Methodology, 12(2):147-160. https://doi.org/10.1080/ 13645570902752324

Hunter, M. 2015. The race for education: Class, white tone, and desegregated schooling in South Africa. Journal of Historical Sociology, 29(3). https://doi.org/10.1111/johs.12097 
Independent Online. 2005. "Racial row over UCT quotas.” 21 February. https://bit.ly/ 2HzyuH5 [Accessed 18 February 2019].

Independent Online (Sunday Tribune). 2016. "UKZN med school student charged with fraud." 7 July. https://bit.ly/2W30jvu [Accessed 18 February 2019].

Independent Online (Daily News). 2016. "UKZN med school quotas biased: ANC.” 21 July. https://bit.ly/2O6IOHH [Accessed 18 February 2019].

Jansen, J. 2012. "Politicians must stay out of it." The Times, 12 July.

Joshua, P. 2014. Post-racial futures: Imagining post-racialist anti-racism(s). Ethnic and Racial Studies, 37:702-718. https://doi.org/ 10.1080/01419870.2014.857031

Kathrada, A. 2012. A Selection of Ahmed Kathrada's Speeches, Writings and Interviews. https://bit.ly/2XZEkHB [Accessed 18 February 2019].

Kraftl, P. 2007. Utopia, performativity, and the unhomely. Environment and Planning D: Society and space, 25(1). https://doi.org/ $10.1068 / \mathrm{d} 397 \mathrm{t}$

Kraftl, P. 2008. Young people, hope, and childhood-hope. Space and Culture, 11(2). https://doi.org/10.1177/1206331208 315930

Levitas, R. 2003. Introduction: The elusive idea of utopia. History of the Human Sciences, 16(1). https://doi.rg/10.1177/09526951 03016001002

Malila, V. \& Garman, A. 2016. Listening to the "Born Frees": Politics and disillusionment in South Africa. African Journalism Studies, 37(1).

Mangcu, X. 2015. What moving beyond race can actually mean: Towards a joint culture. In: X. Mangcu (ed.). The Colour of Our Future: Does race matter in post-apartheid South Africa? Johannesburg: Wits University Press. https://doi.org/10.187 72/22015075690.7

Maré, G. 2001. Race counts in contemporary South Africa: An illusion of ordinariness. Transformation, 47.
McKay, T. 2015. Schooling, the underclass and intergenerational mobility: A dual education system dilemma. The Journal for Transdisciplinary Research in Southern Africa, 11(1). https://doi.org/10.4102/ td.v11i1.34

Murji, K. \& Solomos, J. 2015. Introduction: Situating the present. In: K. Murji \& J. Solomos (eds). Theories of Race and Ethnicity. Cambridge, UK: Cambridge University Press. https://doi.org/10.1017/ CBO9781139015431.002

Ndebele, N. 2002. The African National Congress and the policy of non-racialism: A study of the membership issue. Politikon: South African Journal of Political Studies, 29(2). https://doi.org/10.1080/0258934 022000027763

Nelson, J. 2015. “Speaking” racism and antiracism: Perspectives of local anti-racism actors. Ethnic and Racial Studies, 38(2). https://doi.org/10.1080/01419870.2014. 889837

Paul, J. 2014. Post-racial futures: Imagining postracialist antiracism(s). Ethnic and Racial Studies, 37(4). https://doi.org/10.1080/01 419870.2014.857031

Phillips, A. 2007. Multiculturalism without Culture. Princeton, NJ: Princeton University Press.

Pillay, J. 2014. Has democracy led to the demise of racism in South Africa? A search for the answer in Gauteng schools. Africa Education Review, 11(2).

Pillay, S. 2015. Why I am no longer a non-racialist: Identity and difference. In: X. Mangcu (ed.). The Colour of Our Future: Does race matter in post-apartheid South Africa? Johannesburg: Wits University Press. https://doi.org/10.18 772/22015075690.14

Posel, D. 2001. Race as common sense: Racial classification in twentieth-century South Africa. African Studies Review, 44(2). https://doi.org/10.2307/525576

Posel, D. 2015. Whither "non-racialism": The "new" South Africa turns twenty-one. Ethnic and Racial Studies, 38(13):2167-2174. https://doi.org/10.1080/01419870.2015.1 058511 [Accessed 18 February 2019]. 
Ramphele, Mamphela. 2013. Rekindling the South African dream. https://bit.ly/2O4 D2GA [Accessed 18 February 2019].

Silva, G.M.D. 2012. Folk conceptualisations of racism and antiracism in Brazil and South Africa. Ethnic and Racial Studies, 35(3). https://doi.org/10.1080/01419870.2011. 589523

Soudien, C. 2004. Constituting the class: An analysis of the process of "integration" in South African schools. In: L. Chisholm (ed.). Education and Social Change in South Africa. Pretoria: HSRC Press.

Soudien, C. 2012. Realising the Dream: Unlearning the logic of race in the South African school. Cape Town: HSRC Press.

South African Human Rights Commission. 1999. Racism, 'Racial Integration' and Desegregation in South African Public Secondary Schools. https://bit.ly/2F1R6g0 [Accessed February 2017].

Sunday Tribune. 2017. "And she's off to med school." 8 January:7.
Taylor, R. \& Orkin, M. 1998. The racialisation of social scientific research on South Africa. Revija za sociologiju, 29(1-2).

Turner, R. 2015. The Eye of the Needle: Towards participatory democracy in South Africa. T. Morphet (ed.). Africa List series. Kolkata, India: Seagull Books.

Williams, Phumla. 2016. On track to realising the South African dream. https://bit.ly/ 1QbU39n [Accessed 18 February 2019].

Zegeye, A. \& Maxted, J. 2002. Our Dream Deferred: The poor in South Africa. Pretoria: SAHO and Unisa Press.

Zille, Helen. 2008. Delivering the South African dream: One nation one future. https://bit.ly/2UE1Vvc [Accessed 18 February 2019].

Zinn, A. (ed.). 2016. Non-Racialism in South Africa: The life and times of Neville Alexander. Stellenbosch: AFRICAN SUN MeDIA. https://doi.org/10.18820/9781928314066 

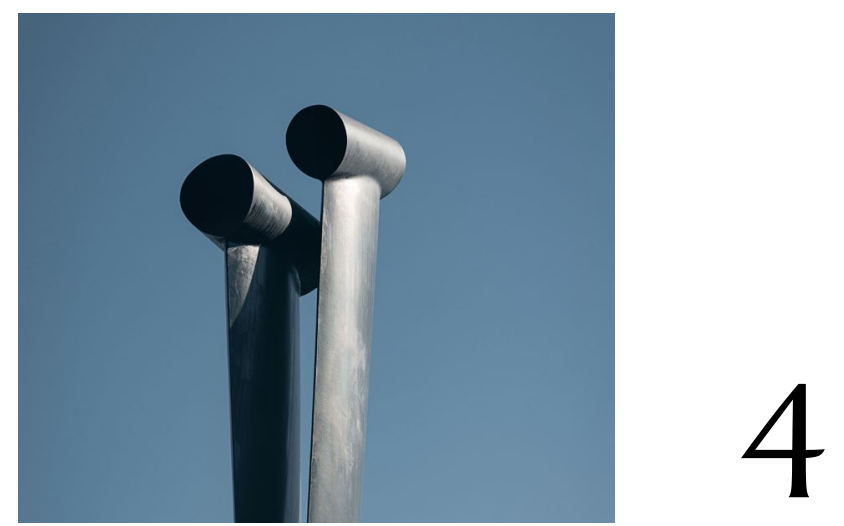

\title{
RACIAL CLASSIFICATION AND THE SPECTRE THAT HAUNTS
}

\author{
Handri Walters
}

Ruins are not just found, they are made.

Benjamin Dawids was 42 years of age, born of mixed descent to "European" and "Hottentot" parents in Stellenbosch (according to his data sheet). The Von Luschan table indicated that Benjamin's skin colour measured between numbers 9 and 18 for the various parts of his body. Fischer's table indicated that his hair colour corresponded to number 4, while his eye colour corresponded to number 2 on Martin's table. ${ }^{1}$ Further measurements detailed the shape of Benjamin's head and the characteristics of his face and nose. The prognathy of the jaw measured 2 on a scale of $0-5$. His nose had a narrow root, medium and straight bridge, a downwardly directed tip, a short and narrow septum, and an obliquely oval, wide and large opening. His face was round and moderately flat. Further observations noted his spindle-shaped eyes, thin lips and large, yellowish teeth; his large, broad and flat feet,

1 Felix von Luschan's skin colour table was designed in 1905, Eugen Fischer's hair colour table in 1907, and Rudolf Martin's eye colour table in 1903. 
and his thick long fingers with bluish nails. Benjamin had tattoos on his left upper and lower arm, and a scar adorned his right thigh. On 22 October 1937, Benjamin Dawids was the first of 133 coloured males to be meticulously measured by staff members and students of the Zoology Department of Stellenbosch University. ${ }^{2}$

It was a summer's afternoon in February of 2013, when I was confronted with the instruments used to measure Benjamin Dawids (and many others) in a corner office of the Stellenbosch University Museum. A silver casing bearing the name of Eugen Fischer, opened to reveal 30 strings of synthetic hair ranging from dark to light, from straight to curly, was placed on the table in front of me. This was followed by a bruised and battered metal box reading Augenfarbe along with the name of Rudolf Martin on its sliding metal lid. Upon my opening the metal box, 16 eyes stared back. And, finally, a human skull wrapped in tissue paper was placed on the table. The recognition of the historical use of these objects was instantaneous. The taken-for-granted nature of such recognition and of supposed "race knowledge" in general was suddenly revealed in all its problematic proportions. Confronting these objects evoked what Freud would refer to as "the uncanny" (unheimlich). While the uncanny can be related to that which arouses "dread and creeping horror" (Freud, 1919) or evoke a sense of uncertainty, Freud (1955 [1919]:229-230) conceptualises the uncanny as "something familiar and old", something "established in the mind that has been estranged only by the process of repression". Simply said, the uncanny signifies the return of the repressed. For Freud, an uncanny feeling is experienced "in the highest degree in relation to ... the return of the dead, and to spirits and ghosts" (Freud, 1955 [1919]:230). The uncanny in this sense is evoked by a ghostly presence.

The measurements and methods employed to measure Benjamin Dawids in 1937 were broadly used in worldwide physical anthropology during the early twentieth century to determine racial characteristics and racial affinity. ${ }^{3}$ For many scientists

2 While anonymisation has historically been used to safeguard the identity of vulnerable persons, it simultaneously has the effect of dehumanising and alienating these individuals. Thus, throughout this chapter, the full names of those measured by the Zoology Department in 1937 is used as it appears on the data collection sheets - documents that are open to the public. The use of the full names is here employed to humanise those who were subjected to, and objectified by, a scientific gaze. Similar arguments for the use of full names have been made by Rory du Plessis (2015) and Julie Parle (2007) in relation to their work dealing with pathological subjects.

3 The subject matter of this chapter requires an extensive footnote on the use of race. In the social sciences, the broad consensus, for the better part of a century now, has been to regard race as a social construction - a turning point that occurred when UNESCO proclaimed race to be a myth in 1952. Since then, writings on race within the social sciences have had to provide a (by now) familiar disclaimer to distance the use of racial terms from ideas that these relate to biological difference. In addition to such disclaimers, many a text has made 
at the time, separate human races were natural biological entities of which the characteristics "were essential and given" (Winant, 2000:174). In this regard, visible characteristics, generally referring to the complexion of the skin, the colour of the eyes, the colour and texture of the hair, and general features of the face, became the primary sources for racial classification (Wilder \& Wentworth, 1918:61). Standardised practices for anthropometric measurements developed and internationally prescribed between 1910 and 1914 aided this process of classification (Grobbelaar, 1948:53; Van Wyk, 1939:61). The development of the skin colour, the eye colour, and the hair colour and texture tables, respectively, in the early twentieth century, similarly aided these forms of classifications based on visible physical characteristics. ${ }^{4}$ The methods for classification stemmed from Linnaean typology and rested on a notion of natural racial groupings based on the Aristotelian logic of a fundamentum (a particular character) shared by every member of the group (Daly, 1961:176). Racial groupings were thus divided by the appearance of common characters found in this group. While not all members of the group possessed exactly the same characteristics, the notion of aggregates, or the "estimate of the degree of overall similarity" (Daly, 1961:176), were employed to categorise individuals into the main racial groupings. This logic would have far reaching consequences for racial classification and the implementation of race-based policies around the world (Ford \& Airhihenbuwa, 2010:S30).

use of quotation marks when writing the very word "race" to indicate the constructed and contentious nature of the concept. Similar rules have applied for the expression of racial categories - using quotation marks to highlight the problematic nature of naming groups along lines of racial difference. Following the arguments made by David Theo Goldberg (2016), Gerhard Maré (2014) and W.J.T. Mitchell (2012), I will not make use of "scare quotes" when referring to race. I accept that race is indeed a social construction, and I ask my reader to remember this as they engage my work. The use of designated racial categories in the South African context offers another dilemma. The risk of writing about racial categories is the perpetuation of the power located in the continued use of words that differentiate along lines of race. The word alone gives power to its meaning. As argued by Derrida in 1978, we are left with "the restrained and restraining language of Western reason ... Nothing within this language, and no one among those who speak it, can escape" (cited in Comaroff and Comaroff, 1992:15). In South Africa, we remain constrained by a continued use of apartheid-era racial categories. In this chapter, I attempt to offer a response. Similar to the way in which we have de-capitalised apartheid in order to disempower as well as delegitimise not only the word but the ideology behind it, all racial designations will be de-capitalised in this text. In defiance of the rules of grammar, I attempt to strip these words of their power while simultaneously acknowledging their continued existence, use, and very real effects in society.

4 Marketed specifically for scientists and researchers (Powerhouse Museum Collection, 2015), the tables were manufactured by Artur Gneupel in Zurich, Switzerland (Grobbelaar, 1956:107) and sold by P. Hermann at 71 Scheuchzerstrasse, Zurich, for a "moderate price" (Eye table, \$15.00; Hair table, \$6.50; Skin table, \$2.50) (Wilder \& Wentworth, 1918:68). 
In the South African context, the study launched by the Zoology Department of Stellenbosch University came in the midst of an increased interest in the coloured population during a political climate of rising Afrikaner nationalism, racial division, and a road paved for the establishment of the apartheid government. This study attempted to offer a scientific engagement to determine the racial make-up of the local coloureds. The extent to which "scientific" engagements informed the constitution of racial categories as implemented by the apartheid state have been addressed and for the most part dismissed by Saul Dubow (1995, 2010, 2014) and Deborah Posel (2001) - two authors regarded as authorities on the issue. Taking heed of its unavoidable presence in the "obsession with purity of blood" Dubow (2010) argues for the selective use of racial science in the development and implementation of the apartheid state. By no means a definitive presence, racial science is viewed by Dubow as a "scavenger piece" - a tool to be implemented by the apartheid state if, and when, needed. Posel (2001) on the other hand argues for a "strategic ambiguity" maintained by the apartheid state in the conceptualisation and implementation of racial categories. In this regard, Posel (2001:101) argues for an unuttered acknowledgement on the side of the state that "scientific precision in the definition of race" would be "detrimental to the project". Yet, in the decades preceding the implementation of apartheid, there was a concerted effort to determine and cement the coloured category through scientific contributions, stemming from the fields of physical anthropology, the medical sciences, and psychology.

Posel and Dubow both argue for a fluidity and ambiguity in the conceptualisation and application of racial categories in apartheid South Africa - something that can hardly be contested. However, whether this was a strategic manoeuvre on the part of the state becomes a curious point of contestation when the spotlight is placed on the engagements with the coloured population under the apartheid government. Here the government was confronted with a population closely aligned to the white European, so close that many were able to "pass" for white. The inherent threat such "passing" posed to racial purity and the political and economic power of "white Europeans" required careful regulation. It also required a persistent engagement with the coloured population to formulate and define this category as different, and separate, from whites. The increased interest in racial difference thus spoke to an ever-increasing need to regulate and control populations deemed threatening for the continued existence and ensured power of a white minority. In this regard, the coloureds posed a particular problem to clear-cut categorisations and, more importantly, as separate and different from whites.

Coloureds were first recognised as a separate group in Cape Town towards the end of the nineteenth century, but it was particularly in the 1930s that the concerns with racial distance (and miscegenation) with regard to coloureds manifested in 
academic debate and government action. Deemed a source of danger (posing a threat to the preservation of whites), the possibility of coloureds passing for white was also seemingly a source of great paranoia. In 1936, George Findlay proclaimed that a large number of individuals that should be classified as coloured had somehow passed as "white". In this sense, Findlay's 1936 publication, Miscegenation: A study of the biological sources of inheritance of the South African population, caused quite a stir. ${ }^{5}$ This was followed by the published results of the Commission of Inquiry Regarding Cape Coloured Population of the Union (more commonly known as the Wilcocks Commission). The Commission offered a comprehensive report of the coloureds in 1937 - a report that also became one of the catalysts for a deeper social scientific engagement with this population at government level (Jensen, 2008:21). ${ }^{6}$ The decades following this moment marked a heightened interest in the coloureds especially in the Cape Province where this population was predominantly located. Later rather vaguely defined as "not a white person or a native" by the Population Registration Act, No. 30 of 1950, the racial designation of coloured remains unique to South Africa.

\section{The formation of subjects: a coloured category}

Michel Foucault argues that "the subject does not exist as a determinate form with specific qualities before the practices that made up the 'rapport à soi' bring it into being" (quoted in Olssen, 2010:65). Foucault spoke to the social construction of categories - or rather, he spoke of categories as something to be constructed. The construction of categories become of particular importance when related to the state or modern power. In this regard, Colin Jones and Roy Porter (1994:99) described the "peculiarity of modern power" as operating by "producing the subject" that becomes "the target of other strategies". It relates to Albert Memmi's (1965:71) notion of colonial power: to first establish something as "an 'absolute fact' [after which] colonisers are free to exploit it for their own benefit". For instance,

5 At the time, Findlay's publication was deemed important enough to motivate an Afrikaans translation, Bloedvermenging. Swart en wit in Suid-Afrika: die faktore wat bloedvermenging vertraag of versnel (translating to: "Miscegenation. Black and White in South Africa: the factors that delay or accelerate miscegenation" - the title not being a direct translation of the original, but reformulated to appeal to an Afrikaans audience).

6 Over the course of the next decade, this was followed by the Commission of Inquiry into Mixed Marriages in South Africa, UG nr. 30, 1939; Committee of Inquiry nominated to investigate conditions on the Cape Flats and in areas in the Cape Division where similar conditions prevail, 1942; the Cape Coloured Liquor Commission in 1945; the Interdepartmental Committee on Coloured Relations, Coloured Mission Stations, Reserves and Settlements, UG nr. 33, 1947; and the Commission of Inquiry into Deviate Children (Non-European) in 1950. 
Christopher Bracken (1997) illustrated how colonial correspondence constructed the North American potlatch. He argues that "the legal text gave administrators a potlatch to regulate" (Bracken, 1997:228).

For Foucault (quoted in Faubion, 2001:326), classification is deemed a technology of domination through "dividing practices", where - the individual is divided from others and objectified by the state. In his analysis of the modern state, James Scott (1998:77) emphasises the importance of reducing "a large and complex reality" to a "legible landscape" - in other words "an infinite array of detail" needs to be reduced "to a set of categories that will facilitate summary descriptions, comparisons and aggregation" (Scott, 1998:77). The creation of categories and the act of classification becomes of key importance for a state-wide "legible landscape" - mad, sick, healthy; developed, underdeveloped; civilised, uncivilised; white, black, coloured, indian. Through prolonged implementation, categories that were once "artificial inventions" can become "categories that organise people's daily experience" (Scott, 1998:82-83). For Ann Stoler (2008:202), such "imperial projects" are defined as "state projects that require resources and planning [and dictate] how people are supposed to live", and have the propensity to "bring ruin upon [and] exert material and social force in the present" (Stoler, 2013:11). Imperial projects embody the longitudinal - a patient project stretching over decades, centuries even. It is persistent in its implementation, it is allowed to gain momentum, it is allowed to continue until it is no longer questioned, until the project itself and the results it renders become taken for granted or gain the force of simple habits of mind. These longitudinal imperial projects are bound to produce ruins - the severity of their effects located in their most unassuming forms.

Over the course of 1937, 133 coloured males of the Stellenbosch area were subjected to detailed observations and measurements (each providing a sum of 80 measurements of the corporeal body). In this regard, the standardised measurements, as globally prescribed by Rudolf Martin's Lehrbuch der Antropologie (1914), were applied. The data sheets contained the name, sex, age, place of birth, place of residence, and maternal and paternal descent of the subject. Skin, eye, and hair colour (as found on various parts of the body) were determined by using the tables respectively designed by Fischer, Martin and Von Luschan. Further observations were made regarding the "types" of the head, face, nose, jaw, lips, teeth and ears. A section titled "special observations", very reminiscent of Alphonse Bertillon's (1895) identification of criminals by individual characteristics such as scars and tattoos (in addition to visible innate physical characteristics and measurements of the head and body), was left open for the researcher to complete at their own discretion. This particular section contained all kinds of information from tattoos to bodily scars, comments on cleanliness, and personal observations 
related to the individuals' perceived intelligence. It is particularly within the section designated for special observations that the assumptions, racial stereotypes, and slanted interpretations of those entrusted with the data collection process (C.S. Grobbelaar and his students) became evident. Klaas Fram was labelled as "very stupid" (baie onnosel); Gert Rippenaar was described as "not too clean!"; Berend Solomon had "many cut wounds due to stabbings" (baie snyplekke as gevolg van messteke); Arnold Maart was described as a "very typical coloured - farmboy and pretty stupid" (baie tipiese kleurling - plaasjong en taamlik onnosel); Willie Abrahams, of white and hottentot descent, had a "very intelligent face ... a long thin face" (baie intelligente gesig ... lang dun gesig); Abram Abrahamse, on the other hand, had a "very uncivilised face" (baie onbeskaafde gesig); while Gert Bekker, of European and "a bit of hottentot" descent was simply "a bad example of a human being" ('n swak voorbeeld van 'n mens) (Department of Zoology, 1937).

The engagement came from the standpoint of physical anthropology - at that time a field of study housed by the Zoology Department under the guidance of Professor C.G.S. (Con) de Villiers and Dr C.S. (Coert) Grobbelaar. ${ }^{7}$ Both had received their doctoral training in Europe in the early 1920s - De Villiers in Zurich and Grobbelaar in Berlin. At the Zoology Department of Stellenbosch University, they introduced a course on practical anthropometry in 1924 and prescribed Rudolf Martin's Lehrbuch der Anthropologie (Handbook for Anthropology), Wilder's Laboratory Manual of Anthropometry, and the English translation of Boule's Les Hommes Fossiles (Fossil Man) for the course. In addition to the prescribed literature, the instruments developed by Martin were used (Stellenbosch University [Calendar], 1924:195). The course at Stellenbosch University was seemingly informed by the discipline's international roots. It was particularly Grobbelaar who pursued studies of the physical-anthropological kind. Deeply influenced by his German training, Grobbelaar envisioned a great role for physical anthropology, more specifically the "practical applications" of anthropometric studies in South Africa (Grobbelaar, 1948:53). Citing Eugen Fischer, Grobbelaar (1948:53-54) stated the body's physical constitution was heritable and that specific characteristics within the body were often linked to a particular race. In this regard, racial differences in the physical constitution of the "European population, of the Coloured Races and of the Bantu" (Grobbelaar, 1948:53) was envisioned as an avenue for possible groundbreaking contributions by the field of physical

7 The roots of physical anthropology are to be found in a variety of disciplines, but once it gained autonomy and was offered as a field of study at universities it mostly fell within the realm of the medical sciences (Morris, 2012). At Stellenbosch University, where no medical faculty had yet been established, the Zoology Department offered courses in comparative anatomy and introduced physical anthropology as a subject. 
anthropology to South African policy development. ${ }^{8}$ The studies produced by the Zoology Department as related to physical anthropology between 1925 and 1960 addressed racial categories in terms of racial constitution and racial difference.

In South African physical anthropology, the study of racial types and "the origins of the Southern African peoples", was very common during the first half of the twentieth century (Morris \& Tobias, 1997:969). Notable academics who committed their energies to this field of study included Matthew Drennan of the University of Cape Town, Raymond Dart of the University of Witwatersrand, T.F. Dreyer of the University of the Orange Free State, and Robert Broom, who had taught in the Zoology Department of Stellenbosch University, then Victoria College, between 1903 and 1910 (Morris \& Tobias, 1997:969). It was particularly the relation of the modern races to ancient types that became the focus of these academics - most notably illustrated by the engagements with, and debates about, the so-called "Boskop skull" found in 1913 (Morris, 2008). This included the identification and categorisation of racial types as found in Southern Africa more particularly the non-European populations of South Africa - and inherently engaged arguments for the biological distinctiveness of certain categories. Following Crain Soudien (2006:56) in his analysis of the making of bantu identity in South Africa, it could similarly be argued, the engagements with the coloured population involved the empirical recognition of a human category which then became "systematically classifiable and, like any zoological species, available as an object of knowledge for inspection and analysis" (Soudien, 2006:56).

The data collected during 1937 were eventually published in 1939 as "A preliminary account of the physical anthropology of the 'Cape Coloured People' (Males)" with a focus on "the purely physical characteristics of the Coloured population" (Van Wyk, 1939:61). Here the bodily summation, framed as "typical" characteristics to be found in the research subjects (and thereby extended to an entire coloured category), included "a lighter complexion" (relative to the hottentot or bantu), brown eye-colour, woolly dark hair, and a flat nose with a broad nasal root, amongst other characteristics. For Van Wyk (1939:5), "European blood seemed to be obviously present in the Coloured People". The undeniable presence of European blood was apparently revealed through the relative height of the subjects (inheriting the taller stature of the European) and the shape and size of the nose (which revealed traces of the narrower and higher nose of Europeans) (Van Wyk, 1939:50, 55).

While the relative closeness of the coloured subject to the white European was identified, the study mostly provided the scientific underpinnings for a population

8 For Grobbelaar (1948:60), these policies would ensure "the preservation and development of the most valuable genetic types of the population". 
that was to be considered as separate and different from whites and supported the conclusion with the work of German anthropologists and eugenicist Eugen Fischer (1913). Fischer's The Rehoboth Bastards and the Problem of Miscegenation among Humans particularly focused on hybrid populations resulting from racial mixture and intermarriage between the hottentot and European colonists. For Fischer (1931:114), "the tint of the skin, the growth of the hair, the shape of the nose, the lips, and the skull" were seen to illustrate the "plainly inheritable differences" aiding the division of groups into races (Fischer, 1931:165). He concluded that "all European nations which have undergone the infiltration of inferior blood have had to pay for this sin by an appreciable decline in their intellectual and cultural standards" (as quoted in Hertz, 1928:131). Fischer's work, as highlighting "negative outcomes of racial intermixture" (Venter, 2009:124), was often cited during the 1930s and 1940s (and even beyond) by South African academics in relation to the coloured question. The coloured may have been the result of racial mixture, but through scientific engagements the category was transformed into a unique hybrid racial category with measurable racial characteristics (read "separate racial category").

The coloured population remained a source of interest to the Zoology Department of Stellenbosch University. In 1959, J.S. van der Spuy, a student in the department, compared the physique and growth of white and coloured boys between the ages of 13 and 17.9 A total of 474 white European boys and 500 coloured boys were measured (Van der Spuy, 1959:69). Van der Spuy (1959:67) found the white European boys to be taller than the coloured boys with significant statistical differences to be found between the two groups. The white boys were also found to be larger in their physique and greater in their weight (Van der Spuy, 1959:135, 136). While Van der Spuy (1959:138) stated that the coloureds were often viewed as a more heterogeneous group (due to miscegenation), through measurements and observations of physical characteristics he found this group to be very homogeneous indeed.

Van der Spuy's study on the physique and growth of white and coloured boys was published at the end of the 1950s and much had transpired during this decade. By this time, the scientific information comprising more insights into the coloured had emerged. In 1952, Dr J.A. Keen of the University of Cape Town published a "Craniometric Study of the Cape Coloured Population". Keen (1952:40) found "the mean for the male Cape Coloured skull [to be] well below the European group, but above that of the male bantu". The results were based on the measurement

9 See "'n Studie van die liggaamsbou en liggaamsgroei van blanke en kleurlingseuns in die Westelike Provinsie, ouderdomsgroep 13 tot 17 jaar" (A study of the physique and growth of white and coloured boys in the Western Province, age group 13 to 17 years). 
of 141 adult male skulls obtained from "dissecting-room cadavers" in the Department of Anatomy. Regarding the coloureds as "a distinct ethnic group" (Keen, 1952:29), and one that was "as homogeneous as two of the parent racial groups" (1952:50), Keen (1952:42) proclaimed the cranium to be "neither typically Bantu, nor typically Hottentot; [and] certainly not European". The study, produced shortly after the Population Registration Act of 1950 was introduced by the apartheid government, provided scientific reinforcement for the existence of the coloured as a separate racial category. The measured difference in skull size offered by Keen (1952) spoke to an existing debate regarding the intelligence of coloureds as related to whites and natives. In this regard, M.L. Fick (1929) argued for a racial hierarchy based on mental capabilities with the "coloured" occupying a middle position (achievements higher than natives but lower than "whites"). Stellenbosch student Frederich Albertus Sadie similarly drew correlations between the presence of "European blood" and learning capability in The Relation between the learning ability and the degree of European blood in SA Non-Europeans (1942) - with a greater degree of European blood resulting in a greater learning ability. A.P. Blignaut (c.1940), another Stellenbosch student, also found the learning ability of whites to be superior to coloureds who were in turn superior to natives. ${ }^{10}$

Continued attempts to provide scientific justifications for the acceptance of coloured as separate and different from whites and natives transpired in many disciplines in the 1940s and 1950s. By the early 1950s, there was seemingly hardly a need to elaborate anymore when the Stellenbosch-based South African Bureau for Racial Affairs (SABRA) argued the differences between whites, coloureds and natives were "obvious" as related to culture, language, psychology, and biological race (SABRA, 1953:30-31). These decades also provided great political change in South Africa. The National Party came to power in 1948 - officially bringing forth the apartheid state. This was followed by the introduction of the Prohibition of Mixed Marriages Act (1949), the Population Registration Act (1950), the Immorality Amendment Act (1950), the Separate Representation of Voters Act (1951), the Group Areas Act (1952), and the Reservation of Separate Amenities Act (1953). Each of these laws would cement, at least in practice, a racial divide between white and coloured. Yet, even in the aftermath of implementing these laws, there remained a continued interest in confirming the hybrid category of coloured as racially separate from white - thereby assisting in the implementation of stricter state controls over, and regulation of, these categories. In the early 1950s, even after

10 See unpublished MA thesis submitted to the Psychology Department of Stellenbosch University: "The Learning Capability of the Graaff-Reinet Coloured compared with that of the Europeans and Natives" (Die Leerbekwaamheid van die Graaff-Reinetse Kleurling in vergelyking met dié van die Blanke en Naturel). 
the implementation of apartheid laws, the state was dealing with a category that was not only broadly accepted as a demarcated, essentialised and homogenised category written into law, but also one which seemingly evaded clear-cut definitions or markers for categorisation. This was partly evidenced by continued attempts during the 1950s to define the coloured category more concisely. In this regard, an interdepartmental committee was appointed to produce "a basic definition which would be a 'master-definition' applicable to all laws requiring racial definition" (Dönges, 1959). The minister of the Interior, Dr Eben Dönges, unfortunately had to report back to parliament after 30 months that the committee "could not find a basic legal definition" (Dönges, 1959). The category of coloured was accepted, yet undefined (and seemingly undefinable).

In the absence of a clear-cut definition, the state pushed forward. At Stellenbosch University, the coloured question took precedence in the 1950s. The Stellenboschbased SABRA dedicated considerable energy towards further investigations of this category of people. In this regard, two annual conferences were dedicated to the cause: "What is the future of the coloured?" (Wat is die toekoms van die kleurling?) in 1954, and "The coloured in South African society" (Die kleurling in die Suid-Afrikaanse samelewing) in 1955. This was followed by the independent establishment of an interdisciplinary research committee at Stellenbosch University in 1955 to provide an encompassing study of the Western Cape area with a focus on the Cape coloured and the native population in this area. ${ }^{11}$ The Western Cape Research Project (Wes-Kaaplandse Navorsingsprojek or WKNP) enjoyed government attention from its inception and was funded by the National Council for Social Research for a period of three years, 1956-1958. Attended by a number of important stakeholders, the first meeting revealed broad government interest in the project and its results. The Division for Coloured Affairs (later the fully-fledged Department of Coloured Affairs), the Department of Native Affairs, and the Department of Home Affairs all sent representatives to attend (Eikestadnuus, 1955:1).

Although the "ethnic demarcation" of coloured was seemingly to be determined by the committee, an existing conceptualisation of this population drove the study. Johannes Petrus van Schalkwyk (Hannes) Bruwer, head of the Department of

11 The following lecturers represented their departments on the committee:

Prof. C.G.W. Schumann (Business Economics), and director of the project; Prof. J.L. Sadie

(Economics and Demography); Prof. P. Serton, Prof. A. Nel, and Dr D.J. Conradie

(Geography); Prof. P.E. de Waal (Agriculture); Prof. N.J.J. Olivier (Native Administration);

Prof. P.S. du Toit (Education); Prof. E. Theron and Prof. S.P. Cilliers (Sociology and Social

Work); and Prof. J.P. Bruwer (Volkekunde) (Cilliers, 1964:4). 
Volkekunde ${ }^{12}$ and tasked with the responsibility of developing a research scheme for the project (Bruwer, 1956), reported back to the committee on 3 June 1956:

[...] a somatic survey of the Coloureds does not justify the estimated expenditure of $£ 500$. Therefore, the Department of Volkekunde will not launch a comprehensive investigation in this regard, but could rather get valuable information from studies conducted by the Department of Zoology. (Bruwer, 1956) [my translation]

In this regard, the 133 coloured males measured over the course of 1937 came to be regarded as the accepted embodiment of a coloured category. Seemingly deeply influenced by notions of race as found in pre-World War II physical anthropology, Bruwer regarded race as a biological entity and defined it as:

$[\ldots]$ a group or division of mankind having certain recognisable and inherited physical characteristics in common by which those individuals belonging to it can be distinguished from those belonging to other races, whose members will have their own peculiar and common physical characteristics.

(Bruwer, 1958:10-11)

Coupled with his skepticism of the UNESCO statements on race (see 1950 and 1952), Bruwer provided further evidence of his possibly "archaic" views on the subject matter when he referenced Fischer's hair texture and colour table, Martin's eye colour table, and Von Luschan's skin colour table as part of the methodology to "classify the main race groups of the world" (Bruwer, 1958:12). Here, the typical language of early twentieth-century racial science was drawn upon for distinguishing racial characteristics: wavy, straight or woolly hair was related to the various racial groups; the occurrence of blonde versus black hair, and dark versus light skin as related to the various races was highlighted; the occurrence of blue eyes as "practically confined to the Caucasian group" was mentioned; a reference was made to the narrow nostrils and high bridge of the nose for caucasians as opposed to the broad and flat nose with a low bridge found in the "Negroids" (sic); and the mention of the significance of the angle of the lower jaw (prognathy) and the cephalic index as found in the different races were all part of this discussion (see Bruwer, 1958:14-19).

12 "Volkekunde" is generally regarded as an Afrikaner brand of social anthropology (Sharp, 1981), taught at Afrikaans-medium universities. First established at Stellenbosch University in 1926, Volkekunde was eventually extended to all other Afrikaans-medium universities in South Africa. Historically, it has been clearly distinguished from the kind of social anthropology taught at English-medium universities. Much like the institutions it was part of, Volkekunde has often been linked with a conservative nationalist agenda, while social anthropology has been regarded as providing a more liberal approach. This is, however, a broad generalisation and simplification of academic engagements within these respective "camps". 
It comes as little surprise then that the man responsible for developing a research methodology for the Western Cape Research Project considered coloureds to be separate from whites and natives in a "race-biological sense" (Bruwer, 1964:101). The natural and non-negotiable nature of separate racial categories made the Population Registration Act a mere formality for Bruwer, who proclaimed that the "exist[ence] of various races in South Africa cannot be laid at the doorstep of the Act" (Bruwer, 1964:76). In the face of increasing criticism aimed at this Act due to the many individual classifications brought in front of the Review Board, Bruwer proposed more diligent research pertaining to individual classification (as opposed to questioning the existence of separate races) in order to guard against wrongful classification. With regards to definitions for the various racial categories, there was a truth to be found. The nature or the essence of the racial category was there to be discovered. This disposition was particularly significant in the context of policy development as it allowed a steadfast, non-negotiable approach to the reality of the designated racial categories of the apartheid state.

The research project at Stellenbosch University thus spoke to the particular political context of the 1950s, a time when there was a move towards a more strictly defined coloured population, and a more strictly defined position of this population within the apartheid state. An early result that stemmed from the project was the determination of the "Eiselen line" - a geographical demarcation for the control of native influx in the Western Cape area (the name inspired by its main proponent, secretary of Native Affairs, W.W.M. Eiselen). It came shortly after Eiselen announced his official stance at the 1955 SABRA conference: "All foreign Natives are gradually to leave the Western Province and no more of them are to be permitted in this region" (Eiselen, 1955:111). ${ }^{13}$ Coupled with minister of Native Affairs Hendrik Verwoerd's proposal that coloureds should enjoy labour preference in the Western Cape, the removal of the "native-element" was also considered to provide the opportunity for coloureds to pursue their status of distinctiveness. The removal of natives was thus also propagated to create a sense of identification with the coloured category which would allow this population "to develop as a distinct population with a sense of national pride" (nasietrots) (SABRA, 1955:128).

The WKNP's contribution to the position of coloureds in the Western Cape proved to be noteworthy, as the government's interest in this project did not dwindle. On 22 June 1959, the commissioner of Coloured Affairs, I.D. du Plessis, was reminded of the continued policy of coloured labour preference in written correspondence with the deputy minister of Labour and the secretary of Labour.

13 The distinction between coloured and native within labour law manifested legally in the Industrial Conciliation Act of 1956 when, for the first time, a distinction was made between coloureds and natives with regards to trade union membership and job reservation (SAHO, 2016). 
The inputs of the WKNP were cited as a significant contribution in this regard. The Department of Coloured Affairs seemingly also took notice and requested a sub-investigation into the viability of replacing native workers with a coloured labour force ("Komitee insake Arbeid in Wes-Kaapland", 1959). By September 1963, the secretary of Coloured Affairs, D.J. Bosman, announced the creation of local committees across the Cape Province charged with implementing the labour preference policy ("Komitee insake Arbeid in Wes-Kaapland", 1966). In this regard, the close ties between the WKNP and the relevant state departments were reasserted in 1965, one year after the official results of the WKNP study was published in book form, when the "Symposium Regarding Coloured Labour" was organised for these local labour committees. These local committees were all subsections of its more encompassing and province-wide title: Committee Regarding Labour in the Western Cape. The symposium was organised by Stellenbosch University in partnership with the Directorate for National Development and Management of the Western Cape Region (Streek Wes-Kaapland van die Nasionale Ontwikkelingsen Bestuursrigting). The one-day conference, entitled "The Mobilisation of Forces for the Development of the Western Cape" ("Die Mobilisasie van Kragte vir die Ontwikkeling van Wes-Kaapland"), communicated many of the ideas that had been developed by the WKNP and by SABRA (both Stellenbosch based) over the course of the previous decade. Here the Committee Regarding Labour in the Western Cape was treated to the insights of Stellenbosch academics and state officials with regards to the implementation of a coloured labour preference policy and an overall replacement of native labour with coloured and white labour (“Komitee insake Arbeid in Wes-Kaapland", 1966).

By this time, the Division for Coloured Affairs was converted in 1960 into the Department for Coloured Affairs, a full state department dedicated to coloureds with P.W. Botha appointed as the first minister of Coloured Affairs. The vague definitions that had transpired over the course of a few decades, and more particularly in the 1950s, definitions that spoke of conceptual failure, apparently did little to deter the acceptance of "coloured" as a separate racial category and the subsequent targeted implementation of policy. Once the category of coloured was created and accepted as "absolute fact" those who ruled were "free to exploit it for their own benefit” (Bracken, 1997:231).

The engagements of the previous decade by social scientists, built on the knowledge produced by physical anthropologists in the decades prior, had real and visceral effects in everyday life. As Robert Chia (2000:513) argues: “... [i]t is through this process of differentiating, fixing, naming, labelling, classifying and relating ... that social reality is systematically constructed." These effects were probably most evident in the large-scale forced removals of coloured populations during the 1960s 
and 1970s. Stellenbosch, the breeding ground for academic engagements with the coloured category, also became one of the first towns to implement Proclamation No. 211 as it appeared on 28 August 1964 in the Government Gazette. Less than a week after this announcement, Stellenbosch municipality proclaimed group areas in the town, and the process of forced removals was initiated. It was particularly the area near the centre of town that was proclaimed as a "whites-only" area. Predominantly occupied by coloureds at the publication of the proclamation, these areas were systematically cleared of coloured residents over the course of the next year. The apparent suddenness of the government's proclamation, which seemingly even took the town council by surprise, resulted in the establishment of Noodkamp (meaning emergency camp) 1 and 2, as liminal spaces for coloured residents before they were moved to the new coloured areas still being constructed on the outskirts of the town (here referring to Ida's Valley and Cloetesville, respectively).

By 1968, the emergency camps were still housing coloured families in about 100 shacks. A local resident by the name of Paul Edmunds brought the "hardships, [and] the minimal facilities available to these people and to the Municipality's refusal to help them move" to the attention of the town council and the readers of the local newspaper, Eikestadnuus. Meanwhile the vacated centre of town became the site for demolition, restoration and renovation - prepared for its new white occupants. The infrastructural development of Stellenbosch University, the institution that contributed in its own way to the construction of an identifiable coloured population, benefited in part from the forced removals. In June 1969, an architectural drawing of the new Education building (G.G. Cillié building) to be constructed on the corner of Ryneveld and Crozier streets graced the pages of the local newspaper. Construction was completed in 1970. By 1978, the construction of the new Arts and Social Sciences building (then known as the B.J. Vorster building) began on the corner of Ryneveld Street and Merriman Avenue. The predominantly coloured population who had once been located on this land, commonly known as Die Vlakte, had now been moved to the outskirts of town.

The coloured category had been successfully constructed and it had been done in the absence of clear-cut definitions. Yet, this category became the target of implemented policy - policy specifically developed for them. As Jensen (2008:17) argues, the apartheid government "ended up producing what it had asserted was there from the beginning, namely a coloured group". The visceral effects of these policies on the everyday lives of a population had little interest in the reality of the category it came to regulate. It simply regulated and controlled, taking no heed of its lasting effects and the grip it would impose on the future. As John Tagg (1993:4) argues: "What is real is not just the material item but also the discursive system of which [it] is part" - here speaking to "the conscious and unconscious processes" 
that underline "practices and institutions". In his letter to Eikestadnuus, Paul Edmunds concluded: "I would like to risk a generalisation about this town ... It seems to me that there are so many who have so much and there are so many with so little" (Eikestadnuus, 1968).

\section{A project of ruination}

The vague definition provided by the Population Registration Act No. 31 of 1950 and employed by the government, and the subsequent failure in the 1950s to narrow down a definition of coloured, did not discredit the existence of the category. Continued attempts by the government to provide more concise conceptualisations of the coloured category ultimately ended in failure and a vague definition of this category of people persisted. While Posel (2001) and Dubow (2010) would argue there was a strategic intent in keeping definitions vague and that this worked in favour of the apartheid government, the actions of the apartheid government in relation to the coloured category spoke of a desperate National Party that attempted, yet failed, to pin down a clear definition of a hybrid population. Definition or no definition, the racial categories of the apartheid state were accepted by the majority as real, and experienced as real. They continued to exude effects and repercussions in practice and life - one of which was the normalisation of coloured as a separate and subordinate racial category (Jensen, 2008:21-22). But what had allowed this to occur in the midst of conceptual failure?

Notably, it required a steadfast belief in the existence of a racial essence to be found in the plural races - a belief that predated the implementation of apartheid and the unionisation of South Africa in 1910. The designated racial categories of the apartheid state were perceived by its makers as inherently natural (readily found in nature). While there might have been a realisation that the designated categories were, at times, hard to distinguish (with a number of individuals challenging their racial classification as provided by state officials [see Posel, 2001]), the government was seemingly under the impression that more thorough research and the addition of scientific knowledge could remedy the dilemma. In other words, it was rather an admission to incomplete knowledge than admission to faulty reasoning. ${ }^{14}$ But it might have been challenging for a government (and the people of South Africa)

14 Yvonne Erasmus and George T.H. Ellison argue that the cases of the Review Board illustrate a "lack of explicit references to science". Based on the absence of science in these cases, Erasmus and Ellison postulate that there was an admission by the state that race was a social construct (2008:451). In this case, I argue there was a continued need and concerted effort to underpin this social construct of race with scientific evidence in the 1950s (and even in the 1960s). The close connection between science and society as shaping notions of race and racial categorisation was a dialectical process. Science remained a major role player in efforts to conceptualise race in South Africa. 
to suddenly reconsider the existence of separate racial categories (and the racial essences to be found in these respective categories) when visual markers were so readily available for a deduction of inherent difference. For that reason, it often provided persuasive evidence to the officials of the apartheid state who examined "complexion, eyes, hair, features, and bone structure" (Bowker \& Star, 2000:210).

The prominence of visual markers in racial categorisation was, however, not developed by the apartheid state. It stemmed from early scientific engagements with the natural world. Anthropological engagements in the late 1800s and early 1900 s - and this was particularly the case for the subfield of physical anthropology relied on visible physical characteristics to identify and define human, or rather racial categories. It was already in the mid-1800s that Paul Broca had associated the type of skull with specific skin tones and hair texture. Throughout the 1900s "racial scientists searched desperately for more and more trivial manifestations of race" - including the "curliness or twist in the hair" as a fundamental factor of division (Malik, 1996:120). These visible characteristics were related to a human hierarchy ranging from the social inferior to the superior - embodied by the very specific characteristics of "a straight face [rather than a forward-jutting face], more or less white skin and straight hair" (Gould, 1981:84). In the field of physical anthropology, visual representations in conjunction with scientific measurements thus became primary elements for illustrating difference. Such visual illustrations were drawn upon to "identify and define the characteristic or typical features of race, class or social group" (Green, 1984:4). As Elizabeth Edwards (2001:8) argues: "Fragments come to stand for a whole, as an expression of an apparent essence."

David Green argues that, through meticulous description and scientific knowledge, appearance was translated to fact: "the perception of a natural order of social structure and stratification was thought to be readily available in the evidence of the human body" (1984:6). In this sense, visual markers not only communicated bodily difference, but rather became representative of a host of biological as well as psychological, cultural and social differences. Green (1984:8) thus argues that these visual markers communicated "a complex system of social knowledge". In this sense, the representation of the "other" takes the form of complete portrayal where the visible becomes inherently linked to the social. Through a variety of forms of representation of individuals, the possibility exists to create "some greater class or classes to which the individual is seen to belong" - aiding a process of perceived homogeneity and uniformity (Gilman, 1985:204). In other words, visual markers and the law of racial aggregates support and often dictate, the process of racial classification. Visual markers (as related to race) is coupled with an "expectation of meaning" (Edwards, 2001:184), that is not informed by the medium itself, but in fact by an existing framework of interpretation - here referring to the "conscious and unconscious processes" (Tagg, 1993:4) of the onlooker. 
In this regard, Deborah Poole (2005:162) writes that visual representations, and particularly photography, were able to "craft racial common sense" by conflating "'popular' and 'scientific' understandings of embodied difference". For Pierre Bourdieu (2003:80), a "commonsense world" speaks of a broad "consensus on the meaning of practices", or that which has "settle[d] into our unconscious" (Bourdieu, 2003:79). The notion of race as commonsense is also a framework of interpretation for Deborah Posel (2001) to explain both the persistence of race in modern South Africa and its ability to function in the absence of pure "scientific" evidence or reasoning under apartheid. Posel (2001) and Dubow (2010) are in agreement that race had become habits of mind by the time apartheid was officially implemented - Dubow refers to the naturalisation of race, while Posel emphasises the commonsensical nature of race. Decades of global scientific engagements prescribing the measurement of skulls, facial features, bodily features and intelligence had ingrained the notion of human races, rather than a single human race, in the minds of the majority. Armed with this kind of "race knowledge", classification became accessible to laymen. Racial science had been translated for the public realm. No need for calipers or any other instruments of measurement, no need for scientists or textbooks for guidance: the populace had been educated on the many ways to spot the markers of racial difference and, more importantly, what those visual markers revealed of their bearer.

In his writings on neoliberalism, David Harvey (2006) briefly interrogates the notion of "commonsense understandings" in his attempt to understand how "systems of thought become hegemonic":

For this to occur not any old concepts will do. A conceptual apparatus has to be constructed that appeals almost 'naturally' to our intuitions and instincts, to our values and our desires, as well as to the possibilities that seem to inhere in the social world we inhabit. (Harvey, 2006:146)

\section{Debris and ruins}

Notions of racial difference coupled with added notions of an existing human hierarchy were able to develop into habits of mind (as both Dubow [2010] and Posel [2001] would refer to it). These habits of mind were nurtured and harnessed, resulting in (often legislated) discrimination around the world. Even under the guises of "separate but equal development" the case was no different for South Africa where any individual classified in a category other than "white" soon felt the hand of the state press down. These legislated state interventions under apartheid not only created categories to be regulated, but regulated those categories in a highly discriminatory fashion. In this regard, the construction of populations, here specifically referring to the coloured population, and the 
implementation of apartheid policies, are both viewed as "imperial formations" conceptualised by Stoler (2008:193) as being "defined by racialised relations of allocations and appropriations". For Stoler, such formations have a lasting impact and often produce debris or ruins, they "exert material and social force in the present" (Stoler, 2013:11). Imperial formations can thus more broadly be viewed as projects of ruination - defined as "a corrosive process that weighs on the future and shapes the present" (Stoler, 2008:194). It entails political projects "that lay waste to certain peoples and places, relations and things" (Stoler, 2008:196). These ruins are often produced by state projects that require "resources and planning [that] dictates how people are supposed to live" (Stoler, 2008:202). In this sense, Stoler's (2013) project of ruination can be related to Harvey's (2006) notion of creative destruction - entailing a continued effort to implement policies with ruinous effects.

Ruination thus embodies the "artefacts of destruction and violation" (NavaroYashin, 2009:5). As explained by Stoler (2008:193), the importance lies in "the longevity of structures of dominance, and the uneven pace with which people can extricate themselves". Today, national statistics still reveal discrepancies in access to health, education and a stable income when comparing the racial categories as inherited from the apartheid state. On a social level the coloured category, specifically in the Western Cape, are often plagued by "general processes of social exclusion based on derogatory stereotypes" (Jensen, 2008:11). In this regard, Bourdieu (1977:85) would refer to these long-lasting effects as "durable dispositions" - closely related to the long-lasting effects of imperial projects. These dispositions are defined by Bourdieu (1997:82) as "a past which survives in the present and tends to perpetuate itself into the future by making itself present in practices structured according to its principles”. Following Stoler (2008:194), one can thus think of ruination as "what people are left with".

\section{Conclusion: the spectre that haunts}

When you see, in a photograph or in a hat or in a footprint, the hand of the state ... you have seen the ghostly matter: the lost beloveds and the force that made them disposable. (Gordon, 2008:205)

Benjamin Dawids was measured by the Zoology Department of Stellenbosch University on 22 October 1937. By employing the prescribed techniques of global physical anthropology, Benjamin's eye, hair, and skin colour and the various indices of his "coloured male body" were translated to an all-encompassing racial data sheet. The name of Benjamin Dawids is not noted in any history book. Who can say what happened to him? However, it can be confidently assumed that he most likely became the target of apartheid policies. In this regard, he would have had to adhere 
to the Population Registration Act - to which Benjamin, a result of a mixed union, possibly posed a categorical problem; and subsequently would have been subjected to the rest of apartheid's imposing policies. A category was created and deployed against itself.

Time has passed: had Benjamin been alive today, he would have lived in a society where his movements and social interactions would not have been dictated by racial laws, but he would still have been designated as coloured on official government documentation. And should an immortal Benjamin Dawids have decided to apply to Stellenbosch University today, he would also have been requested to reveal his racial designation. Had he been a descendant of those who lived on Die Vlakte, those who were forcefully removed post-1964, he would have qualified for a bursary from this University - a bursary created "in addition to existing recruitment bursaries available to coloured, black and Indian students" (Stellenbosch University, 2015).

In 1993, Jacques Derrida proclaimed that the spectre of Marx was haunting Europe. One year after the release of this proclamation South Africa entered a political transition resulting, at least in theory, in a definitive break between an oppressive past and a new democratic present. But the effects of an outdated racial science and the official implementation of apartheid policies are still made manifest in our society more than two decades after the transition. The most obvious lingering effect, or daily practice, is that of racial classification - or rather the existence of fixed racial categories to aid such classification. Closely related to these racial categories are visible discrepancies in access to resources and relations to poverty. It is a history that has proven to be "residual and tenacious" (Stoler, 2008:211). The spectre of racial classification is haunting South Africa.

Derrida draws on "the figure of the ghost to pursue that which haunts like a ghost and, by way of this haunting, demands justice, or at least a response" (Del Pilar Blanco \& Peeren, 2010:9).

When I confronted the instruments used to measure Benjamin Dawids and so many others the feelings of shock and horror were accompanied by a form of recognition. These instruments were immediately recognised as the indicators of so-called racial attributes. The spectre of racial classification was made manifest in these objects. It embodied the ruins of an archaic science, but also the ruins of a society that functions according to racial classification. When age-old, archaic scientific objects can cause an upheaval, when it is able to haunt, its ghost has not been laid to rest. In this regard, the objects retained a sense of Freudian repression rather than a simple history. It illuminated "that which appear[ed] absent", but was in fact "a seething presence" (Gordon, 2008:115); that which "is dominant but hard to see" (Stoler, 2008:211). In this regard, the notion of race as common 
sense, illustrated beyond the apartheid state through a legacy of "race knowledge" that dictates definitions of race as rampant in public perception (and confirmed through its continued salience in institutional use), becomes a seething presence.

For Derrida, in particular, "the ghost or spectre is seen to signify precisely that which escapes full cognition or comprehension" (Del Pilar Blanco \& Peeren, 2013:9). The confrontation, the active haunting that demands a response, becomes possible only where the ghost is seemingly comprehended. The comprehension of a ghostly presence, however, requires a reflexive engagement with history. For Gordon (2008:118), an effective history allows us to "[put] life back in where only a vague memory or a bare trace was visible to those who bothered to look" (Gordon, 2008:118). It requires interrogation, confrontation, and finally comprehension - an awareness of the processes that produced ruins, for "ruins are not just found, they are made" (Stoler, 2013:20). It is for this reason that Stoler (2013:14) makes a case for the importance of ruins as "privileged sites of reflection". Through the instruments for measurement, the spectre of racial classification was made manifest and a moment for reflection presented itself. Another recent illustration of the spectre made manifest has been the Rhodes statue located on the campus of the University of Cape Town. For decades, this statue stood in silence, present but largely ignored, and then it became hyper-visible. Its presence became most profound as a symbol of oppression and the eventual removal of the statue became a way to address the past. In the post-apartheid South Africa, remembering is seemingly as threatening as forgetting.

For some, an acknowledged haunting "represents an opportunity to understand and come to terms with mystery", for once the "monster becomes visible; the ghost [can be] laid to rest" (Holloway \& Kneale, 2008:300). The alternative - one that is seemingly often pursued - is repression upon confrontation. We erase and silence before we have truly comprehended. We remove all reminders of that which causes discomfort. In this regard, we can pack away the scientific instruments used for measurement where they are hard to locate, or where they cannot confront, we can remove statues because their presence becomes an imposing burden, we can attempt to erase parts of history in order to move forward and thereby unleash a haunting onto the future. But this comes with a note of caution. As Christine Tan (2013:4) argues: “... blinded as we are, we fix our gaze towards paths that tend to imprison us further." 


\section{References}

Bertillon, A. 1895. Identification anthropométrique: Instructions signalétiques (Vol. 1). Melun, France: Typographie-Lithographie Administrative.

Blignaut, A.P. c.1940. Die Leerbekwaamheid van die Graaff-Reinetse Kleurling in vergelyking met dié van die Blanke en Naturel. Unpublished MA Thesis, Stellenbosch University.

Bourdieu, P. 2003 [1977]. Outline of a Theory of Practice. Cambridge, UK: Cambridge University Press.

Bowker, G.C. \& Star, S.L. 2000. Sorting Things Out: Classification and its consequences. Cambridge, MA: The MIT Press.

Bracken, C. 1997. The Potlatch Papers: A colonial case history. Chicago, IL: Chicago University Press.

Bruwer, J.P. van S. 1956. Agendas, notules en besluite. Nie-blankes in Wes-Kaapland. Bruwer Collection. PV123 1/5/1. University of the Free State, Bloemfontein, South Africa: National Party Archives.

Bruwer, J.P. van S. 1958. The races of mankind. In: J.P. van S. Bruwer, J.C. Grobbelaar, H.J. van Zyl \& R.F. Weaver. Race studies (ethnography) (Differentiated Syllabus) For standard VII. Johannesburg: Voortrekker Pers Bpk.

Bruwer, J.P. van S. 1964. Die posisie van die Kleurlingbevolking: Historiese agtergrond. In: S.P. Cilliers (ed.). Wes-Kaapland: 'n Sosio-ekonomiese studie (Western Cape: A Socio-Economic Study). Stellenbosch, South Africa: Kosmo Publishers.

Chia, R. 2000. Discourse analysis as organizational analysis.Organization, 7(3). https://doi.org/10.1177/135050840073009

Cilliers, S.P. (ed.). 1964. Wes-Kaapland: in Sosio-ekonomiese studie (Western Cape: A Socio-Economic Study). Stellenbosch, South Africa: Kosmo Publishers.

Comaroff, J. \& Comaroff, J. 1992. Ethnography and the Historical Imagination. Boulder, CO: Westview Press.
Daly, H.V. 1961. Phenetic classification and typology. Systematic Zoology, 10(4): 176-179. https://doi.org/10.2307/ 2411615

Del Pilar Blanco, M. \& Peeren, E. 2010. Introduction. In: M. del Pilar Blanco \& E. Peeren (eds). Popular Ghosts: The haunted spaces of everyday culture. London: Continuum.

Department of Zoology. 1937. Data sheets: Coloured males of Stellenbosch. C.S. Grobbelaar collection, 250.N1(64-194). J.S. Gericke Library Document Centre, Stellenbosch University.

Dönges, T.E. 1959. T.E. Dönges-collection, 1909-1967. Vol. 444, A1646. Cape Town: National Archives.

Dubow, S. 1995. Scientific Racism in Modern South Africa. Cambridge, UK: Cambridge University Press.

Dubow, S. 2010. South Africa: Paradoxes in the place of race. In: A. Bashford \& P. Levine (eds). The Oxford Handbook of the History of Eugenics. Oxford, UK: Oxford University Press.

Dubow, S. 2014. Apartheid, 1948-1994. Oxford, UK: Oxford University Press.

Du Plessis, R. 2015. Beyond a clinical narrative: Casebook photographs from the Grahamstown Lunatic Asylum, c.1890s. Critical Arts, 29(1). https://doi.org/10.1080/ 02560046.2015 .1102258

Edwards, E. 2001. Raw Histories: Photographs, anthropology and museums. Oxford, UK: Berg.

Eikestadnuus. 1955. "Studie van nie-blankes se posisie in W.P.: Universiteit onderneem omvattende ondersoek.” 11 November:1-2.

Eikestadnuus. 1968. "Ons lesers se briewe: Stellenbosch Slum Area." Paul Edmunds. 29 November:7.

Eiselen, W.W.M. 1955. Die Kleurling en die Naturel. In: Die Kleurling in die SuidAfrikaanse samelewing: Referate gelewer 
op die sesde jaarvergadering van die SuidAfrikaanse Buro vir Rasse-Aangeleenthede (SABRA). Pretoria and Stellenbosch, South Africa: SABRA. 109-125.

Erasmus, Y. \& Ellison, G.T.H. 2008. What can we learn about the meaning of race from the classification of population groups during apartheid? South African Journal of Science, 104(11-12). https://doi.org/10.1590/ S0038-23532008000600016

Faubion, J.D. (ed.). 2001. Michel Foucault: Power. Essential works of Foucault, Vol. 3. New York: The New Press.

Fick, M.L. 1929. Intelligence test results of poor white, native (Zulu), coloured, and Indian school children and the educational and social implications. South African Journal of Science, 26.

Fields, B.J. 1982. Ideology and race in American history. In: J.M. Kousser \& J.M. McPherson (eds). Region, Race, and Reconstruction: Essays in honor of C. Vann Woodward. New York: Oxford University Press.

Findlay, G. 1936. Miscegenation: A study of the biological sources of inheritance of the South African population. Pretoria: Pretoria News \& Printing Work.

Fischer, E. 1913. Die Rehobother Bastards und das Bastardierungsproblem beim Menschen: Anthropologische und ethnographische Studien am Rehobother Bastardvolk in Deutsch-Südwest-Afrika. Graz, Austria: Akademische Druck-u. Verlagsanstalt.

Fischer, E. 1931. Variable characters in human beings. In: B. Erwin, E. Fischer \& F. Lenz. Human heredity. E. Paul \& C. Paul (transl.). New York: The Macmillan Company.

Ford, C.L. \& Airhihenbuwa, C.O. 2010. Critical race theory, race equity, and public health: Toward antiracism praxis. American Journal of Public Health, 100:S30-S35. https://bit.ly/2TPfOEJ

Freud, S. 1955 [1919]. The "Uncanny". In: S. Freud. From the history of an infantile neurosis and other works. Vol. 17 (1917-1919). The Standard Edition of the Complete Psychological Works of
Sigmund Freud. J. Strachey, A. Freud, A. Strachey \& A. Tyson (transl.).

London: The Hogarth Press.

Gilman, S. 1985. Black bodies, white bodies:

Toward an iconography of female sexuality in late nineteenth-century art, medicine, and literature. Critical Inquiry, 12(1). https://doi.org/10.1086/448327

Goldberg, D.T. 2016. Racial Subjects: Writing on race in America. New York: Routledge. https://doi.org/10.4324/9781315865751

Gordon, A.F. 2008. Ghostly Matters: Haunting and the sociological imagination. Minneapolis, MN: University of Minnesota Press.

Gould, S.J. 1981. The Mismeasure of Man. London: W.W. Norton.

Green, D. 1984. Veins of resemblance: Photography and eugenics. The Oxford Art Journal, 7(2):3-16. https://doi.org/ 10.1093/oxartj/7.2.3

Green, L.; Condy, J. \& Chigona, A. 2012. Developing the language of thinking within a classroom community in inquiry: Pre-service teachers' experience. South African Journal of Education, 32(3). https://doi.org/10.15700/saje.v32n3a583

Grobbelaar, C.S. 1948. Anthropometry and its role in South Africa. Presidential address to Section 'D' of the South African Association for the Advancement of Science. South African Journal of Science, 44.

Grobbelaar, C.S. 1956. The physical characteristics of the Korana. South African Journal of Science, 53(4):97-143.

Harvey, D. 2006. Neo-liberalism as creative destruction. Geografiska Annaler (Series B, Human Geography), 88B(2):145-158.

Hertz, F. 1928. Race and Civilization. A.S. Levetus \& W. Entz (transl.). New York: The Macmillan Co.

Holloway, J. \& Kneale, J. 2008. Locating haunting: A ghost-hunter's guide. Cultural Geographies, 15(3). https://doi.org/10.11 77/1474474008091329

Jensen, S. 2008. Gangs, Politics and Dignity in Cape Town. London: James Currey. 
Jones, C. \& Porter, R. (eds). 1994. Reassessing Foucault: Power medicine and the body. London: Routledge.

Keen, J.A. 1952. Craniometric study of the Cape Coloured population. Transactions of the Royal Society of South Africa, 33(1). https://doi.org/10.1080/0035919 5109519876

Komitee insake Arbeid in Wes-Kaapland. 1959. Beskerming van Kleurlingarbeid, 1959-1961. KUS Vol. 35, 23/9. Cape Town: National Archives.

Komitee insake Arbeid in Wes-Kaapland. 1966. Agenda en Notule: Simposium oor Kleurlingarbeid. CRN Vol. 1/26, K3/5. Cape Town: National Archives.

Krogman, W.M. 1948. Physical anthropology and race relations: A biosocial evaluation. The Scientific Monthly, 66(4).

Malik, K. 1996. The Meaning of Race: Race, history and culture in Western society. London: Macmillan. https://doi.org/10.10 07/978-1-349-24770-7

Martin, R. 1914. Lebrbuch der Anthropologie: In systematischer darstellung mit besonderer berüksichtigung der anthropolgischen methoden für studierende ästze und forschungsreisende. Jena, Germany: Gustav Fischer.

Maré, G. 2014. Declassified: Moving beyond the dead end of race in South Africa. Johannesburg: Jacana.

Memmi, A. 1965. The Colonizer and the Colonized. H. Greenfeld (transl.). London: Earthscan.

Mitchell, W.J.T. 2012. Seeing through Race. Cambridge, MA: Harvard University Press. https://doi.org/10.4159/harvard.97806 74065352

Morris, A.G. 2008. Searching for "real" hottentots: The Khoekhoe in the history of South African physical anthropology. Southern African Humanities, 20.

Morris, A.G. 2012. Biological anthropology at the southern tip of Africa: Carrying European baggage in an African context. Current Anthropology, 53(5). https://doi.org/ $10.1086 / 662289$
Morris, A.G. \& Tobias, P.V. 1997. Physical anthropology: South Africa. In: F. Spencer (ed.). History of Physical Anthropology, Volume 2: $M-Z$. New York: Garland Publishing.

Navaro-Yashin, Y. 2009. Affective spaces, melancholic objects: Ruination and the production of anthropological knowledge. The Journal of the Royal Anthropological Institute, 15(1). https://doi.org/10.1111/ j.1467-9655.2008.01527.x

Olssen, M. 2010. The school as the microscope of conduction: Doing Foucauldian research in education. In: J.D. Marshall (ed.). Poststructuralism, Philosophy, Pedagogy. London: Kluwer Academic Publishers.

Parle, J. 2007. The voice of history? Patients, privacy and archival research ethics in histories of insanity. Journal of Natal and Zulu History, 24(1). https://doi.org/10.108 0/02590123.2006.11964140

Poole, D. 2005. An excess of description: Ethnography, race, and visual technologies. Annual Review of Anthropology, 34.

Posel, D. 2001. Race as common sense: Racial classification in twentieth-century South Africa. African Studies Review, 44(2). https://doi.org/10.2307/525576

Powerhouse Museum Collection. 2015. Set of 16 glass eyes in a tin by Rudolf Martin made in Germany in the late 19th century representing an early stage in the development of prosthetic eyes, 1880-1899. https://collection.maas.museum/object/ 38774 [Accessed 24 August 2015].

SABRA. 1953. Memorandum opgestel deur die Suid-Afrikaanse Buro vir RasseAangeleenthede (SABRA) ter voorlegging aan die Parlementêre Kommissie insake die Afsonderlike Verteenwoordiging van Kiesers. In: Union of South Africa. Report of the Commission to Enquire into the Subject Matter of the Separate Representation of Voters' Act Validation and Amendment Bill, Part II. A. Memoranda Received by the Commission to Enquire into the Subject Matter of the Separate Representation of Voters Act Validation and Amendment Bill, 1953. 
B.Official Memoranda, Statistical Returns and other Information Supplied to the Commission, 25-37. U.G. no. 20/1954.

SABRA. 1955. Resolusies. In: Die Kleurling in die Suid-Afrikaanse samelewing: Referate gelewer op die sesde jaarvergadering van die Suid-Afrikaanse Buro vir RasseAangeleenthede (SABRA), 126-128.

Sadie, F.A. 1942. The Relation between the learning ability and the degree of European blood in SA Non-Europeans. Unpublished MA Thesis, Stellenbosch University.

Scott, J.C. 1998. Seeing Like a State: How certain schemes to improve the human condition have failed. New Haven, CT: Yale University Press.

Sharp, J. 1981. The roots and development of volkekunde in South Africa. Journal of Southern African Studies, 8(1). https://doi. org/10.1080/03057078108708032

Soudien, C. 2006. Racial discourse in the Commission on Native Education (Eiselen Commission), 1949-1951: The making of a "bantu" identity. Southern African Review of Education with Education with Production, 11(1).

South African History Online (SAHO). 2016. Apartheid legislation 1850s-1970s. https://bit.ly/2N8qcG5 [Accessed 25 May 2016].

Stellenbosch University. 1924. Universiteit van Stellenbosch Jaarboek. Cape Town: Nasionale Pers.

Stellenbosch University. 2015. Applications open for SU's “Die Vlakte" bursary. https://bit.ly/1LvzqCR [Accessed 15 January 2017].

Stoler, A.L. 2008. Imperial debris: Reflections on ruins and ruination. Cultural Anthropology, 23(2). https://doi.org/10.11 11/j.1548-1360.2008.00007.x

Stoler, A.L. (ed.) 2013. Imperial Debris: On ruins and ruination. London: Duke University Press. https://doi.org/10.12 15/9780822395850
Tagg, J. 1993 The Burden of Representation: Essays on photographies and histories. Minneapolis, MN: University of Minnesota Press.

Tan, C.A.L. 2013. The Kristevan aesthetic of the sublime: Lapses of meaning from the meaningless abject. Paper presented at the 6th DLSU Arts Congress, held at the De La Salle University, Manila, Philippines, February.

UNESCO. 1950. Fallacies of Racism Exposed: UNESCO Publishes Declaration by World's Scientists. UNESCO Courier, 3(6/7):1-16.

UNESCO. 1952. The Race Concept: Results of an inquiry. Paris: United Nations.

Van der Spuy, J.S. 1959. 'n Studie van die liggaamsbou en liggaamsgroei van blanke en kleurlingseuns in die Westelike Provinsie, ouderdomsgroep 13 tot 17 jaar. Annals of the University of Stellenbosch, $35 \mathrm{~A}(2): 67-140$.

Van Wyk, G.F. 1939. A preliminary account of the physical anthropology of the "Cape Coloured People" (Males). Annals of the University of Stellenbosch, 17A(2):1-61.

Venter, C. 2009. The influence of early apartheid intellectualisation on twentiethcentury Afrikaans music historiography. Unpublished Master's Thesis (Musicology), Stellenbosch University.

Wilder, H.H. 1921. A Laboratory Manual of Anthropometry. Philadelphia, PA: P. Blakiston's Son \& Co.

Wilder, H.H. \& Wentworth, B. 1918. Personal Identification: Methods for the identification of individuals, living or dead. Boston, MA: The Gorham Press.

Winant, H. 2000. Race and race theory. Annual Review of Sociology, 26. https://doi.org/10.1 146/annurev.soc.26.1.169 


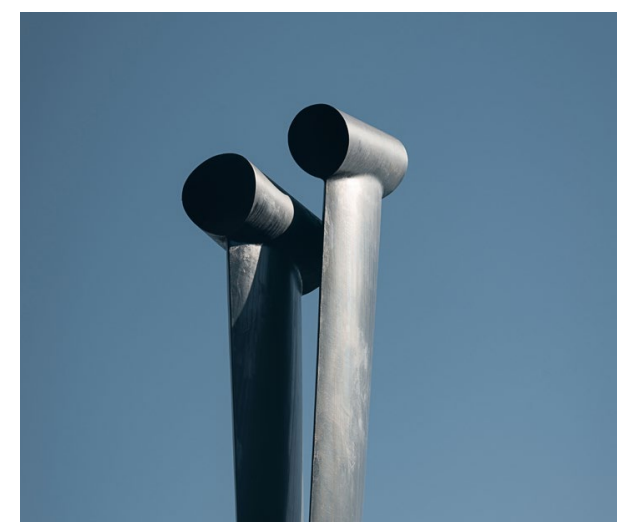

\section{LIST OF CONTRIBUTORS}

Vivienne Bozalek is Senior Professor and the Director of Teaching and Learning at the University of the Western Cape, South Africa. She holds a PhD from Utrecht University. Her research interests and publications include the political ethics of care and social justice, posthumanism and feminist new materialisms, innovative pedagogical practices in higher education, post-qualitative and participatory methodologies. Her most recent co-edited books include Theorising Learning to Teach in Higher Education (with Brenda Leibowitz and Peter Kahn), and Socially Just Pedagogies: Posthumanist, Feminist and Materialist Perspectives in Higher Education (with Rosi Braidotti, Tamara Shefer and Michalinos Zembyla).

JANET Condy is Professor in the Faculty of Education at Cape Peninsula University of Technology, South Africa, where she teaches both undergraduate and postgraduate students in Professional Studies, Inclusive Education, and Research Methodology. She has supervised many master's and doctoral students in a wide range of subjects on various aspects of literacy, including digital storytelling, rural literacy education and inclusive education. More recently, she has been holding the Chair of Literacy Research Unit. 
KIRA ERWIN is a sociologist and senior researcher at the Urban Futures Centre at the Durban University of Technology (DUT), South Africa. Her research and publications focus largely on race, racialisation, racism and anti-racism work in South Africa, but also on the formation and reproduction of different social identities in urban spaces. Her projects make use of creative participatory methods, and she collaborates with colleagues in various creative fields to produce forms of public storytelling that extend research beyond the walls of academia.

Daniela Gachago is Associate Professor in the Centre for Innovative Educational Technology at the Cape Peninsula University of Technology, South Africa. Her research interests lie in the potential of innovative technologies to transform teaching and learning in higher education. Current research projects focus on the ethics of blended and open learning in contexts of inequality and multimodal pedagogies such as digital storytelling as decolonial classroom practices.

LENA GREeN is currently Extraordinary Professor in the Faculty of Education at the University of the Western Cape, South Africa, after having retired as Professor of Educational Psychology. She has published a number of papers related to the development and enhancement of thinking, of which several focus on philosophical inquiry with children, students and teachers. Her current research is concerned with the role of school leaders in supporting educators as teachers of thinking.

Gerhard Maré is Professor Emeritus at the University of KwaZulu-Natal, South Africa. He had been Chair of Sociology and Director of the Centre for Critical Research on Race and Identity at the same institution. He has published widely on a range of subjects, especially on ethnic mobilisation and race/racialism. His most recent books are Declassified: moving beyond the dead end of race in South Africa (2017 NIHSS Award); Living Together, Living Apart? Social cohesion in a future South Africa (co-edited with Christopher Ballantine, Michael Chapman and Kira Erwin), and The Effects of Race (with Nina Jablonski).

Kathryn Pillay is Senior Lecturer in Sociology at the University of KwaZuluNatal (UKZN), South Africa. She holds a PhD in Sociology from UKZN. Her areas of teaching and research include that of 'race', migration, identity and belonging. Her most recent publication is the co-edited volume, Relating Worlds of Racism Dehumanisation, Belonging and the Normativity of European Whiteness (Palgrave Macmillan, 2019), which unmasks and foregrounds the ways in which notions of European whiteness have found form in a variety of global contexts that continue to sustain racism as an operational norm resulting in exclusion, violence, human rights violations, isolation and limited full citizenship for individuals who are not racialised as white. 
HANDRI WALTers is a post-doctoral Fellow in the Sociology and Social Anthropology Department of Stellenbosch University, South Africa. Her research traces the intersections of race, science and state policy during the pre-apartheid and apartheid period. The research further questions the remnants of racial science in post-apartheid South Africa as embedded in the continuance of formal racial categorisation.

Michalinos Zembylas is Professor of Educational Theory and Curriculum Studies at the Open University of Cyprus. He is also Honorary Professor in the Chair for Critical Studies in Higher Education Transformation at Nelson Mandela University, South Africa. He has written extensively on emotion and affect in relation to social justice pedagogies, intercultural and peace education, human rights education and citizenship education. His recent books include Psychologized Language in Education: Denaturalizing a Regime of Truth (with Z. Bekerman), and Socially Just Pedagogies in Higher Education (co-edited with V. Bozalek, R. Braidotti and T. Shefer). In 2016, he received the Distinguished Researcher Award in "Social Sciences and Humanities” from the Cyprus Research Promotion Foundation. 


\section{stios PUBLICATION}

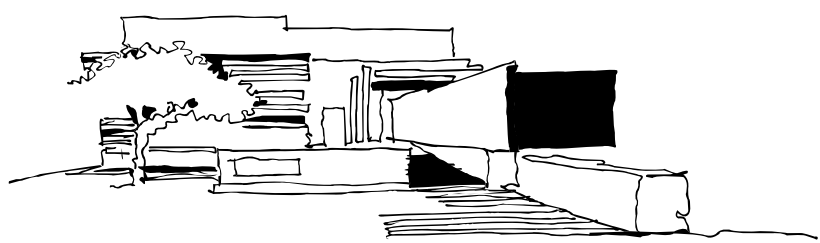

A CREATIVE SPACE FOR THE MIND

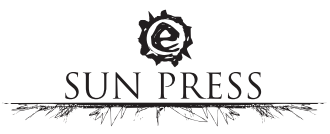

\section{VOLUMES IN THE SERIES}
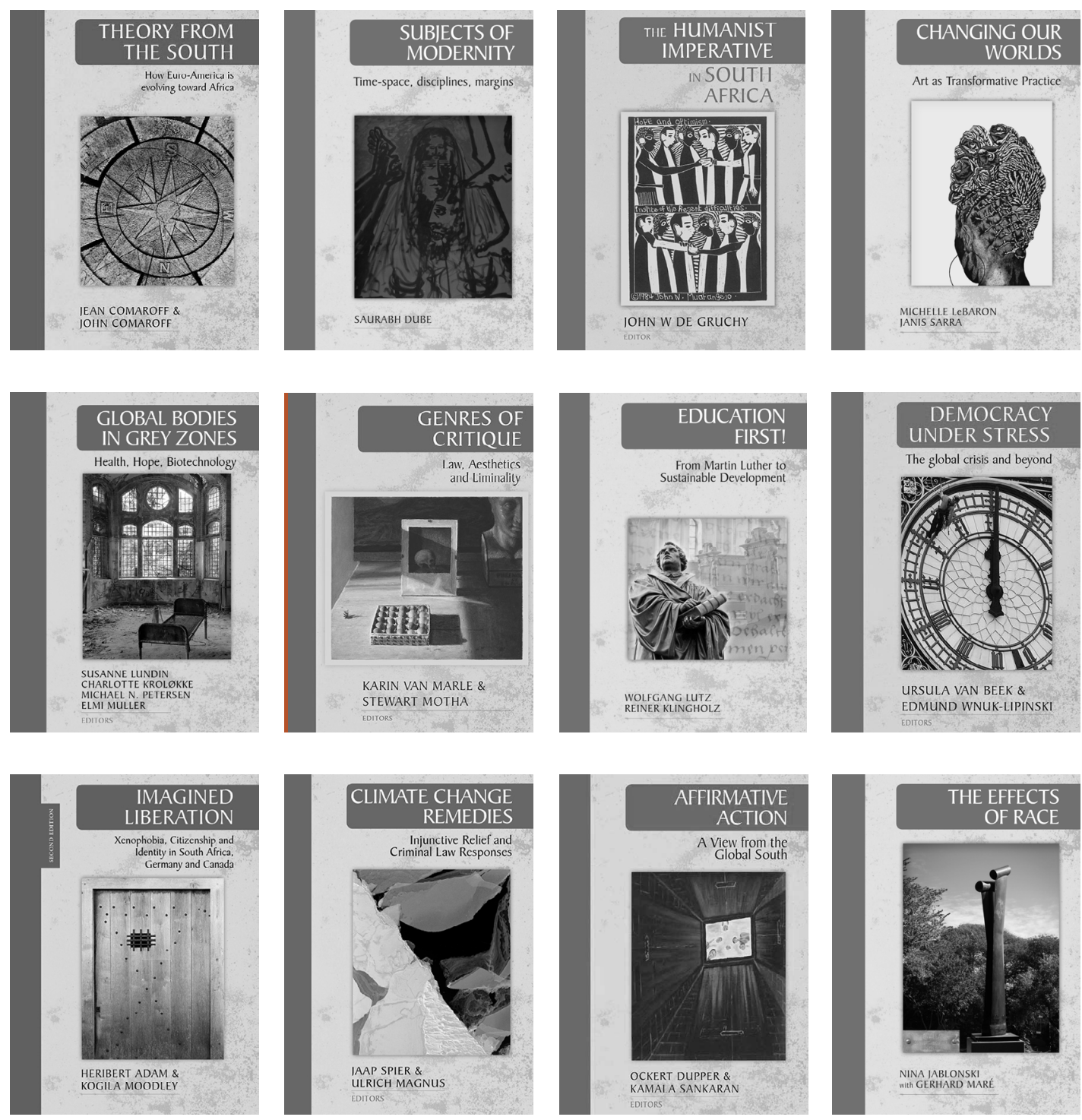